\title{
Restabelecimento de Energia com Busca Local e Corte de Cargas
}

José Paulo Ramos Fernandes 



\title{
Restabelecimento de Energia com Busca Local e Corte de Cargas
}

\author{
José Paulo Ramos Fernandes
}

Dissertação apresentada à Escola de Engenharia de São Carlos da Universidade de São Paulo para a obtenção do título de Mestre em Ciências pelo Programa de PósGraduação em Engenharia Elétrica.

Área de concentração: Sistemas Elétricos de Potência

Orientador: Prof. Dr. João Bosco Augusto London Junior

Trata-se da versão corrigida da dissertação. A versão original se encontra disponível na EESC/USP que aloja o Programa de Pós-Graduação de Engenharia Elétrica. 


\section{AUTORIZO A REPRODUÇÃO TOTAL OU PARCIAL DESTE TRABALHO, POR QUALQUER MEIO COONVENCIONAL OU ELETRÔNICO, PARA FINS DE ESTUDO E PESQUISA, DESDE QUE CITADA A FONTE.}

Ficha catalográfica elaborada pela Biblioteca Prof. Dr. Sérgio Rodrigues Fontes da EESC/USP com os dados inseridos pelo(a) autor(a).

R363r Ramos Fernandes, José Paulo de Cargas / José Paulo Ramos Fernandes; orientador João Bosco Augusto London Jr. São Carlos, 2019.

Dissertação (Mestrado) - Programa de Pós-Graduação em Engenharia Elétrica e Área de Concentração em Sistemas Elétricos de Potência -- Escola de Engenharia de São Carlos da Universidade de São Paulo, 2019.

1. restabelecimento de energia. 2. sistemas de distribuição. 3. busca local. 4. corte de cargas. 5. sequência de chaveamento. 6. algoritmo evolutivo multiobjetivo. I. Título.

Eduardo Graziosi Silva - CRB - 8/8907 


\section{FOLHA DE JULGAMENTO}

Candidato: Bacharel JOSÉ PAULO RAMOS FERNANDES.

Título da dissertação: "Restabelecimento de energia com busca local e corte de cargas".

Data da defesa: 04/07/2019.

Comissão Julgadora:

Prof. Associado João Bosco Augusto London Junior (Orientador)

(Escola de Engenharia de São Carlos/EESC)
Resultado:

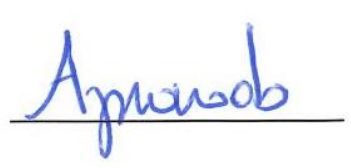

Prof. Dr. Adriano Batista de Almeida

(Universidade Estadual do Oeste do Paraná/UNIOESTE)

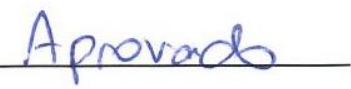

Profa. Dra. Madeleine Rocio Medrano Castillo Albertini Aprovado
(Universidade Federal do Triângulo Mineiro/UFTM)

Coordenador do Programa de Pós-Graduação em Engenharia Elétrica: Prof. Associado Ivan Nunes da Silva

Presidente da Comissão de Pós-Graduação:

Prof. Titular Murilo Araujo Romero 



\section{AGRADECIMENTOS}

Aos meus pais, Marcus e Beatriz, meus irmãos, Marcus Jr. e João Augusto, e toda minha família pelo apoio e compreensão todos esses anos.

Aos meus irmãozinhos, Joe, a quem dedico este trabalho, Zora, Zelda e Jack por tantos anos de diversão.

A Ebony por todo o seu amor e apoio que me fazem tão feliz.

A todos os meus amigos que me acompanharam e incentivaram a seguir os estudos.

Aos professores João Bosco, Madeleine e Virgílio, que tanto contribuíram em minha formação.

A todos os demais professores e colegas da Universidade de São Paulo e da Universidade Federal do Triângulo Mineiro que contribuíram na realização deste trabalho.

À Escola de Engenharia de São Carlos pelo apoio institucional.

Agência(s) de fomento e $n^{\circ}$ (s) de processo(s): FAPESP e CAPES, processo no 2017/23728-0, Fundação de Amparo à Pesquisa do Estado de São Paulo (FAPESP). 



\section{RESUMO}

FERNANDES, J. P. R. Restabelecimento de Energia com Busca Local e Corte de Cargas. 2019. 127p. Dissertação (Mestrado) - Escola de Engenharia de São Carlos, Universidade de São Paulo, São Carlos.

Apesar de serem usualmente construídos formando malhas, os sistemas de distribuição primária são operados na configuração radial. Dessa forma, faltas permanentes nesses sistemas podem provocar o desligamento de diversos consumidores por um grande período de tempo. Para reduzir o tempo de desligamento desses consumidores, devem ser utilizadas ferramentas computacionais eficientes capazes de gerar planos de restabelecimento em um curto intervalo de tempo. Estes planos consistem na apresentação de uma sequência de chaveamento capaz de minimizar a energia não suprida, com o menor número de manobras possível, atendendo as restrições operacionais da rede, como níveis de tensão e carregamento.

Neste trabalho, é apresentado um método que faz uso de um algoritmo evolutivo multiobjetivo em tabelas, capaz de lidar com objetivos conflitantes sem a necessidade de atribuição de diferentes pesos por objetivo, precedido por uma etapa determinística concentrada na região problema. Este método é uma variação de propostas já conhecidas e é capaz de lidar com consumidores de níveis de prioridade diferentes, dando um tratamento diferenciado para chaves manuais e remotas. Destaca-se ainda que apesar de considerar a possibilidade de corte de cargas, o método prioriza a geração de planos que não provoquem desligamentos temporários. A fim de avaliar o desempenho do método proposto, são comparados os resultados obtidos por ele com o método que serviu de base para seu desenvolvimento. A comparação é feita a partir dos melhores resultados obtidos após uma quantidade de simulações em um sistema de pequeno porte e um sistema real de grande porte.

Os resultados obtidos indicam que o método proposto apresenta ganhos significativos em sistemas de pequeno porte, com ganhos menores em sistemas de grande porte, devido às limitações computacionais envolvidas.

Palavras-chave: restabelecimento de energia, sistemas de distribuição, algoritmo evolutivo multiobjetivo, sequência de chaveamento, busca local, corte de cargas. 



\section{ABSTRACT}

FERNANDES, J. P. R. Service Restoration with Local Search and Load Shedding. 2019. 127p. Dissertação (Mestrado) - Escola de Engenharia de São Carlos, Universidade de São Paulo, São Carlos.

Although distribution systems are built in mesh structures, they are usually operated in a radial configuration. Faults in distribution systems can cause undesired blackouts to healthy consumers. To reduce theirs effects, computational tools able to generate restoration plans in short time are used. These plans consist in presenting a switching sequence able to minimize system's non supplied energy with the lowest switching operations number possible, while respecting the system operational restrictions, such as load and voltage limits.

In this project, a method that uses a multiobjective evolutive algorithm in tables, able to deal with conflicting objectives without the need of assigning different weights to each one, preceded by a deterministic stage applied to the fault region, is presented. This method is a variation of known models and can evaluate different consumers priorities and differentiate remote and manual switches, while also favors the achievement of restoration plans that cause no temporary turn offs.

To evaluate the proposed method effectiveness, its results are compared to the method used as base for its development. This comparison is based on the best results obtained by each method after a set of simulations in a small and a real large-scale distribution system.

Results indicate that the proposed method allows meaningful improvements over the base method in small systems, with smaller gains in large-scale systems, due to computational limitations.

Keywords: service restoration, distribution systems, multiobjective evolutive algorithm, switching sequence, local search, load shedding. 



\section{LISTA DE SIGLAS E ABREVIATURAS}

AE - Algoritmo Evolutivo

AEMO - Algoritmo Evolutivo Multiobjetivo

AEMT - Algoritmo Evolutivo Multiobjetivo em Tabelas

$\mathrm{CAO}$ - Change Ancestor Operator

CCM - Chave Controlada Manualmente

CCR - Chave Controlada Remotamente

$\mathrm{CE}$ - Consumidores Especiais

DEC - Duração Equivalente de Interrupção por Unidade Consumidora

ENS - Energia Não-Suprida

FEC - Frequência Equivalente de Interrupção por Unidade Consumidora

LACOSEP-USP - Laboratório de Análise Computacional de Sistemas Elétricos de Potência da Universidade de São Paulo

LRO - Load Reconnect Operator

LSO - Load Shedding Operator

NA - Normalmente Aberta

NF - Normalmente Fechada

NSGA-II - Non-Dominated Sorting Genetic Algorithm

PAO - Preserve Ancestor Operator

PNS - Potência Não-Suprida

PRE - Plano de Restabelecimento de Energia

RNP - Representação Nó-Profundidade

SD - Sistemas de Distribuição 



\section{LISTA DE SÍMBOLOS}

$\varepsilon$ - energia não suprida durante o tempo de operação

$\psi$ - número total de manobras para obtenção de uma configuração

$A$ - matriz de incidência da rede

$x$ - vetor de correntes de linha complexas

$c$ - vetor de correntes complexas nas barras de carga e subestações

$Y_{x}$ - matriz diagonal de admitâncias da rede

$v$ - vetor de tensões nodais complexas

$X$ - carregamento máximo da rede

$\bar{x}_{j}$ - limite superior para magnitude de corrente em uma linha

$B$ - carregamento máximo da subestação

$\bar{b}_{S}$ - limite superior de corrente injetada por uma subestação

$V$ - máxima queda de tensão relativa

$\delta$ - máxima queda de tensão relativa permitida

$\Omega_{I}-$ conjunto formado por todas as configurações intermediárias de $G$

$\dot{I}_{i}^{(k)}$ - corrente demandada pela barra $i$ na iteração $k$

$\dot{V}_{i}^{(k-1)}-$ tensão da barra $i$ na iteração $k-1$

$Y_{i}^{s h}$ - soma dos elementos shunt conectados à barra $i$

$S_{i}$ - potência aparente da barra $i$

$Z_{n}$ - impedância de um trecho $n$ que conecta duas barras 



\section{LISTA DE FIGURAS}

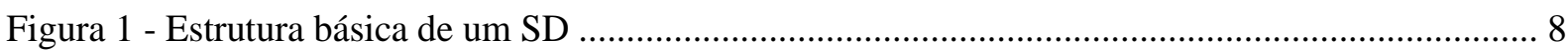

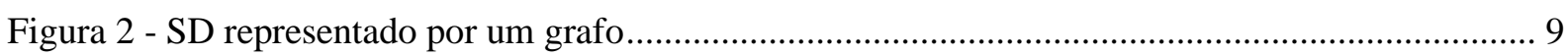

Figura 3 - Linha de tempo de um problema de restabelecimento ........................................................ 10

Figura 4 - Sequência de etapas realizadas pelo método base ............................................................ 21

Figura 5 - Sistema de distribuição com falta identificada e possibilidade de restauração parcial pela

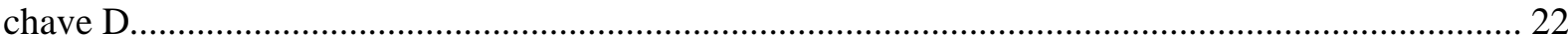

Figura 6 - Sistema de distribuição em falta com setores afetados identificados .................................. 22

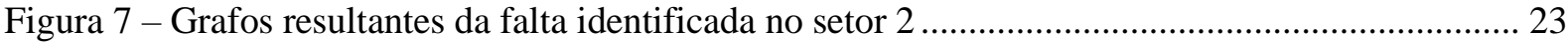

Figura 8 - Grafo do indivíduo gerado pela busca exaustiva contendo os setores a serem restaurados (em amarelo) e um trecho representando o trecho não afetado pela falta (em verde) ................................... 24

Figura 9 - Fluxograma simplificado do processo de busca exaustiva contendo as principais etapas realizadas para a geração dos indivíduos que irão compor a população inicial ou a solução final ....... 24 Figura 10 - Fluxograma simplificado do processo evolutivo realizado pelo AEMT com destaque às principais etapas envolvendo aleatoriedade ou algum processo de decisão relativo ao problema de restabelecimento

Figura 11 - Fluxograma representando as principais etapas do processo de seleção e impressão dos resultados

Figura 12 - Fluxograma mostrando de maneira resumida o funcionamento completo do algoritmo base

Figura 13 - Grafo formado por setores desenergizados conectados a um nó de subestação fictício.... 32

Figura 14 - Grafos formadas pela combinação gerada durante o processo de busca local................... 35

Figura 15 - Grafo da porção desenergizada reorganizado para aplicação de manobras ........................ 37

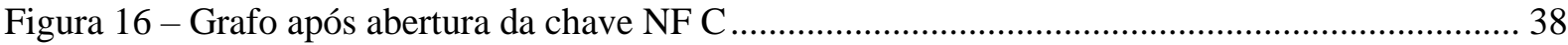

Figura 17 - Novas configurações dos grafos após a aplicação de todas as manobras ........................... 38

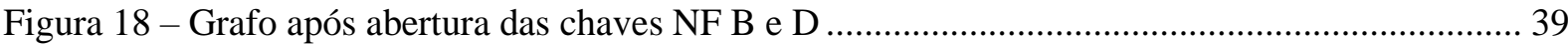

Figura 19 - Novos grafos após a aplicação das manobras necessárias ................................................... 39

Figura 20 - Grafo referente a RNP fictícia reorganizada para aplicação de manobras.......................... 41

Figura 21 - Fluxograma representando o funcionamento geral do conjunto de operações realizadas no processo de busca local

Figura 22 - Grafos de um SD com conjunto desenergizado vazio .................................................... 50

Figura 23 - Grafos de um SD após a realização de uma manobra de corte de cargas ........................... 50

Figura 24 - Fluxograma mostrando de maneira resumida o funcionamento completo do método proposto 
Figura 25 - Sistema de 53 barras representado no formato barra-chave em sua configuração pré-falta 61

Figura 26 - Fronteira formada pelas melhores soluções encontradas para falta no setor 3................... 65

Figura 27 - Fronteira formada pelas melhores soluções encontradas para a falta no setor 45 .............. 66

Figura 28 - Fronteira formada pelas melhores soluções encontradas para a falta no setor 11 .............. 68 


\section{LISTA DE TABELAS}

Tabela 1 - Comparação entre os dois métodos

Tabela 2 - Parâmetros utilizados para execução das simulações ....................................................... 58

Tabela 3 - Informações dos sistemas nas configurações pré-falta...................................................... 59

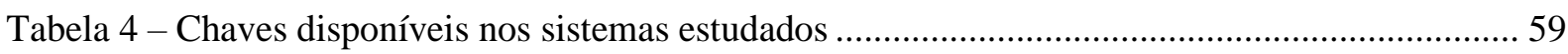

Tabela 5 - Consumidores por nível de prioridade nos sistemas estudados........................................... 59

Tabela 6 - Restrições do problema e tempos utilizados para a simulação com o sistema de pequeno porte

Tabela 7 - Melhores valores de energia não suprida obtidos em cada caso que apareceram em pelo menos metade das simulações, com respectivos números de manobras e potências não suprida finais 62 Tabela 8 - Características dos indivíduos finais obtidos nas 35 simulações para falta no setor 3 com o método base.

Tabela 9 - Características dos indivíduos finais obtidos nas 35 simulações para faltas no setor 3 com o método proposto

Tabela 10 - Sequência de chaveamento do indivíduo com melhor energia não suprida obtido pelo método proposto.

Tabela 11 - Sequência de chaveamento do indivíduo com melhor energia não suprida obtido pelo método base.

Tabela 12 - Características dos indivíduos finais obtidos nas 35 simulações para faltas no setor 45 com o método base.

Tabela 13 - Características dos indivíduos finais obtidos nas 35 simulações para faltas no setor 45 com o método proposto.

Tabela 14 - Características dos indivíduos finais obtidos nas 35 simulações para faltas no setor 11 com o método base

Tabela 15 - Características dos indivíduos finais obtidos nas 35 simulações para faltas no setor 11 com o método proposto.

Tabela 16 - Tempos de simulação médios em segundos

Tabela 17 - Restrições do problema e tempos utilizados para a simulação com o sistema de grande porte

Tabela 18 - Características dos indivíduos finais obtidos nas 35 simulações para faltas no setor 2532 com o método base

Tabela 19 - Características dos indivíduos finais obtidos nas 35 simulações para faltas no setor 2532 com o método proposto 
Tabela 20 - Características de um indivíduo obtido exclusivamente pelo método proposto para faltas no setor 2571

Tabela 21 - Características do indivíduo com menor energia não suprida obtido pelo método base para faltas no setor 2571

Tabela 22 - Características dos indivíduos finais obtidos nas 35 simulações para faltas no setor 1587 com o método proposto

Tabela 23 - Características dos indivíduos finais obtidos nas 35 simulações para faltas no setor 1587 com o método base

Tabela 24 - Características dos indivíduos finais obtidos nas 35 simulações para faltas no setor 1349 com o método base

Tabela 25 - Características dos indivíduos finais obtidos nas 35 simulações para faltas no setor 1349 com o método proposto

Tabela 26 - Tempos de simulação médios em segundos 74 


\section{SUMÁRIO}

1. INTRODUÇÃO ................................................................................................................................

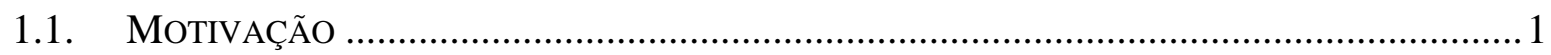

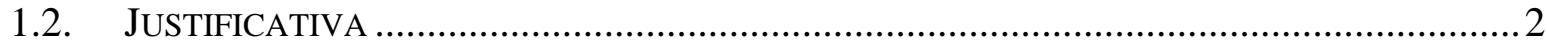

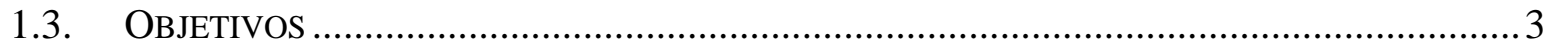

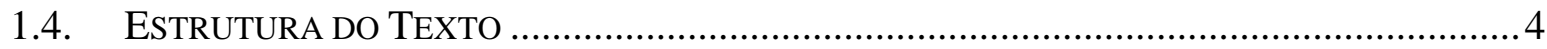

2. APRESENTAÇÃO DO PROBLEMA

2.1. SISTEMAS DE DISTRIBUIÇÃO ......................................................................... 7

2.2. APRESENTAÇÃO do PROBLEMA DE RESTABELECIMENTO …........................................

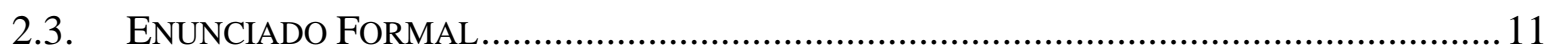

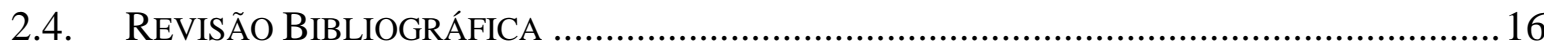

2.4.1. Trabalhos do Grupo de Pesquisa LACOSEP-USP .......................................... 19

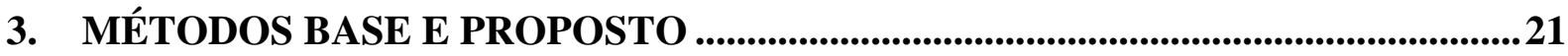

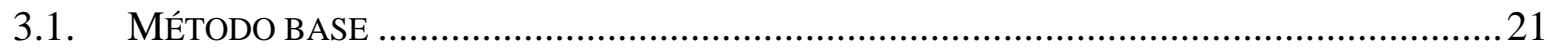

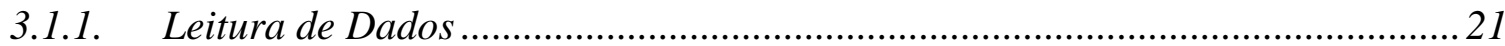

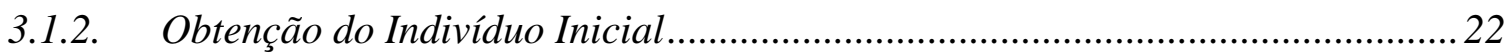

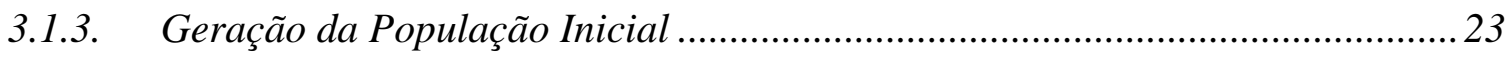

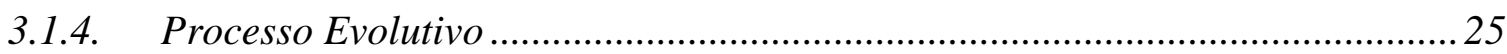

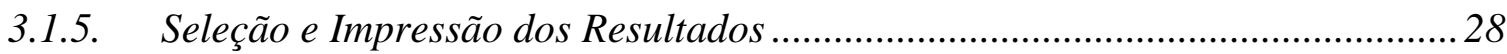

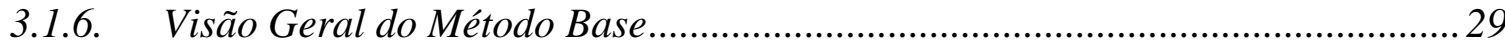

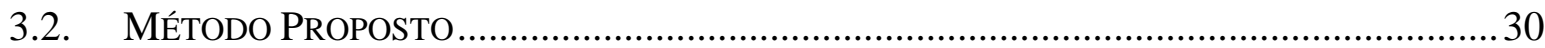

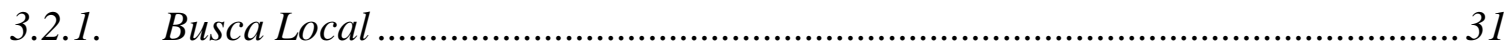

3.2.1.1. Princípio de Funcionamento da Busca Local............................................... 32

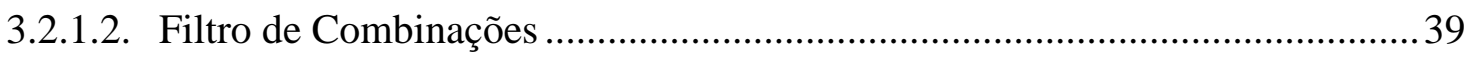

3.2.1.3. Aplicações em Sistemas de Grande Porte..................................................... 47

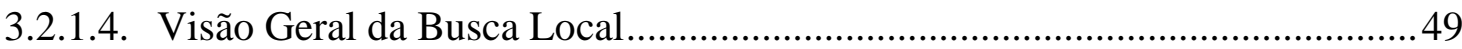

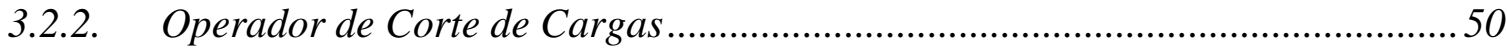

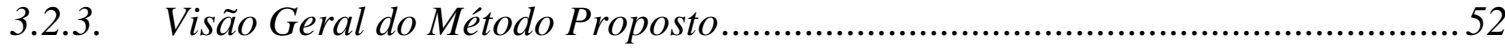

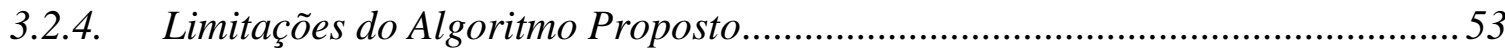




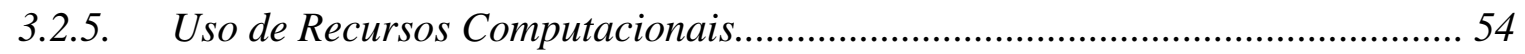

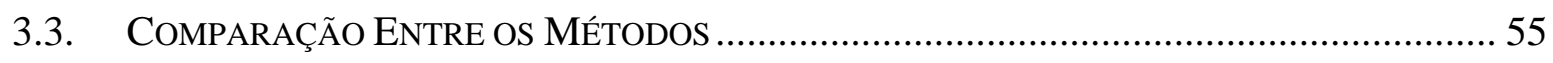

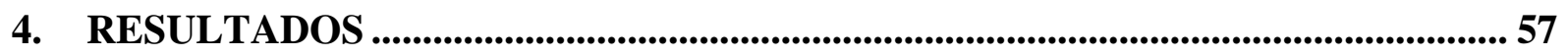

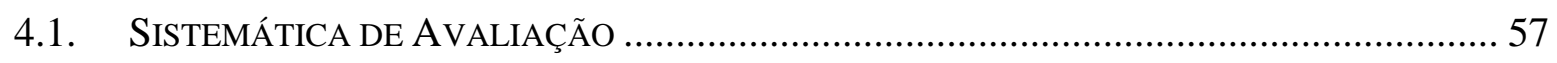

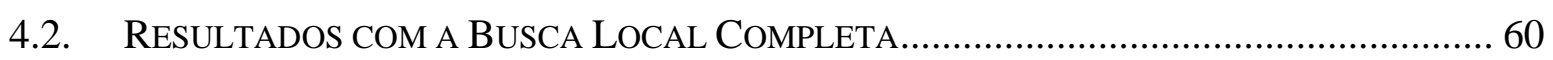

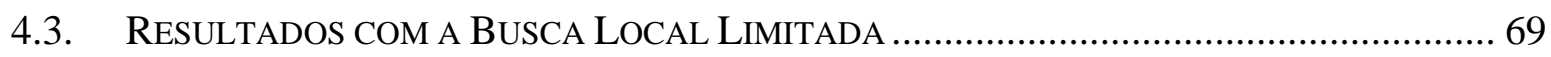

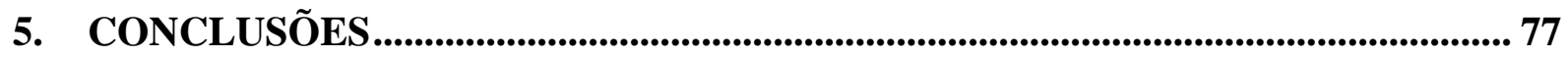

5.1. OBSERVAÇÕES FINAIS E CONTRIBUIÇÕES ................................................................ 77

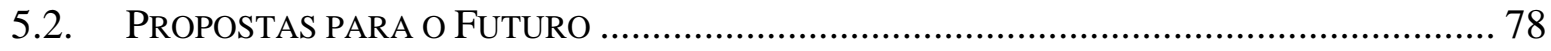

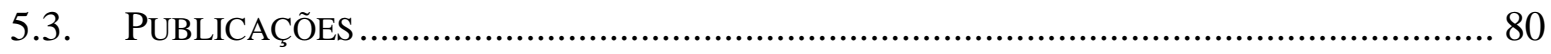

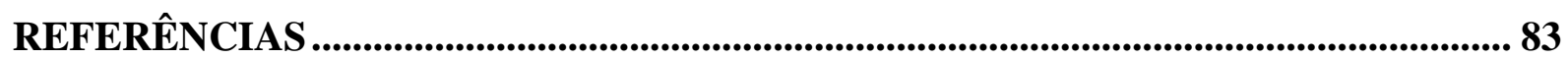

APÊNDICE A - REPRESENTAÇÃO NÓ-PROFUNDIDADE .................................... 93

APÊNDICE B - ALGORITMO EVOLUTIVO MULTIOBJETIVO EM TABELAS .... 97

APÊNDICE C - DOMINÂNCIA DE PARETO ........................................................ 99

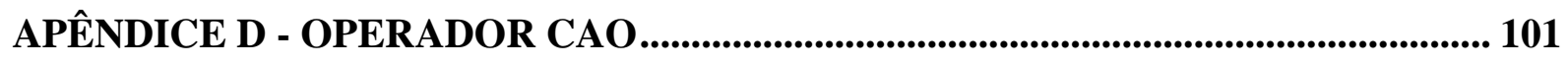

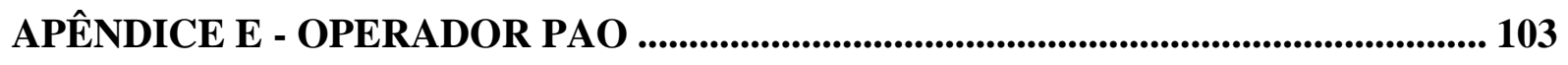

APÊNDICE F - TABELAS USADAS NO AEMT ................................................... 105 


\section{INTRODUÇÃO}

\subsection{Motivação}

A disponibilidade de energia elétrica é fundamental para a sociedade moderna. Cientes dos prejuízos sociais e econômicos que falhas nos sistemas de distribuição (SDs) podem causar, órgãos governamentais criaram normas e indicadores de qualidade para operação destes. O descumprimento dessas regras pode resultar em grandes perdas financeiras para as concessionárias. Dentre os principais indicadores de qualidade do serviço prestado estão a Duração Equivalente de Interrupção por Unidade Consumidora (DEC) e a Frequência Equivalente de Interrupção por Unidade Consumidora (FEC), computados conforme as ocorrências de faltas permanentes de duração maior que 3 minutos (ANEEL - Agência Nacional de Energia Elétrica, 2018).

Normalmente, problemas nos sistemas de distribuição são resolvidos com base no conhecimento do operador do sistema, que estabelece Planos de Restabelecimento de Energia (PREs) e realiza manobras a fim de minimizar o número de consumidores sem serviço quando há uma falta qualquer. $\mathrm{O}$ avanço computacional e surgimento de dispositivos inteligentes observados nos últimos anos tem mudado esse cenário, aumentando o investimento em sistemas de inteligência artificial para orientar na tomada de decisão dos operadores ou até mesmo religar trechos dos sistemas automaticamente. Investimentos em métodos automatizados se justificam pelo alto custo das compensações impostas por descumprimento de metas dos indicadores DEC e FEC e pelo fato de que durante as contingências as concessionárias deixam de vender uma grande quantidade de energia, reduzindo seu lucro e afetando negativamente a satisfação de seus clientes.

O uso de computadores para resolver problemas de restabelecimento de energia em SDs apresenta ganhos consideráveis em relação às soluções baseadas somente no conhecimento prévio dos operadores. As ferramentas computacionais podem se adaptar à situação da rede em tempo real e fornecer uma grande variedade de opções em pouco tempo, o que é crucial dada a necessidade de agir rapidamente, avaliando inclusive como cada configuração da rede afetará os níveis de tensão e carregamento do sistema.

Este problema tem sido objeto de estudo recorrente do grupo de pesquisa no qual este projeto de mestrado está vinculado, o grupo do Laboratório de Análise Computacional de Sistemas Elétricos de Potência da Universidade de São Paulo (LACOSEP-USP). Desde o início 
das pesquisas na área, importantes avanços foram feitos para a criação de uma ferramenta computacional robusta para tratamento do problema de restabelecimento em sistemas reais, conforme será apresentado no Capítulo 2.

Nesta dissertação é proposto um método para restabelecimento de energia baseado no algoritmo apresentado em (MARQUES, 2018), com a adição de algumas funcionalidades que buscam aprimorar seu desempenho. O algoritmo original é capaz de lidar com sistemas de grande porte (com milhares de barras e chaves) sem simplificações, dar preferência a consumidores prioritários e chaves controladas remotamente e ainda avaliar a sequência de chaveamento. As funções adicionadas aprimoram a busca por combinações de chaveamento que não provoquem quedas temporárias de energia para consumidores não afetados inicialmente pela falta. Permitem, ainda, que seja feito o corte de cargas, caso necessário para restaurar consumidores prioritários e reduzir a quantidade de energia que a concessionária deixa de fornecer, chamada de Energia Não-Suprida (ENS), o que impacta diretamente nos indicadores DEC e FEC.

\subsection{Justificativa}

O uso de técnicas de inteligência artificial baseada em modelos evolutivos já se mostrou bastante eficiente para lidar com problemas combinatórios como o restabelecimento de energia. Algoritmos evolutivos (AEs) são facilmente adaptáveis para trabalhar em problemas diferentes, cobrindo grandes espaços de busca em pouco tempo. Entretanto, não há garantia de que um AE encontrará a melhor combinação (solução ótima) (YAGIURA, IBARAKI, 1996).

Buscando manter as características do Algoritmo Evolutivo Multiobjetivo (AEMO) desenvolvido em (MARQUES, 2018), mas também garantir que haja uma avaliação mais profunda de combinações de chaves (solução do problema de restabelecimento) que dão preferência àquelas presentes na região de falta (em setores ${ }^{1}$ que foram desligados para isolamento dos setores em falta ou que reconectem algum destes à região energizada), o método proposto adiciona uma etapa de busca determinística (chamada de busca local ao longo deste trabalho) ao algoritmo original. Também é adicionada, na etapa evolutiva, a possibilidade do corte de cargas, a fim de aumentar a variabilidade das soluções favorecendo a restauração de cargas prioritárias, e também compensar algumas das limitações da busca local realizada pelo método apresentado em (MARQUES, 2018).

\footnotetext{
${ }^{1}$ Define-se por setor o conjunto de barras separada das demais por chaves seccionadoras.
} 
Deste modo, o método proposto mantém todas as vantagens do apresentado em (MARQUES, 2018), que considera questões práticas do problema de restabelecimento. São estas:

i) Tratamento diferenciado para chaves controladas remotamente (CCRs) e chaves controladas manualmente (CCMs), devido ao tempo de manobra diferente entre as chaves;

ii) Priorização da restauração de energia para consumidores especiais (hospitais, indústrias, prestadores de serviços essenciais, etc.), definidos também como consumidores prioritários;

iii) Determinação de uma sequência por meio da qual as chaves possam ser operadas, a fim de isolar os setores em falta e reconectar o maior número de consumidores saudáveis ${ }^{2}$ desligados, executando-se o mínimo de manobras em chaves;

iv) Seleção de cargas menos prioritárias para permanecerem desligadas nas situações em que não é possível obter uma solução que restaure todas as cargas de setores saudáveis que ficaram fora de serviço;

v) Tratamento do problema considerando os objetivos de redução da ENS e do número de manobras a serem realizadas, permitindo soluções factíveis que não restaurem todos os setores saudáveis desligados em função do isolamento da falta.

Além disso, a Representação Nó-Profundidade (RNP) (DELBEM et al., 2004), usada pelo algoritmo base, já foi provada em SANTOS et al. (2010) ser computacionalmente eficiente, mesmo em sistemas de grande porte. O uso da RNP e seus operadores garante também a geração apenas de configurações radiais.

\subsection{Objetivos}

Este trabalho tem como objetivo aprimorar o método proposto por MARQUES (2018) para lidar com o problema de restabelecimento de energia, ampliando a busca por soluções que

\footnotetext{
${ }^{2}$ Entende-se por consumidor saudável aquele que, apesar de estar desenergizado, não possui nenhum problema que o impeça de ser reconectado ao sistema elétrico.
} 
envolvam apenas manobras em chaves Normalmente Abertas (NAs) e Normalmente Fechadas (NFs) diretamente conectadas aos setores saudáveis que foram desligados e incluindo a possibilidade do corte de cargas.

Todas as melhorias realizadas no método tomado como base foram feitas de modo a manter suas vantagens. Deste modo, todas as melhorias implementadas se comunicam com a estrutura já existente no algoritmo base.

O novo método adiciona, portanto, duas funções específicas ao método base:

1) Geração e análise de soluções que consideram a possibilidade de cortes de cargas em setores saudáveis que não foram desligados em função do isolamento dos setores em falta, assim como a possibilidade de não restabelecimento de setores saudáveis que foram desligados para isolamento dos setores em falta;

2) Inclusão de um procedimento, executado antes do processo evolutivo, de busca local por soluções que envolvam manobras apenas em chaves NAs e NFs diretamente conectadas aos setores saudáveis que foram desligados para isolamento dos setores em falta (região da rede chamada em (MIL; CHIANG; MCNULTY, 2000) de Tier 1). Esse procedimento visa aumentar a possibilidade de o método encontrar planos de restabelecimento de energia que não exigem desligamentos momentâneos de setores que não foram desligados pelo isolamento dos setores em falta.

Ainda que não seja o objetivo principal, este trabalho ainda apresenta uma nova estrutura para representar trechos do sistema de distribuição de modo eficiente afim de tornar possível a implementação do processo de busca local descrito.

\subsection{Estrutura do Texto}

Esta dissertação foi dividida em cinco capítulos, além de Referências e Apêndices. O Capítulo 1 é a breve discussão a respeito da motivação e objetivos deste trabalho, apresentada anteriormente.

No Capítulo 2 é feita a apresentação formal do problema de restabelecimento de energia em SDs. Esta apresentação consiste na discussão teórica e formulação do problema, além de uma revisão bibliográfica tratando dos trabalhos desenvolvidos na área e das contribuições já realizadas pelo grupo de pesquisa do LACOSEP-USP. 
O Capítulo 3 apresenta, de forma sucinta, a metodologia proposta em (MARQUES, 2018), adotada como base no desenvolvimento deste trabalho. De maneira mais detalhada, apresenta o método proposto, incluindo exemplos de aplicação. Também são feitas breves discussões a respeito da viabilidade da aplicação prática do método proposto em SDs de grande porte.

No Capítulo 4 são apresentados os resultados obtidos pelo método desenvolvido, incluindo uma comparação com resultados do método proposto em (MARQUES, 2018).

Por fim, no Capítulo 5 são feitas algumas observações a respeito de todo o trabalho e propostas para aprimorar o que é apresentado. Também são citados os artigos científicos desenvolvidos e publicados durante o período de realização do curso de mestrado.

Ao final do texto principal, são citadas as Referências e apresentadas algumas informações relevantes ao entendimento do trabalho nos Apêndices. 



\section{APRESENTAÇÃO DO PROBLEMA}

Neste capítulo é apresentado conceitualmente o problema de restabelecimento de energia em SDs, especificando-se suas etapas e principais objetivos. São também mostrados seu enunciado formal e uma breve revisão bibliográfica. O embasamento teórico para entendimento dos conceitos apresentados é mostrado nos Apêndices A, B e C.

\subsection{Sistemas de Distribuição}

Conforme estabelecido pela ANEEL (2015), "a distribuição se caracteriza como o segmento do setor elétrico dedicado ao rebaixamento da tensão proveniente do sistema de transmissão, à conexão de centrais geradoras e ao fornecimento de energia elétrica ao consumidor".

As redes de distribuição são compostas principalmente por linhas (ou cabos), equipamentos de proteção, transformação e manobra, sendo usualmente divididas em dois tipos (KAGAN et al., 2005): a rede de Distribuição Primária, ou de média tensão, e a rede de Distribuição Secundária, ou de baixa tensão.

A distribuição primária normalmente opera em $13,8 \mathrm{kV}$ e de forma radial, apesar de ser construída em malhas. A operação radial simplifica consideravelmente a coordenação das proteções do sistema, porém reduz a confiabilidade quanto à continuidade do fornecimento de energia. Para minimizar este problema, os projetos em malha preveem a possibilidade de transferência de blocos de carga (ou setores) entre alimentadores através de manobras em chaves NAs e NFs. Este processo de troca de alimentadores através de manobras de chaveamento é conhecido como reconfiguração de redes.

Já a distribuição secundária é aquela que atende diretamente aos consumidores residenciais, comerciais e industriais de pequeno porte, operando normalmente em tensões de $127 \mathrm{~V}$ ou $220 \mathrm{~V}$ fase-neutro e $220 \mathrm{~V}$ ou $380 \mathrm{~V}$ fase-fase. Normalmente estas redes não possuem muitas alternativas para lidar com contingências, sendo a reconfiguração de rede realizada na rede primária.

A Figura 1 mostra de maneira simplificada como se conectam as redes primária e secundária de um SD. Trata-se de um sistema com alimentador em $23,2 \mathrm{kV}$ e consumidores operando em 220V. Os dispositivos MT e MR representam equipamentos para monitoração de 
transformadores e de residências, respectivamente. Chaves e dispositivos de segurança foram omitidos da imagem.

Figura 1 - Estrutura básica de um SD

Alimentador de $23,2 \mathrm{kV}$

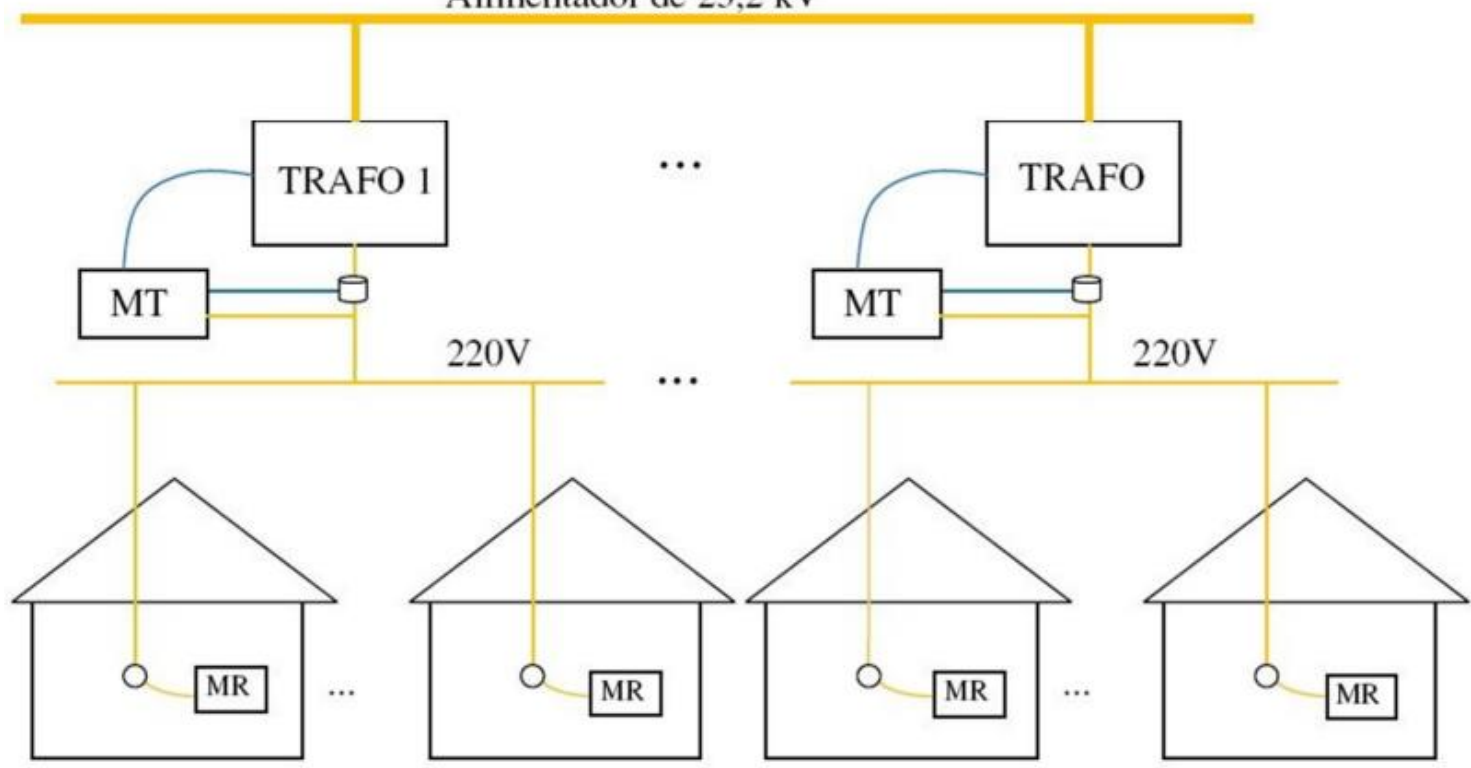

Fonte: Portal O Setor Elétrico.

Os SDs podem ter tamanhos variados, dependendo do local. Uma cidade grande, por exemplo, tende a ter uma rede bem maior que uma cidade pequena. Também são sistemas que variam muito ao longo do tempo, com o crescimento populacional, entrada de indústrias e até mesmo pelo avanço tecnológico, que muda o perfil das cargas conectadas, a disponibilidade de dispositivos inteligentes na rede e a própria estrutura de linhas, subestações, transformadores e outros aparelhos.

No problema de restabelecimento é comum representar os SDs a partir de grafos, conforme apresentado na Figura 2, em que os vértices (ou nós) representam setores (agrupamento de barras de carga, subestação ou de passagem, interconectados por chaves seccionadoras) e as arestas representam chaves seccionadoras (pontilhadas do tipo NA e contínuas do tipo NF). Assim, sistemas elaborados podem ser representados matricialmente. A Figura 2 mostra um SD com 2 alimentadores e 7 barras (incluindo as barras das subestações) na forma de grafo. Estes grafos podem ser representados computacionalmente de forma eficiente através da RNP (apresentada no Apêndice A). 
Figura 2 - SD representado por um grafo

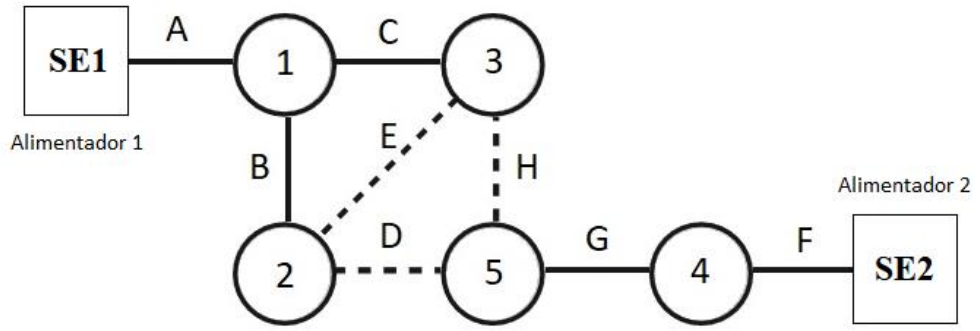

Fonte: Adaptado de CAMILLO et al, 2016.

\subsection{Apresentação do Problema de Restabelecimento}

Conforme mencionado no Capítulo 1, um dos itens de qualidade mais importante atualmente para as empresas distribuidoras de energia elétrica é a continuidade do fornecimento de energia. Entretanto, interrupções no fornecimento de energia nos SDs são inevitáveis e podem ser causadas tanto por uma operação de manutenção na rede quanto pela ocorrência de faltas permanentes. No primeiro caso, alguns trechos da rede são desligados pela própria concessionária de distribuição, para possibilitar a execução de forma segura dos trabalhos das equipes de campo. No segundo caso, o desligamento é ocasionado pela ação dos equipamentos de proteção da rede (por exemplo, disjuntores e chaves-fusíveis) em decorrência de uma falta permanente como um curto-circuito.

Devido à estrutura radial de operação da rede primária, desde que não haja a presença de geração distribuída, o sentido do fluxo de potência é único nos alimentadores dessas redes, e a energia chega aos setores por um único caminho. Portanto, se dispositivos de proteção são abertos em função de faltas permanentes, todos os setores à jusante desses dispositivos ficarão sem energia, sendo possível e muito provável que, devido a uma falta em um único setor, muitos setores em perfeito estado de funcionamento (não atingidos pela falta) fiquem fora de serviço (sem energia). Neste caso, é necessária a elaboração, através do processo de reconfiguração de redes (manobras em chaves seccionadoras), de um Plano de Restabelecimento de Energia (PRE) para que as cargas, localizadas nos setores sem defeito que ficaram sem energia, sejam reconectadas ao sistema elétrico.

Vale destacar que desde o instante da ocorrência de uma falta permanente, causando algum defeito em algum componente da rede elétrica, até a completa recuperação desse equipamento, diversos eventos ocorrem. Conforme detalhado na Figura 3, esses eventos ocorrem em intervalos de tempo conceitualmente bem definidos. 
Figura 3 - Linha de tempo de um problema de restabelecimento

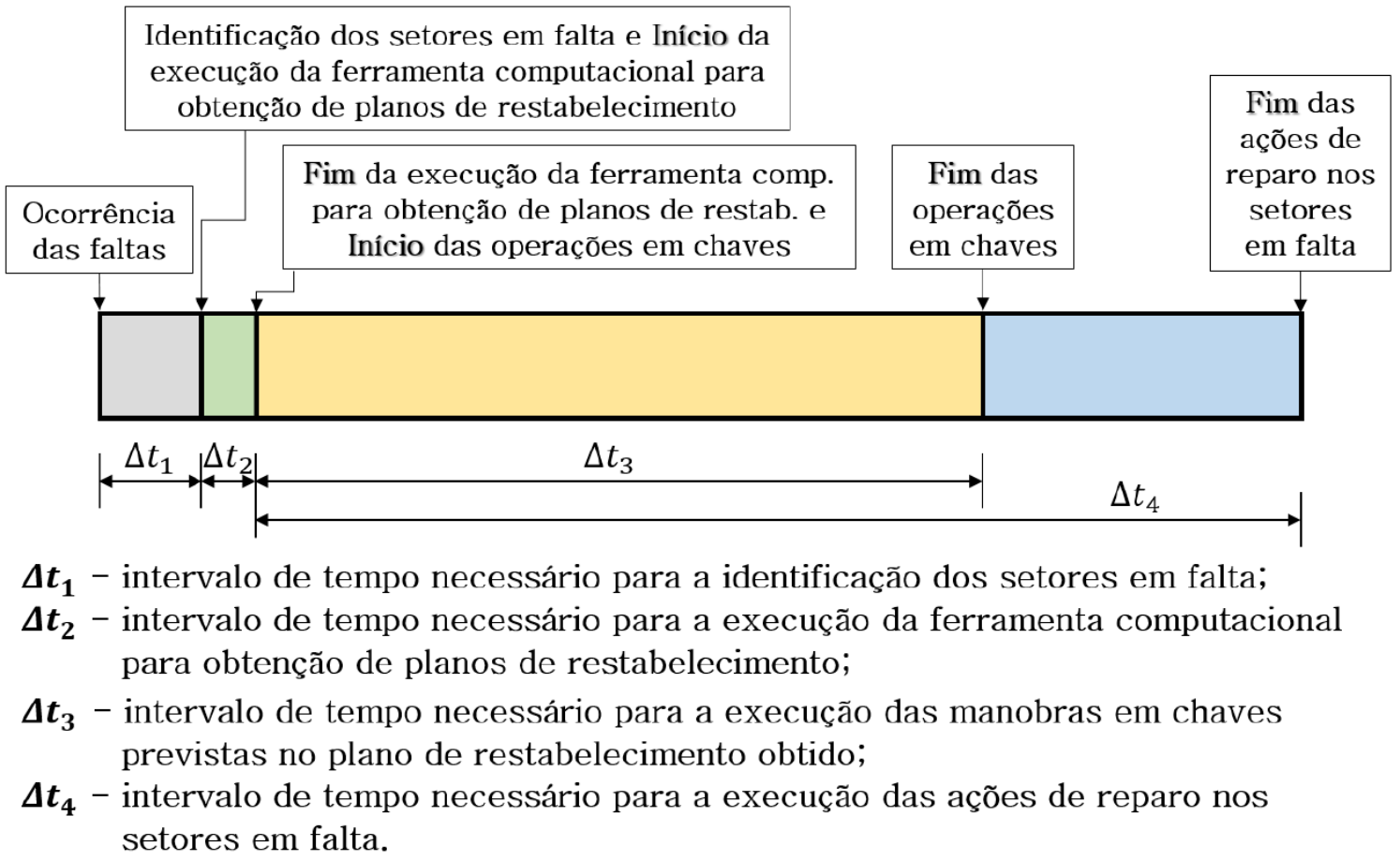

Fonte: MARQUES, 2018.

Considerando todos os detalhes do processo de restabelecimento de energia, após a ocorrência de faltas permanentes, os dispositivos seccionadores do sistema de proteção localizados à montante e mais próximos dos setores em falta atuam, abrindo a rede. Consequentemente, são deixados sem energia: os setores em falta, os setores sadios localizados à montante dos setores em falta e à jusante dos dispositivos de proteção que atuaram e, finalmente, os setores sadios localizados à jusante dos setores em falta. Na sequência, realizase a localização dos setores em falta. O método proposto neste trabalho, assim como o método base, lida com os intervalos de tempo descritos por $\Delta t_{2}$ e $\Delta t_{3}$, considerando apenas uma estimativa dos acontecimentos de $\Delta t 4$.

Uma vez que os setores em falta são identificados (intervalo de tempo $\Delta t_{1}$ ) pode-se iniciar a execução de uma ferramenta computacional para obtenção de PREs (início do intervalo de tempo $\Delta t_{2}$ ). Importa destacar, no entanto, que após a identificação e isolação dos setores em falta, a energia pode ser imediatamente restabelecida para os setores sadios localizados à montante dos setores em falta e à jusante dos dispositivos de proteção que atuaram. Isto através do fechamento desses dispositivos. Usualmente, as ferramentas e metodologias desenvolvidas para obtenção de PREs não contemplam a manobra dos dispositivos de proteção para restabelecimento dos setores sadios à montante dos setores em falta. Dessa forma, elas se preocupam usualmente em indicar apenas as manobras necessárias para isolação do setor em 
falta e para restabelecimento de energia para os setores sadios à jusante dos setores em falta. Ou seja, elas admitem a hipótese de os dispositivos de proteção serem fechados após a identificação e isolação dos setores em falta. Após a execução de uma ferramenta computacional para obtenção de pelo menos um PRE, realiza-se, no intervalo de tempo $\Delta t_{3}$, a implantação prática desse PRE de acordo com a sequência de manobras definida no PRE. Ao longo deste intervalo é que são restaurados parcial ou totalmente os consumidores saudáveis desligados pela ocorrência da falta. Ao término do intervalo $\Delta t_{3}$ a rede irá operar na configuração prevista no plano de restabelecimento. Durante o intervalo $\Delta t_{4}$ ocorrem as ações para o reparo da falha. Após este intervalo, isto é, após a recuperação total dos elementos defeituosos, iniciam-se as ações para retornar a rede para sua configuração pré-falta (ou para configuração planejada para operação naquele instante).

Um PRE adequado deve considerar (Santos, 2009):

1) Minimização do número de consumidores sem fornecimento, priorizando sempre os Consumidores Especiais ${ }^{3}$ (CEs);

2) Minimização do número de manobras em chaves seccionadoras, priorizando manobras em Chaves Controladas Remotamente (CCRs);

3) Atendimento das restrições operacionais das redes elétricas, dadas por:

a. Ausência de sobrecargas de rede ou subestação (transformadores);

b. Manutenção dos níveis adequados de tensão (conforme a legislação aplicável);

c. Manutenção da radialidade da rede;

d. Capacidade de determinação em tempo real.

\subsection{Enunciado Formal}

Como mostrado na seção anterior, a consideração dos tempos gastos em cada etapa do problema e a utilização da ENS ao invés da potência não-suprida (PNS) tornam o problema mais complexo, mas também permite a obtenção de soluções mais eficientes. Pensando nisso, é necessário diferenciar os tempos gastos por chaves manuais das remotas e os níveis de prioridade de cada consumidor.

\footnotetext{
${ }^{3}$ São considerados Consumidores Especiais aqueles cuja prioridade de fornecimento é superior aos demais. Por exemplo: hospitais, aeroportos, áreas de segurança pública, etc.
} 
Apresenta-se, a seguir, o enunciado formal do problema de restabelecimento de energia apresentado em (MARQUES, 2018), trabalho utilizado como base para o desenvolvimento do método proposto nesta dissertação.

Considerando a necessidade de definição de uma sequência adequada de chaveamento e a representação de SDs através de grafos, formalmente pode-se definir o problema de restabelecimento de energia em SD da seguinte forma (MARQUES, 2018):

\section{Minimizar}

$$
\varepsilon(G), \psi(G)
$$

Sujeito a

$$
\begin{array}{r}
A\left(G^{e}\right) x\left(G^{e}\right)=c\left(G^{e}\right) \\
A\left(G^{e}\right) Y_{x}\left(G^{e}\right) A\left(G^{e}\right)^{t} v\left(G^{e}\right)=c\left(G^{e}\right) \\
X\left(G^{e}\right) \leq 1 \\
B\left(G^{e}\right) \leq 1 \\
V\left(G^{e}\right) \leq \delta \\
G^{e} \text { deve ser uma floresta de grafos } \\
G=G^{e} \cup G^{n e} \\
\text { seq }(G) \text { ser factível }
\end{array}
$$

Onde:

$G$ é uma configuração radial do SD representado por uma floresta de grafo;

$G^{e}$ é a porção da rede que se encontra em serviço;

$G^{\text {ne }}$ é a porção da rede que se encontra fora de serviço ${ }^{4}$;

$\varepsilon(G)$ é a energia total não suprida durante o intervalo de tempo $\Delta t_{4}$ (requerido para obtenção e implementação de $G)^{5}$;

$\psi(G)$ é o número total de manobras para obtenção de $G$ a partir da configuração em operação antes da atuação do sistema de proteção (definida usualmente como configuração pré-falta $\left(G^{p f}\right)$ );

$A\left(G^{e}\right)$ é a matriz de incidência nó-aresta pseudo-orientada (obtida através de um grafo orientado pelo fluxo das correntes) de $G^{e}$;

\footnotetext{
4 Para garantir que $G^{\text {ne }}$ seja uma floresta de grafo, i.e., um conjunto de grafos acíclicos e conexos, os agrupamentos de setores saudáveis fora de serviço são conectados em nós-raiz fictícios.

${ }^{5} \mathrm{Em} \mathrm{G} \mathrm{G}^{\text {ne }}$ são desconsiderados os setores saudáveis fora de serviço que não podem ser restaurados devido à ausência de chaves e também os setores em falta.
} 
$x\left(G^{e}\right)$ é o vetor de correntes complexas nas linhas em $G^{e}$ $c\left(G^{e}\right)$ é o vetor de correntes complexas demandadas em barras de carga e injetadas em barras de subestações em $G^{e}$;

$Y_{x}\left(G^{e}\right)$ é a matriz diagonal de admitâncias da rede em $G^{e}$;

$v\left(G^{e}\right)$ é o vetor de tensões complexas nas barras em $G^{e}$;

$X\left(G^{e}\right)$ é o máximo valor de carregamento de rede em $G^{e}$ dado por $X\left(G^{e}\right)=$ $\operatorname{MAX}\left\{\mathrm{x}_{\mathrm{j}} / \overline{\mathrm{x}}_{\mathrm{j}}\right\}$, no qual $\overline{\mathrm{x}}_{\mathrm{j}}$ é um limitante superior de corrente para cada magnitude de corrente $x j$ em uma linha $j$;

$B\left(G^{e}\right)$ é o máximo valor para carregamento de subestação (transformador) em $G^{e}$, dado por $B\left(G^{e}\right)=M A X\left(b_{s} / \overline{b_{s}}\right)$, sendo $\overline{\mathrm{b}_{\mathrm{s}}}$ um limitante superior para cada magnitude de injeção de corrente $b_{s}$ provida por uma subestação s;

$V\left(G^{e}\right)$ é a máxima queda de tensão em $G^{e}$, dada por $V\left(G^{e}\right)=M A X\left(\left|v_{s}-v_{k}\right| / \delta\right)$, sendo $\mathrm{V}_{\mathrm{S}}$ a magnitude de tensão na barra de uma subestação $s$ (mais especificamente, na barra secundária do transformador da subestação $s$ ), $\mathrm{v}_{\mathrm{k}}$ é a magnitude de tensão em uma barra $k$ da rede e $\delta$ é a máxima queda de tensão admissível (em (MARQUES, 2018) , $\delta=0,1$, isto é, $10 \%)$;

$\operatorname{seq}(G)$ representa a sequência de chaveamento a ser executada para obtenção de $G$, isto é, a sequência na qual devem ser executadas as manobras necessárias para obtenção de $G$ a partir de $G^{p f}$.

A equação (2.1) refere-se aos objetivos do problema. Já as restrições apresentadas pelas equações (2.2) e (2.3) representam, respectivamente, a primeira e a segunda Leis de Kirchoff, enquanto as descritas pelas equações (2.4) e (2.5) tratam dos limites de carregamento da rede e da subestação. A equação (2.6) se refere ao limite para a queda de tensão observada e a (2.7) à necessidade de manter a radialidade do sistema, já a (2.8) indica que o sistema estará dividido em duas porções, uma energizada e uma desenergizada. Finalmente, a equação 2.9 refere-se à necessidade de a solução ser factível, ou seja, atender a todas as restrições operacionais para garantir a operação segura da rede.

Acrescenta-se à definição de factibilidade a necessidade das configurações intermediárias, isto é, configurações pelas quais o sistema passa durante o tempo gasto com a realização de manobras até chegar à sua configuração final, serem factíveis. Neste caso, no

\footnotetext{
${ }^{6}$ Note que neste trabalho não foi considerada a presença de geração distribuída.
} 
entanto, são usadas restrições relaxadas, ou seja, o sistema pode ultrapassar por uma margem alguns dos limites estabelecidos. Deste modo, a equação (2.9) pode ser explicada por:

$\operatorname{seq}(G)$ é factível, SE:

$$
\begin{aligned}
& A\left(g^{e}\right) x\left(g^{e}\right)=c\left(g^{e}\right), \forall g^{e} \in \Omega_{I}(G) \\
& A\left(g^{e}\right) Y_{x}\left(g^{e}\right) A\left(g^{e}\right)^{t} v\left(g^{e}\right)=c\left(g^{e}\right), \forall g^{e} \in \Omega_{I}(G) \\
& X\left(g^{e}\right) \leq 1, \forall g^{e} \in \Omega_{I}(G) \\
& B\left(g^{e}\right) \leq 1+\Delta B, \forall g^{e} \in \Omega_{I}(G) \\
& V\left(g^{e}\right) \leq \delta+\Delta V, \forall g^{e} \in \Omega_{I}(G) \\
& g^{e} \text { deve ser uma floresta de grafos, } \forall g^{e} \in \Omega_{I}(G) \\
& g=g^{e} \cup g^{n e} \\
& A\left(G^{e}\right) x\left(G^{e}\right)=c\left(G^{e}\right) \\
& A\left(G^{e}\right) Y_{x}\left(G^{e}\right) A\left(G^{e}\right)^{t} v\left(G^{e}\right)=\left(G^{e}\right) \\
& X\left(G^{e}\right) \leq 1 \\
& B\left(G^{e}\right) \leq 1 \\
& V\left(G^{e}\right) \leq \delta \\
& G^{e} \text { deve ser uma floresta de grafos } \\
& G=G^{e} \cup G^{\text {ne }}
\end{aligned}
$$

sendo a obtenção de $G$ a partir de $G^{p f}$ realizada por meio da operação de uma sequência de manobras $\operatorname{seq}(G) ; g$ uma configuração intermediária de $G ; g^{e}$ a porção de $g$ que encontra-se em serviço (energizada); $g^{\text {ne }}$ a porção de $g$ que encontra-se fora de serviço (desenergizada); $\Omega_{I}(G)$ o conjunto formado por todas as configurações intermediárias energizadas de $G$, isto é, todas as configurações que ficarão temporariamente em operação enquanto $\operatorname{seq}(G)$ estiver sendo executada para a obtenção de $G ; \Delta B$ e $\Delta V$ representam, respectivamente, carregamentos de subestação e quedas de tensão adicionais que são aceitos temporariamente enquanto $g$ está em operação.

Novamente, são observadas equações para a primeira e segunda Leis de Kirchoff em (2.10) e (2.11), enquanto (2.12), (2.13) e (2.14) representam, respectivamente, as restrições relaxadas para carregamento de rede, carregamento de subestação e queda de tensão. As demais 
equações, de (2.19) a (2.23), correspondem às mesmas exigências dadas de (2.4) a (2.8), para a configuração final $G$.

Pode-se ainda adicionar aspectos práticos importantes do problema de restabelecimento na formulação. Ao distinguir as chaves controladas manualmente das controladas remotamente, a minimização do número de manobras $(\psi(G))$ se torna um problema hierárquico: CCRs têm preferência sobre CCMs devido ao menor tempo gasto nas manobras dessas chaves. Similarmente, a energia não suprida $(\varepsilon(G))$ pode ser decomposta conforme os níveis de prioridade de cargas. Neste caso, quatro níveis são considerados: prioridade alta (PA), prioridade intermediária (PI), prioridade baixa (PB) e sem prioridade (SP). Deste modo, o atendimento de cargas de prioridade mais alta será sempre mais vantajoso que qualquer quantidade de níveis inferiores. Assim, o enunciado formal do problema pode ser reescrito:

Min. $\varepsilon_{A}(G)$, e com o valor $\varepsilon_{\text {Amin }}(G)$ obtido, resolver:

Min. $\varepsilon_{\text {Amin }}(G)+\varepsilon_{I}(G)$, e com o valor $\varepsilon_{\text {Imin }}(G)$ obtido, resolver:

Min. $\varepsilon_{\text {Amin }}(G)+\varepsilon_{\text {Imin }}(G)+\varepsilon_{B}(G)$, e com o valor $\varepsilon_{B \min }(G)$ obtido, resolver:

Min. $\varepsilon_{\text {Amin }}(G)+\varepsilon_{\text {Imin }}(G)+\varepsilon_{B \min }(G)+\varepsilon_{S}(G)$;

Min. $\psi_{M}(G)$, e com o valor $\psi_{M \min }(G)$ obtido, resolver:

$\operatorname{Min} . \psi_{\operatorname{Mmin}}(G)+\psi_{R}(G)$

\section{Sujeito a:}

$$
\begin{aligned}
& A\left(g^{e}\right) x\left(g^{e}\right)=c\left(g^{e}\right), \forall g^{e} \in \Omega_{I}(G) \\
& A\left(g^{e}\right) Y_{x}\left(g^{e}\right) A\left(g^{e}\right)^{t} v\left(g^{e}\right)=c, \forall g^{e} \in \Omega_{I}(G) \\
& X\left(g^{e}\right) \leq 1, \forall g^{e} \in \Omega_{I}(G) \\
& B\left(g^{e}\right) \leq 1+\Delta B, \forall g^{e} \in \Omega_{I}(G) \\
& V\left(g^{e}\right) \leq \delta+\Delta V, \forall g^{e} \in \Omega_{I}(G) \\
& g^{e} \text { deve ser uma floresta de grafos, } \forall g^{e} \in \Omega_{I}(G) \\
& g=g^{e} \cup g^{n e} \\
& A\left(G^{e}\right) x\left(G^{e}\right)=c\left(G^{e}\right) \\
& A\left(G^{e}\right) Y_{x}\left(G^{e}\right) A\left(G^{e}\right)^{t} v\left(G^{e}\right)=c\left(G^{e}\right) \\
& X\left(G^{e}\right) \leq 1 \\
& B\left(G^{e}\right) \leq 1 \\
& V\left(G^{e}\right) \leq \delta
\end{aligned}
$$


$G^{e}$ deve ser uma floresta de grafos

$G=G^{e} \cup G^{n e}$

sendo $\varepsilon_{A}(G)$ a energia não suprida a consumidores de PA durante o intervalo de tempo necessário para a obtenção e a operação de $G ; \varepsilon_{I}(G)$ a energia não suprida a consumidores de PI durante o intervalo de tempo necessário para a obtenção e a operação de $G$; $\varepsilon_{B}(G)$ a energia não suprida a consumidores de PB durante o intervalo de tempo necessário para a obtenção e a operação de $G ; \varepsilon_{S}(G)$ a energia não suprida a consumidores SP durante o intervalo de tempo necessário para a obtenção e a operação de $G ; \psi_{M}(G)$ o número de manobras em CCMs necessárias para a obtenção de $G$ a partir de $G^{p f}$; e $\psi_{R}(G)$ o número de manobras em CCRs necessárias para a obtenção de $G$ a partir de $G^{p f}$.

Um desenvolvimento mais detalhado de todo esse enunciado é apresentado na tese de doutorado de MARQUES (2018).

\subsection{Revisão Bibliográfica}

Os primeiros estudos do problema de restabelecimento de energia em SDs datam da década de 1970. Em 1975, MERLIN \& BACK apresentam uma das primeiras propostas de uso do processo de reconfiguração de redes para otimizar a operação de SDs. Neste trabalho, é proposto o uso da reconfiguração para reduzir perdas técnicas. Apesar de não tratar do problema de restabelecimento diretamente, é um dos pioneiros no uso da técnica de reconfiguração de redes para tratamento de problemas de SDs, que viria a ser aplicada para o restabelecimento em vários trabalhos que tiram proveito do desenvolvimento computacional observado desde então (NGUYEN et al., 2012; SANCHES, 2013; SANCHES et al., 2014; PRADO et al., 2014; ROMERO et al., 2015; DIMITRIJEVIC et al., 2015).

Muitos dos trabalhos na área propõem o uso de buscas heurísticas e técnicas de inteligência artificial para fazer a reconfiguração de redes objetivando a obtenção de PREs ao invés de abordagens mais tradicionais, como métodos matemáticos. Essa escolha se deve às dificuldades em modelar um problema que envolve equações não-lineares e descontínuas, como se observa no restabelecimento. Acrescenta-se ainda o fato de se tratar de um problema combinatório com uma quantidade enorme de combinações, que torna inviável o uso de programação matemática em sistemas de grande porte (DELBEM et al., 2005; SANCHES et al., 2012). 
Grande parte dos algoritmos propostos para lidar com o problema de restabelecimento de energia em SDs baseia-se em meta-heurísticas (DELBEM et al., 2005; KUMAR et al., 2008; MOAZAMI et al., 2013), principalmente AEs, dada sua implementação simples e habilidade de lidar com uma grande variedade de problemas com resultados satisfatórios (KUMAR et al., 2008; SANCHES, 2013; SANTOS et al., 2010; SANCHES et al., 2014; PRADO et al., 2014). Destaca-se ainda o fato de haver relevante suporte da literatura para a aplicação de AEs em problemas multiobjetivo (DEB, 2001; MENDOZA et al., 2006).

Apesar da presença de AEs específicos para problemas multiobjetivo, os AEMOs, observa-se a existência de trabalhos que usam algoritmos mono-objetivo para tratar do problema de restabelecimento (ZHU, 2002; CARRENO et. al., 2008). Isto é feito através de processos de agregação de funções e utilização de fatores de penalização. Diferente dos algoritmos mono-objetivo, os multiobjetivo fazem o tratamento de várias funções objetivo simultaneamente através de conceitos de Dominância de Pareto (DEB, 2001), não sendo necessário o uso de nenhum artifício para ponderar os objetivos. Estes métodos têm sido amplamente usados em trabalhos de restabelecimento de energia (MENDOZA et al., 2006; KUMAR et al., 2008; SANTOS et al., 2010; SANCHES 2013, CARRANO et al., 2016).

Além dos AEs, trabalhos baseados em sistemas especialistas (LIU et al., 1988) e busca heurística (AOKI, K. et al., 1989; DIMITRIJEVIC et al., 2015) também são alternativas aos métodos de otimização mais tradicionais.

Considerando os trabalhos que utilizam formulação matemática para encontrar uma solução exata para o problema de restabelecimento, destaca-se o trabalho de ROMERO et al. (2016). Neste artigo é utilizada programação cônica de segunda ordem inteira mista para modelar o problema, ao invés da modelagem mais tradicional baseada em programação não linear inteira mista. Assim, o problema pode ser resolvido por algoritmos comercialmente disponíveis baseados em brach and bound. Apesar da abordagem diferente utilizada, ainda é necessário limitar o espaço de busca através de modificações nas restrições técnicas e algumas questões práticas do problema acabam sendo desconsideradas.

É comum que muitos algoritmos trabalhem com simplificações do problema ou sejam limitados a sistemas de pequeno porte, tornando-os inadequados para aplicação em sistemas reais. Apesar dessas simplificações permitirem uma aplicação mais ampla, elas levam a geração de PREs comprometidos. Quanto a este problema, os trabalhos do grupo de pesquisa do LACOSEP e também os desenvolvidos em (CHEN; LIN; TSAI, 2002), (LIN et al., 2011) e (CARRANO et al., 2016) se destacam por serem validados em SDs reais, sem exigir simplificações em relação à quantidade de chaves e barras dos SDs testados. 
O método apresentado por LIN et al. (2011) é baseado em sistemas multi-agente e depende da existência de uma infraestrutura específica para seu funcionamento, pois este tipo de sistema é elaborado considerando que existam elementos capazes de tomar decisões isoladas e/ou em conjunto dentro da rede. Esta abordagem é a mesma utilizada em (HAFEZ et al., 2018), que busca simplificar alguns pontos da implementação deste algoritmo. Também baseado em estratégias multi-agente, há o trabalho de (MANTOVANI; LEITE, 2017) que lida com sistemas capazes de se restabelecer automaticamente. Já o algoritmo apresentado em (CHEN; LIN; TSAI, 2002) é baseado em sistemas inteligentes, ou seja, trata-se de um conjunto de estratégias para simular computacionalmente os conhecimentos dos operadores da rede elétrica a respeito do problema de restabelecimento. O principal problema deste tipo de abordagem é a dificuldade de se extrair os conhecimentos dos operadores para implementá-los computacionalmente, o que, além de bastante trabalhoso, varia conforme a filosofia de operação da rede analisada (KUMAR; DAS; SHARMA, 2008).

No trabalho de CARRANO et al. (2016) é proposto um método baseado em um AEMO seguindo o modelo do AEMO-SPEA2 de ZITZLER et al. (2001). Este método foi validado usando um sistema de distribuição real da CEMIG.

Em uma das publicações de destaque mais recentes no Brasil a respeito do problema de restabelecimento, GOULART (2019) propõe uma metodologia de busca em regiões consideradas promissoras, levando em conta os tempos de deslocamento das equipes para a realização de manobras nas chaves. Este método ainda conta com a capacidade de apresentar a sequência de chaveamento da solução proposta e dá preferência a manobras em CCRs.

Ainda tratando de trabalhos mais recentes, em (LÓPEZ et al., 2018) é apresentado um método baseado em programação não linear inteira mista preparada para lidar com o problema de restabelecimento e manutenção de redes trifásicas desbalanceadas e validado para um sistema teste de 123 barras. Já com uma abordagem voltada para a busca de soluções que envolvam manobras na primeira vizinhança da região de falta preferencialmente, (DRAYER et al., 2018) propõe um algoritmo baseado na teoria de grafos e uma arquitetura de controle distribuído para redes com alto índice de automação.

Explorando mais o avanço da geração distribuída, em (CHEN et al., 2018) é proposto um método de programação não linear inteira mista que inclui no problema os geradores distribuídos. Ao contrário do observado em (LÓPEZ et al., 2018), no entanto, este trabalho não considera um modelo trifásico da rede.

O estado da arte do problema de restabelecimento também tem sido assunto de artigos recentes (LATARE, BHAT, SRIVASTAVA, 2017; ZIDAN et al., 2017). Nestes trabalhos são 
discutidos os principais algoritmos desenvolvidos ao longo dos anos para este problema. Os métodos apresentados são baseados em lógica fuzzy, sistemas especialistas, heurísticas, metaheurísticas e diversos outros algoritmos e suas variações. Em (ZIDAN et al., 2017) ainda são discutidas as etapas de detecção e isolamento da falta, que antecedem o processo de reconfiguração de rede, além de uma discussão de tendências para o desenvolvimento futuro de pesquisas na área. Já tratando especificamente de otimização multiobjetiva, em (ZHOU et al., 2011) é feito um levantamento de diversos algoritmos evolutivos utilizados com essa finalidade.

\subsubsection{Trabalhos do Grupo de Pesquisa LACOSEP-USP}

O problema de restabelecimento de energia tem sido objeto de estudo do grupo de pesquisas do LACOSEP-USP há alguns anos. A principal característica dos trabalhos do grupo é o uso da RNP em conjunto com o AEMO em Tabelas (AEMT) (BENAYOUN et al., 1971), conceitos que são discutidos nos Apêndices A e B. Os algoritmos criados a partir dessa combinação se mostraram computacionalmente eficientes e capazes de lidar com sistemas de grande porte sem a exigência de simplificações no número de chaves e barras.

A construção do algoritmo mais recente desenvolvido pela equipe do LACOSEP-USP começa com o trabalho de SANTOS et al. (2008), onde é apresentado um algoritmo de fluxo de potência por soma de correntes (KAGAN et al., 2005) em SDs de grande porte usando a RNP. Este algoritmo é usado para a etapa de avaliação das soluções geradas no processo evolutivo de um AEMT para reconfiguração de redes (SANTOS et al., 2010). Uma grande vantagem deste algoritmo é não exigir o armazenamento do estado das chaves do SD para cada configuração mesmo para determinar o número de manobras a serem realizadas para a implantação dos PREs obtidos.

Dando continuidade à proposta de utilização da RNP em conjunto com o AEMT, em (SANCHES; LONDON; DELBEM, 2014) foi proposta a inclusão de novas tabelas, que são estruturas usadas para armazenar soluções geradas pelo AEMT conforme suas aptidões, no algoritmo para incluir soluções não dominadas ${ }^{7}$ para comparar as configurações factíveis obtidas (DEB, 2001), semelhante ao que é proposto pelo AEMO conhecido por NonDominated Sorting Genetic Algorithm (NSGA-II) de (DEB et al., 2002). O novo algoritmo foi nomeado AEMT com Múltiplas Tabelas e Heurística (AEMT-MH) e apresentou resultados

\footnotetext{
${ }^{7}$ Detalhes sobre os conceitos de soluções dominadas e não dominadas são apresentados no Apêndice C.
} 
promissores, tanto para casos de falta simples quanto múltiplas, como retratado em (SANCHES et al., 2014).

A adição de um processo de busca exaustiva considerando apenas as chaves NAs do Tier 1 deu origem a um novo método (CAMILLO et al., 2016b), agora chamado de AEMT com Múltiplas Tabelas, Heurística e Busca Exaustiva (AEMT-MH+BE). Nesta nova proposta, o processo evolutivo só é realizado se não houver nenhuma solução factível na busca exaustiva.

Os métodos apresentados até então, não apresentavam solução caso não fosse encontrada configuração alguma que restaurasse todos os setores, indicando apenas a necessidade de corte de carga ou impossibilidade de restabelecimento de setores saudáveis que foram desenergizados em função do isolamento dos setores em falta. Para contornar esse problema, foi proposto, em (CAMILLO et al., 2016a), um algoritmo que analisa as soluções não factíveis (configurações que não atendem a todas as restrições do problema) encontradas pelo processo evolutivo do AEMT-MH e, considerando a possibilidade de não religar todos os setores saudáveis que foram desligadas, busca encontrar pelo menos uma solução factível. Este algoritmo não considera a possibilidade de corte de carga, apenas o não religamento de cargas que já foram desligadas em virtude do isolamento dos setores em falta. Acrescenta-se a isso o fato de essa possibilidade não ser considerada no processo evolutivo, mas sim após a sua realização, tendo um espaço de busca bastante restrito.

Combinando as características do AEMT-MH com mais objetivos do problema de restabelecimento, em (MARQUES, DELBEM, LONDON, 2017) é apresentado um método que considera (i) a priorização de CEs; (ii) priorização de CCRs (menor tempo e custo de operação se comparadas às CCMs que exigem deslocamento de equipes); e (iii) a determinação da sequência de chaveamento para aplicação dos PREs obtidos. Este método foi denominado AEMT com Priorização de Chaves, Consumidores e Definição de Sequência de Chaveamento $(\mathrm{AEMT}++)$.

Por fim, juntando todas as características apresentadas em (MARQUES, DELBEM, LONDON, 2017) e ainda incluindo a possibilidade de gerar soluções sem religamento de todas as cargas restauráveis e a busca exaustiva de CAMILLO et al. (2016), foi proposto o AEMT de MARQUES (2018), utilizado como base no desenvolvimento do método proposto nesta dissertação. Esse AEMT foi validado nos sistemas reais de Londrina (PR) e São Carlos (SP), mostrando-se bastante eficiente. 


\section{MÉTODOS BASE E PROPOSTO}

Neste capítulo é explicado o funcionamento do algoritmo tomado como base para desenvolvimento deste trabalho, assim como o novo método proposto e suas principais limitações.

\subsection{Método base}

O método desenvolvido se baseia no método apresentado por MARQUES (2018), conforme explicado anteriormente. Este método consiste em um AEMT, trabalhando com indivíduos que representam um SD através de conjuntos de RNPs. Porém, existem várias etapas do problema de restabelecimento, partindo do isolamento da falta, até a impressão das soluções finais para o operador, que são realizadas pelo mesmo método.

Pode-se dividir o método base de modo simplificado em cinco grandes etapas: leitura de dados, obtenção do indivíduo inicial, geração da população inicial, processo evolutivo e impressão dos resultados, conforme a Figura 4. Cada uma dessas etapas tem características próprias, mas dentro delas acontecem também diversos processos, que são explicados a seguir.

Figura 4 - Sequência de etapas realizadas pelo método base

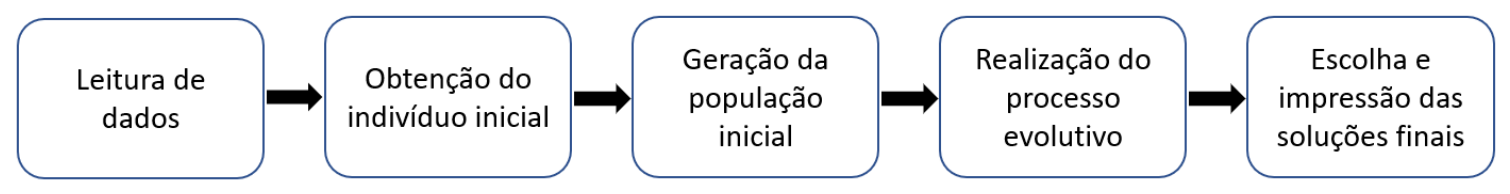

Fonte: Elaborado pelo autor.

\subsubsection{Leitura de Dados}

A primeira tarefa a ser realizada em qualquer problema é organizar os dados conhecidos a seu respeito. Apesar de não ser algo relativo especificamente ao problema de restabelecimento, é nessa etapa que o algoritmo constrói as RNPs que representam o SD e armazena todos os parâmetros da rede.

Esta etapa depende da entrada dos dados por parte do operador. Erros nestes dados podem provocar falhas na representação do sistema e afetar consideravelmente o desempenho do programa. 


\subsubsection{Obtenção do Indivíduo Inicial}

Uma vez que os dados foram devidamente organizados, pode-se dar início às etapas do problema de restabelecimento de fato. A primeira parte do problema de restabelecimento envolve identificar a falta e isolá-la, ou seja, abrir as chaves que a separam do restante do SD.

Com a falta identificada e devidamente isolada, os conjuntos de setores saudáveis que ficaram desenergizados são então movidos para RNPs fictícias, estruturas utilizadas para permitir que seja realizado o processo de busca por soluções. As Figuras 5, 6 e 7 exemplificam o que ocorre ao longo deste processo nos grafos correspondentes a essas RNPs. Começando pela Figura 5, destaca-se um SD representado na forma de grafos com uma falta identificada no setor 2 (em vermelho) e possibilidade de reconexão de setores pela chave NA D (em cinza), que conecta o setor 4 a um setor X qualquer energizado (em verde). A notação de círculos correspondendo a setores e losangos a subestações será utilizada a partir de agora para simplificar a representação de SDs.

Figura 5 - Sistema de distribuição com falta identificada e possibilidade de restauração parcial pela chave D

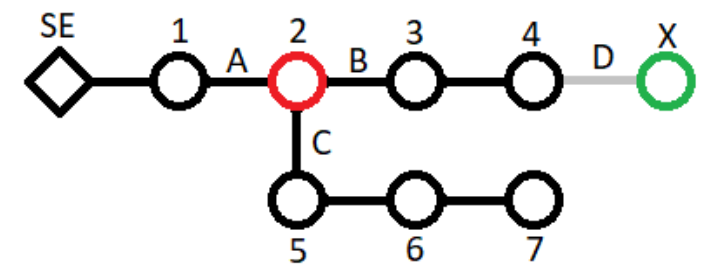

Fonte: Elaborado pelo autor.

Após a identificação do setor em falta, é necessário identificar quais chaves devem ser abertas e realizar essas operações. Nota-se, na Figura 5, que as chaves NF A, B e C deverão ser abertas (em azul) para isolar o setor 2, deixando desenergizados os setores 3, 4, 5, 6 e 7 (em amarelo), conforme a Figura 6.

Figura 6 - Sistema de distribuição em falta com setores afetados identificados

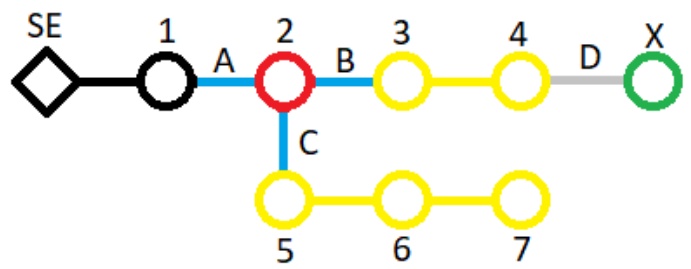

Fonte: Elaborado pelo autor. 
Observa-se, na Figura 6, que os setores 5, 6 e 7, não possuem nenhuma alternativa de restabelecimento disponível, enquanto os setores 3 e 4 podem ser reconectados a partir do fechamento da chave NA D. Assim, a configuração inicial contará com uma RNP fictícia, contendo os setores saudáveis desenergizados e restauráveis, 3 e 4, e uma chave NF conectando o nó 3 a um nó fictício (em roxo), sendo que este representa a origem desta RNP, e a RNP onde ocorreu a falta, agora formada apenas pela subestação e o setor 1 conforme mostra a Figura 7.

\section{Figura 7 - Grafos resultantes da falta identificada no setor 2}

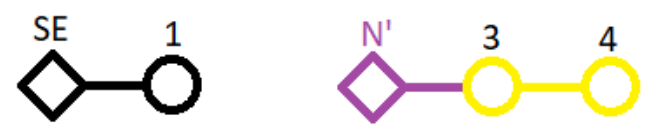

Fonte: Elaborado pelo autor.

As RNPs referentes aos grafos mostrados na Figura 7, juntamente com as demais RNPs do SD, representam a configuração do indivíduo inicial.

Além das RNPs, também são guardadas as informações referentes às manobras realizadas para o isolamento da falta, que são necessárias para avaliar a energia não suprida e montar a sequência de chaveamento para se obter as soluções propostas ao final da execução do método.

Quando não há possibilidade de restauração de setores ou o setor em falta indicado corresponde à uma subestação, o algoritmo é encerrado nesta etapa e retorna uma mensagem de alerta.

\subsubsection{Geração da População Inicial}

Para que um algoritmo evolutivo, caso do AEMT, possa funcionar, é necessário fornecer soluções iniciais, que servem como ponto de partida para o processo evolutivo. São testados então todos os indivíduos em que apenas chaves NA que conectam as regiões desenergizadas com energizadas são manobradas, num processo chamado busca exaustiva (CAMILLO et al., 2016). Essas combinações são testadas de modo exaustivo, ou seja, todas as possibilidades de restaurar o sistema com apenas manobras deste tipo são testadas. Por exemplo, analisando novamente o caso mostrado nas Figuras 5, 6 e 7, a única configuração testada será a que conecta o setor 4 com o setor X, como mostra a Figura 8. 
Figura 8 - Grafo do indivíduo gerado pela busca exaustiva contendo os setores a serem restaurados (em amarelo) e um trecho representando o trecho não afetado pela falta (em verde)

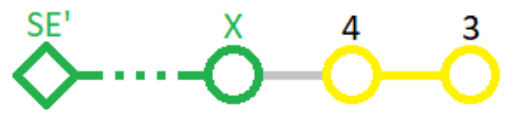

Fonte: Elaborado pelo autor.

Caso durante esta busca exaustiva seja encontrado ao menos um PRE factível (que atenda a todas as restrições) e que restaure todas as cargas possíveis, essa solução é admitida como solução final e o programa irá direto para a etapa de impressão dos resultados. A avaliação de cada PRE é feita através da execução de um fluxo de carga apenas nas RNPs envolvidas nas manobras realizadas, pois os alimentadores não envolvidos nas manobras de restabelecimento não foram afetados. Observa-se que este tipo de solução normalmente terá o menor valor possível de energia não suprida com o mínimo possível de manobras, dado que, de qualquer forma, é necessário fechar pelo menos uma chave NA para restaurar o sistema e a energia não suprida será incrementada durante qualquer manobra.

Figura 9 - Fluxograma simplificado do processo de busca exaustiva contendo as principais etapas realizadas para a geração dos indivíduos que irão compor a população inicial ou a solução final

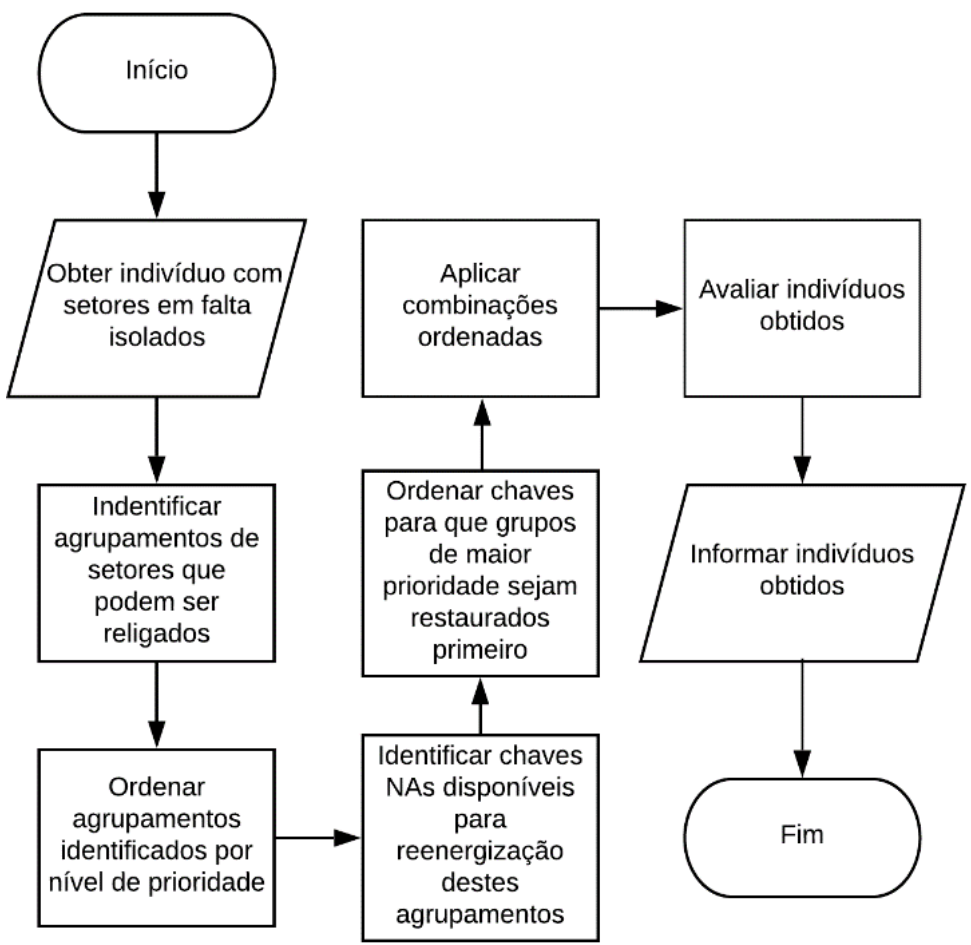

Fonte: Elaborado pelo autor.

Quando não é encontrada uma solução factível que restaure todos os setores saudáveis que foram desligados com possibilidade de conexão com regiões energizadas da rede pela busca 
exaustiva, os indivíduos gerados a partir dela serão usados para preencher as tabelas de subpopulações do AEMT, juntamente com o indivíduo inicial. Obtém-se, então, um ponto de partida para o processo evolutivo, no qual a maioria dos indivíduos será produzida e avaliada. Assim como ocorre na etapa de obtenção do indivíduo inicial, as manobras realizadas durante a busca exaustiva são armazenadas e utilizadas para calcular os valores dos objetivos para cada configuração obtida. Um fluxograma do processo de busca exaustiva é apresentado na Figura 9.

\subsubsection{Processo Evolutivo}

O processo evolutivo é a etapa que exige mais tempo de processamento do algoritmo base. Conforme citado anteriormente, trata-se de um AEMT que trabalha com sistemas representados por RNPs em busca de configurações factíveis com menores energia não suprida e número de manobras.

A duração do processo evolutivo e o tamanho das tabelas de população dependem de parâmetros definidos pelo operador e afetam diretamente o desempenho do algoritmo e a exigência de recursos computacionais. Esta etapa tem caráter iterativo, ou seja, se repete várias vezes até que seja concluída, e depende de fatores de aleatoriedade (afetados, neste caso, por uma semente fornecido ao programa) por ser uma meta-heurística.

Para dar início ao processo evolutivo, o algoritmo seleciona aleatoriamente uma tabela dentre as 26 disponíveis (neste método). Desta tabela, é escolhido, também aleatoriamente, um indivíduo.

Dependendo do indivíduo escolhido, podem ser seguidos dois caminhos:

1) Caso este indivíduo tenha algum setor não fictício (setor saudável desligado) nas RNPs fictícias, ou seja, tenha potência não suprida maior que 0 , será testada a possibilidade de se aplicar o operador Load Reconnect Operator (LRO), que é uma variação dos operadores da RNP que realiza um corte na RNP fictícia e faz seu enxerto em uma RNP real proposto em (MARQUES, 2018);

2) Caso este indivíduo não tenha nenhum setor não fictício nas RNPs fictícias para ser reconectado, será aplicado de maneira aleatória ${ }^{8}$ o operador PAO ou CAO.

\footnotetext{
${ }^{8}$ A chance de aplicação de cada operador dependerá do índice de sucesso deles nas iterações anteriores, baseado na incidência de soluções factíveis obtidas por cada um. Deste modo, ao sortear um número aleatório, haverá mais chances deste valor corresponder a uma aplicação do operador mais bem-sucedido.
} 
Se o indivíduo se encaixar no primeiro caso, ele ainda pode passar pela aplicação do PAO ou CAO na mesma iteração. Assim, existem duas possibilidades para que eles sejam aplicados, mesmo que o indivíduo selecionado tenha potência não suprida diferente de zero:

1) Quando, por algum motivo, o LRO não pôde ser aplicado;

2) Quando, após a aplicação do LRO, surge um indivíduo que, apesar de infactível, está dentro dos limites estabelecidos pelas restrições relaxadas.

Observe que, juntamente com a geração de um indivíduo através de algum dos operadores da RNP, o algoritmo já executará o fluxo de carga e fará a avaliação dos valores de potência e energia não suprida.

Após aplicar os operadores, verifica-se, caso o indivíduo obtido ao final do processo seja factível, se existe alguma chave que retornou ao seu estado inicial (sua posição na configuração com os setores em falta identificados e isolados), ou seja, se a sequência de chaveamento contém apenas manobras necessárias para se obter tal configuração. Esta verificação é feita com base nas informações guardadas de chaves manobradas e indivíduos ancestrais e consiste em (i) obter uma sequência de chaveamento sem as manobras repetidas e (ii) verificar a factibilidade desta nova sequência (conforme a formulação do problema). Para a obtenção da nova sequência de chaveamento utiliza-se o algoritmo de (MARQUES; DELBEM; LONDON JR., 2018).

Por fim, verifica-se se o indivíduo obtido após todas essas etapas está apto a fazer parte de umas das 26 tabelas disponíveis no algoritmo (Apêndice F) e deve-se incrementar em uma unidade ou não o contador de gerações, o que só será feito se (i) o LRO tiver gerado um indivíduo que não viola restrições relaxadas ou (ii) se o indivíduo tiver sido gerado pela aplicação do PAO ou do CAO, independentemente de sua factibilidade. Um indivíduo será salvo em uma tabela caso (i) seu desempenho seja melhor que o do pior indivíduo presente nesta tabela para característica do problema considerada nessa tabela ou (ii) se a tabela ainda não estiver totalmente preenchida (o tamanho das tabelas pode ser definido através de parâmetros de entrada). Caso o indivíduo seja colocado na tabela pela condição (i), o pior indivíduo será então removido.

Esta etapa caracteriza-se por uso intenso de memória RAM do computador, pois ela se repetirá uma quantidade de vezes definida pelos parâmetros informados pelo operador. Portanto, para SDs de grande porte principalmente, é recomendado atenção aos valores 
utilizados. Uma discussão mais aprofundada a respeito do uso de memória é feita na Seção 3.2, onde são discutidas algumas das limitações do método proposto.

O fluxograma que mostra, de modo sucinto, tudo o que acontece durante a etapa de execução do AEMT é apresentado na Figura 10. Este fluxograma desconsidera detalhes da função de verificação da sequência de chaveamento, que podem ser encontrados em (MARQUES; DELBEM; LONDON JR., 2018), e particularidades de cada operador da RNP usadas especificamente neste método, como número de tentativas de sorteio de nós e verificações necessárias ao problema de restabelecimento.

Figura 10 - Fluxograma simplificado do processo evolutivo realizado pelo AEMT com destaque às principais etapas envolvendo aleatoriedade ou algum processo de decisão relativo ao problema de restabelecimento

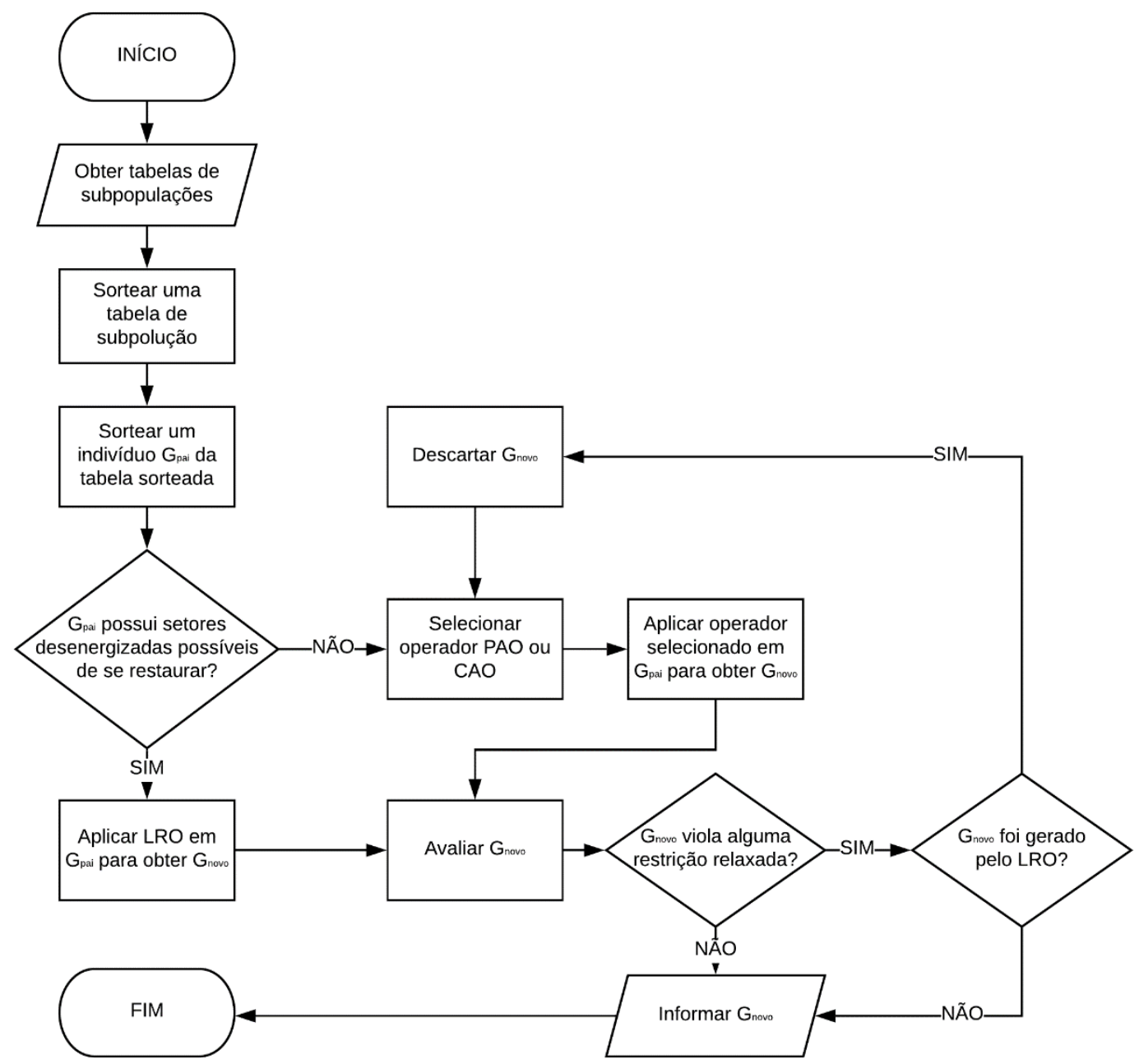




\subsubsection{Seleção e Impressão dos Resultados}

Após a realização de todas as etapas necessárias para geração de soluções para o problema (PREs), é necessário disponibilizar os resultados para o usuário. De fato, a decisão pela aplicação de um PRE ainda cabe ao operador da rede, pois cada solução tem suas particularidades. Pode ser que o operador deseje uma solução com número baixo de manobras, ou então uma que minimize ao mínimo possível a energia não suprida, ou mesmo uma que garanta certo compromisso entre essas duas qualidades, afinal, são os dois objetivos do problema de restabelecimento.

Para auxiliar o operador, o método deve então selecionar as melhores soluções para cada caso, oferecendo alternativas suficientes para que seja tomada uma decisão. O primeiro passo é a leitura dos indivíduos que estão armazenados nas tabelas após o final do processo evolutivo (ou somente da busca exaustiva, caso não tenha sido necessário executar o processo evolutivo).

Os indivíduos lidos das tabelas têm então sua factibilidade verificada, a fim de verificar se atendem às restrições do problema, conforme a formulação apresentada na Seção 2.2. Indivíduos infactíveis são descartados, enquanto os demais são ordenados conforme seu grau de dominância, usando a estratégia apresentada por DEB et al., (2002).

Finalizado o processo de ordenação dos indivíduos, é feita uma aproximação do conjunto Pareto-ótimo. Este conjunto é composto por indivíduos factíveis não-dominados por outros indivíduos e serve de base para a escolha das soluções finais. Vale ressaltar que essa aproximação é feita com base nos valores de energia não suprida total e número de manobras total, dado que esses valores representam as somas das grandezas a serem minimizadas (cada nível de prioridade de energia não suprida e manobras manuais e remotas) e não se conhece uma maneira de traçar uma Fronteira de Pareto que represente o modelo completo. Apesar disso, o uso de tabelas com critérios diversos permite que a aproximação seja mais adequada.

Ainda que seja gerado um conjunto Pareto-ótimo, há uma seleção final a ser feita entre as soluções para que seja apresentada ao operador a fim de facilitar a escolha de um PRE adequado. São separadas as soluções que contém $\left(1^{a}\right)$ o menor valor de $\varepsilon_{T}$ (energia não suprida total), ( $\left.2^{\mathrm{a}}\right)$ o menor valor de $\psi_{T}$ (número total de manobras realizadas) e $\left(3^{\mathrm{a}}\right)$ a melhor ponderação entre $\psi_{T}$ e $\varepsilon_{T}$, ou seja, a solução que mais se aproxima do "joelho" da Fronteira de Pareto. Essas soluções são apresentadas detalhadamente em um arquivo de saída, contendo a sequência de chaveamento e as informações do sistema durante o tempo em que cada configuração estará em operação. 
Outros arquivos de saída também são gerados pelo algoritmo, além do citado no parágrafo anterior. Informações a respeito das tabelas, do conjunto Pareto-ótimo, indivíduos obtidos pela busca exaustiva e outros dados considerados importantes ficam disponíveis em diversos arquivos.

Figura 11 - Fluxograma representando as principais etapas do processo de seleção e impressão dos resultados

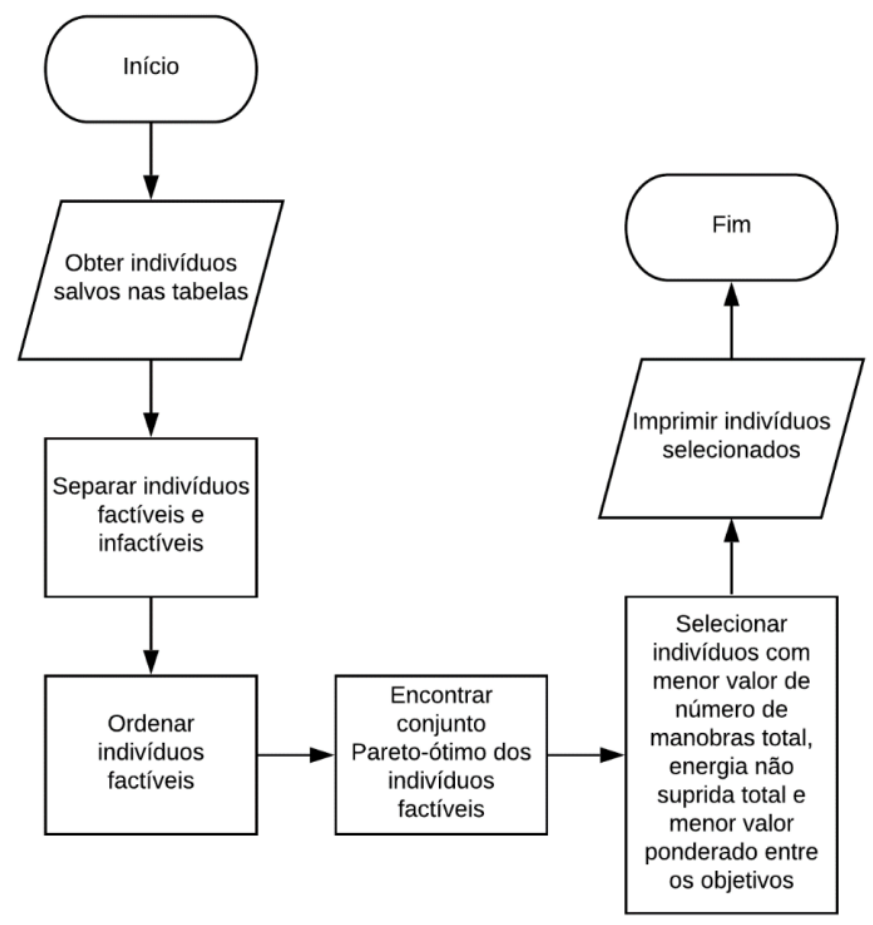

Fonte: Elaborado pelo autor.

Na Figura 11 é apresentado um fluxograma representativo desta etapa. Note que está sendo desprezada a criação dos arquivos adicionais (fora o que carrega as soluções selecionadas por último) e detalhes do funcionamento do conjunto Pareto-ótimo.

\subsubsection{Visão Geral do Método Base}

Todas as etapas explicadas entre as Seções 3.1.1 e 3.1.5 compõem o método de restabelecimento usado como base para desenvolvimento da proposta. É importante também conhecer como todos esses processos atuam juntos. Para facilitar essa visualização, a Figura 12 apresenta, de modo resumido, o processo completo, sem distinção entre as etapas.

Apesar de conter diversas simplificações, a Figura 12 consegue mostrar como os principais processos de cada etapa se conectam para que o método seja capaz de tratar o problema de restabelecimento. 
Figura 12 - Fluxograma mostrando de maneira resumida o funcionamento completo do algoritmo base

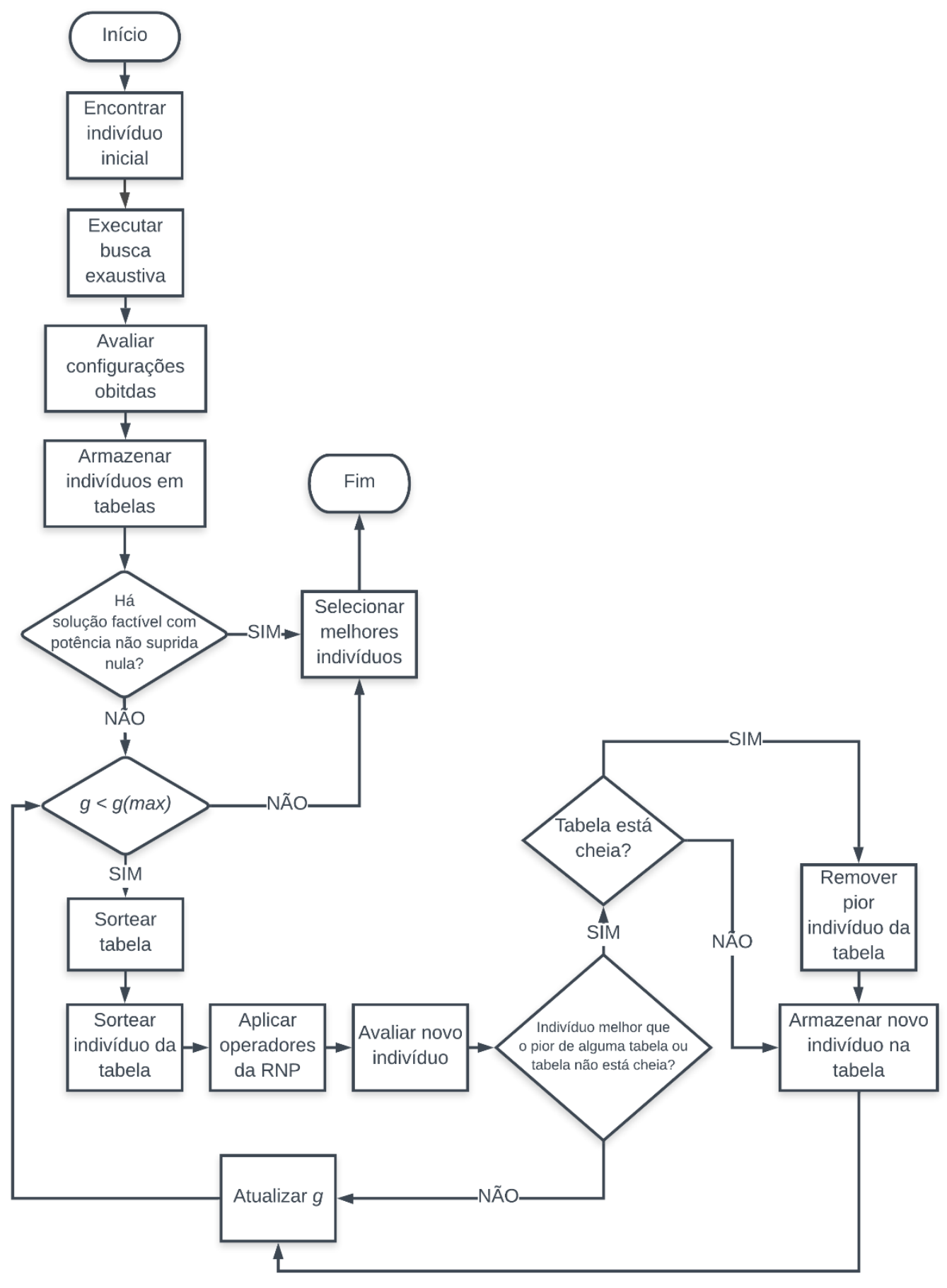

Fonte: Elaborado pelo autor.

\subsection{Método Proposto}

O método proposto possui todas as etapas do método de (MARQUES, 2018), com acréscimo de duas novas funções essenciais: (i) busca local e (ii) operador de corte de cargas. A BL é realizada entre a etapa de obtenção da população inicial e do processo evolutivo (Figura 
4), sendo que há a ocorrência de diversos processos, os quais são discutidos adiante, dentro dela. Já o operador de corte pode ocorrer somente no processo evolutivo. A seguir será apresentado o que fazem, como funcionam e onde se encaixam estas adições em relação ao método base para formar um novo método para solução do problema de restabelecimento de energia.

A fim de preservar a estrutura consolidada usada nos trabalhos do grupo de pesquisa do LACOSEP-USP, foi mantido o uso da RNP e dos seus operadores no processo evolutivo, assim como a leitura de dados, parâmetros de entrada, número de tabelas usadas pelo AEMT e critérios de seleção das soluções finais. No entanto, os resultados finais sofreram mudanças significativas em alguns casos, como será discutido no Capítulo 4.

A primeira diferença entre os dois métodos está na formação da população inicial. Originalmente, era realizada a busca exaustiva com as chaves NAs da primeira vizinhança. No método proposto, caso a busca exaustiva não encontre uma solução, é realizada uma segunda busca local, que testa configurações somente com chaves NAs e NFs da primeira vizinhança, com exceção das chaves NAs internas à região desenergizada. O motivo de desprezar essas chaves é explicado a seguir.

Quanto ao operador de corte de cargas, ele está agora incluído no processo evolutivo e permite a realização de manobras de corte de $\operatorname{cargas}^{9}$ em alimentadores envolvidos no problema de restabelecimento ${ }^{10}$. Agora é considerada a possibilidade de cortes de cargas que não foram desligadas pelo isolamento da falta.

\subsubsection{Busca Local}

Busca local foi o nome escolhido para a busca "pseudo-exaustiva" a ser realizada após a busca exaustiva já existente e antes do processo evolutivo do AEMT. Nessa busca estão envolvidas todas as chaves NAs da primeira vizinhança que conectem um setor energizado a um desenergizado restaurável e todas as chaves NFs que conectem setores desenergizados restauráveis entre si. Isso implica em um aumento considerável no número de combinações possível, que inclui inclusive as próprias combinações da busca exaustiva do método de MARQUES (2018). Isto exige a utilização de estratégias para minimizar o uso de memória e o

\footnotetext{
${ }^{9}$ Considera-se neste caso que o corte de cargas seja a operação de levar um conjunto de setores de uma RNP real (energizada) para uma fictícia (desenergizada).

10 Um alimentador envolve-se no problema de restabelecimento sempre que um PRE incluir pelo menos uma manobra que afete a topologia da rede conectada a ele.
} 
tempo de execução do método através de filtros que analisam quais combinações devem de fato ser analisadas e de simplificações na geração de sequência de chaveamento.

Para todos os indivíduos gerados ao longo da busca local, o ponto de partida é o indivíduo inicial, ou seja, o indivíduo obtido após a falta ser isolada. Portanto, as chaves consideradas são aquelas que estão dentro na região desenergizada ou que conectam a região desenergizada à energizada do indivíduo inicial.

Durante a busca local, o método tentará testar a maior quantidade possível de combinações entre as chaves da primeira vizinhança (Tier 1). Os indivíduos gerados nessa etapa servirão para, em conjunto com os gerados nas etapas anteriores, preencher as tabelas de subpopulações usadas no processo evolutivo, podendo ainda servir como soluções finais eventualmente. $\mathrm{O}$ funcionamento e os artifícios usados pela busca local para torná-la viável em aplicações em tempo real são apresentados nas seções 3.2.1.1 a 3.2.1.3. Estes artifícios vão desde a elaboração de uma representação mais adequada do SD para esta de etapa, até a elaboração de um filtro e modos de execução simplificados que permitam trabalhar em sistemas de grande porte.

\subsubsection{Princípio de Funcionamento da Busca Local}

Para ser realizado o processo de busca local, primeiramente, o método precisa listar quantas e quais são as chaves disponíveis para a busca local. Aproveitando a estrutura já existente baseada em RNPs, a listagem das chaves é feita conforme a ordem em que qualquer dos setores em que elas se conectam aparecem nas RNPs fictícias. Deste modo, suponha que o grafo apresentado na Figura 13 represente setores desenergizados que, para o correto funcionamento do método proposto, estarão conectados à uma SE fíctícia, onde as letras indicam chaves NFs. Este grafo deve passar pelo processo de listagem de chaves para a busca local.

Figura 13 - Grafo formado por setores desenergizados conectados a um nó de subestação fictício

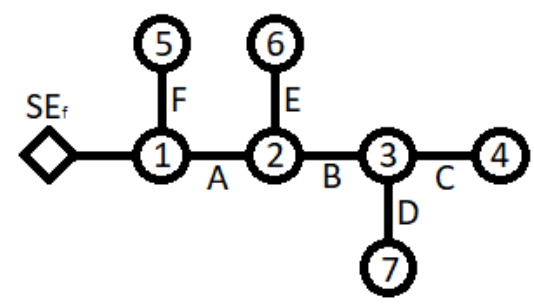

Fonte: Elaborado pelo autor. 
A RNP fictícia correspondente ao grafo apresentado na Figura 13 é:

$$
T=\left[\begin{array}{cccccccc}
S E_{f} & 1 & 2 & 3 & 4 & 7 & 6 & 5 \\
0 & 1 & 2 & 3 & 4 & 4 & 3 & 2
\end{array}\right]
$$

Percorrendo a RNP fictícia para armazenar as chaves disponíveis, conforme a ordem citada anteriormente, será criado um vetor de chaves ordenado da seguinte forma:

$$
C_{N F}=\left[\begin{array}{llllll}
A & F & B & E & C & D
\end{array}\right]
$$

Falta então listar as chaves NAs que conectam estes setores ao trecho energizado. Estas chaves, seguem a mesma lógica, com as que aparecem primeiro, ficando nas primeiras posições de um vetor de chaves NA. Supondo então a existência de chaves NAs conectando os setores 1 (chave $\mathrm{G}$ ) e 4 (chave $\mathrm{H}$ ) à outros energizados, o vetor de chaves NAs será dado por:

$$
C_{N A}=\left[\begin{array}{ll}
G & H
\end{array}\right]
$$

Por fim, junta-se os dois vetores para formar um grande vetor $C$ contendo a ordem em que as chaves aparecem ${ }^{11}$ :

$$
C=\left[\begin{array}{llllllll}
G & H & A & F & B & E & C & D
\end{array}\right]
$$

Com todas as chaves já listadas e ordenadas (lembrando que as informações a respeito dos setores que cada chave conecta também são conhecidas), é criado um vetor de estado das chaves, onde 0 indica aberta e 1 fechada, conforme mostrado abaixo:

$$
C_{c}=\left[\begin{array}{cccccccc}
G & H & A & F & B & E & C & D \\
0 & 0 & 1 & 1 & 1 & 1 & 1 & 1
\end{array}\right]
$$

\footnotetext{
${ }^{11}$ Caso haja mais de uma RNP fictícia, aparecerão primeiro as chaves NA das RNPs fictícias, na ordem dos índices das RNPs, e em seguida as chaves NFs, seguindo o mesmo critério. Por exemplo, para duas RNPs, a composição será [NAs-RNP1 NAs-RNP2 NFs-RNP1 NFs-RNP2]. Apesar de o método não ter sido validado com casos de faltas múltiplas, isso se aplica à casos em que falta simples gera mais de uma RNP fictícia.
} 
A partir deste vetor, são geradas todas as combinações de estados de chaves a serem testadas neste sistema. Essas combinações, no entanto, são testadas a partir de uma estrutura diferente da RNP, baseada na construção de caminhos pelas chaves fechadas, sendo posteriormente convertidas para aplicações dos operadores PAO e CAO adaptados na RNP fictícia.

Na nova estrutura, mantem-se a representação utilizada de 0 e 1 com as mesmas regras, sendo assim, a primeira combinação lida por ela será a configuração representante do indivíduo inicial (sem nenhum setor reconectado ainda e sem mudanças na RNP fictícia). Já para gerar as combinações seguintes, é feita uma contagem no sentido crescente de números binários, ou seja, transformando a primeira combinação em um valor binário, obtém-se 00111111, que tem como próximo valor 01000000. Este novo valor pode ser transformado em um vetor de combinação:

$$
C_{c+1}=\left[\begin{array}{llllllll}
0 & 1 & 0 & 0 & 0 & 0 & 0 & 0
\end{array}\right]
$$

Esta nova combinação corresponde a ter apenas a chave NA $\mathrm{H}$ fechada, religando somente o setor 4, pois as chaves NFs estão abertas. Assim, a nova estrutura fictícia formada, quando convertida a combinação para um grafo, consistiria de uma série de setores "isolados". A representação utilizada, no entanto, consiste de uma estratégia construtiva, ou seja, ao invés de simplesmente levar as chaves para o estado proposto na combinação, são analisadas como se encaixam, partindo de uma chave NA a ser fechada, as chaves que se encontram fechadas e, a partir dela, constroem-se caminhos que formam as novas topologias que representam os setores energizados e desenergizados. Para isso, as chaves em trechos que permanecerão desenergizados, após a realização das manobras, são ignoradas pelo código (independentemente de estarem no estado 0 ou 1), já que não afetam o conjunto energizado da solução final. Deste modo, esta combinação representará, em grafos, a configuração da Figura 14.

Na busca local, no entanto, não podem ser feitas duas manobras simultaneamente (cada manobra da busca local é salva em um indivíduo isoladamente, pois isso é necessário para generalizar o método e aumentar a frequência de indivíduos factíveis), como seria possível sair direto da configuração da Figura 13 para a da Figura 14, pois há a abertura da chave NF C (note que, como o setor 4 será energizado, ela estará conectada com a parte energizada do setor, logo, o valor 0 indica que ela deve ser aberta) e o fechamento da chave NA H. 
Figura 14 - Grafos formadas pela combinação gerada durante o processo de busca local

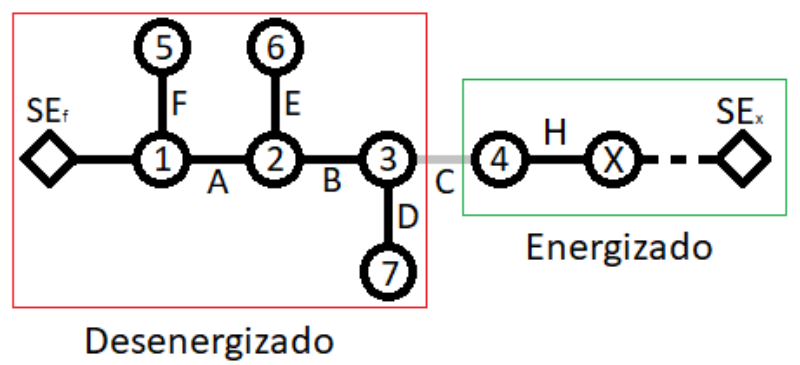

Fonte: Elaborado pelo autor.

Para fazer que a configuração da Figura 14 seja obtida, existem duas possibilidades de sequência de chaveamento: (i) fechar $\mathrm{H}$ e abrir $\mathrm{C}$ ou (ii) abrir $\mathrm{C}$ e fechar $\mathrm{H}$, lembrando que a abertura da chave fictícia que conecta o setor 1 à $S E_{f}$ não contabiliza uma manobra. Apesar disso, há chances muito maiores de (i) ter uma configuração intermediária totalmente infactível (extrapolando inclusive restrições relaxadas) devido à quantidade de setores que serão movidos para um mesmo alimentador se comparado a (ii), em que primeiro o setor 4 é separado dos demais para depois ser conectado a um setor energizado. Escolhe-se, portanto, realizar a sequência (ii) ou similar em todos os casos que não houver a reconexão de todos os setores.

Sabendo que é necessário primeiro separar os setores, para depois reconectá-los em blocos, e que as operações serão feitas através da aplicação dos operadores da RNP nas RNPs envolvidas após a obtenção da combinação a ser testada, a busca local irá converter a estrutura usada por ela para trincas PRA utilizadas pelo PAO e pelo CAO, que serão ordenadas de modo adequado.

A conversão das informações representadas pela combinação para uma ou mais trincas PRA requer alguns passos. A primeira coisa a se fazer é definir os nós $\mathrm{P}, \mathrm{R}$ e $\mathrm{A}^{12}$ correspondentes ao fechamento da chave NA (não é necessário definir P neste caso), sendo:

1) o nó P será usado para guardar um valor para indicar que é necessário rearranjar a RNP antes de aplicar esta operação, conforme será discutido adiante;

2) o nó do lado desenergizado da chave NA a ser fechada é o nó R;

3) o nó do lado energizado da chave NA a ser fechada é o nó A.

Conhecidos os nós que correspondem a trinca PRA que indica o fechamento da chave NA, é necessário estabelecer quantas e quais trincas correspondem às manobras em chaves NF.

12 Os nós P, R e A são os pontos de referência usados para a aplicação dos operadores da RNP. A explicação de cada ponto é apresentada nos Apêndices D e E. 
Para isso, são observadas quais chaves conectadas a setores que foram energizados ao construir o "caminho" formado pela combinação possuem valor 0 no vetor de combinações, que seria o caso da chave $\mathrm{C}$ no exemplo da Figura 14. Logo, os nós $\mathrm{P}, \mathrm{R}$ e A das trincas serão dados por:

1) o nó do lado desenergizado de chaves NF com valor 0 que se encaixem nas condições citadas corresponde ao nó P;

2) o nó R será dado por um valor padrão estabelecido pelo programador, dado que essa operação corresponderá a uma aplicação do operador PAO;

3) o nó A será sempre dado pelo nó raiz da RNP fíctícia ao qual pertence o nó P.

Usando o caso exemplificado na Figura 14, e supondo que -1 seja o valor padrão usado para o nó R do PAO e -2 o valor usado no P da operação envolvendo chaves NAs, as trincas seriam: [-2 $4 \mathrm{X}]$ e [3 -1 $\left.\mathrm{SE}_{\mathrm{f}}\right]$. No entanto, sabe-se que, primeiramente, devem ser executadas as operações de corte, deste modo, a sequência de aplicação das trincas será [3 -1 SEf $]$ seguida por [-2 4 X]. Mas da maneira que está a RNP, não é possível aplicar estas trincas para obter o resultado desejado, dado que as operações na RNP carregam o que tem profundidade maior que do nó R (ou P, caso se trate de um operador PAO). Apesar de isso não ser um problema para a primeira combinação usada como exemplo, seria para uma situação em que são transferidos os setores 3 e 4, mas não os demais, como será tratado a frente.

Para cada vez que for observado o valor padrão no nó P da operação em chaves NA, desde que o nó R já não esteja diretamente conectado ao nó fíctício (caso esteja, essa operação será ignorada), será aplicado um operador CAO, modificado para operar com nós $\mathrm{P}, \mathrm{R}$ e A dentro de uma única RNP, onde:

1) o nó $\mathrm{P}$ é o nó que conecta a sub-árvore na qual está o nó $\mathrm{R}$ da trinca formada com o nó fictício (raiz) da RNP;

2) o nó R será o mesmo da trinca obtida;

3) o nó A será o nó fictício da RNP. Na prática, isso significa que, sempre, para generalizar e simplificar as operações para que possam ser feitas exclusivamente usando os operadores PAO, CAO e LRO já existentes, o nó do lado desenergizado da chave NA a ser fechada sofrerá uma manobra fictícia (não contabiliza tempo de manobra, trata-se apenas de um artifício computacional) para ter profundidade 1 . Assim, para o exemplo da Figura 14, seria necessário aplicar o operador CAO com 
a trinca $\left[\begin{array}{lll}1 & 4 E_{f}\end{array}\right]$, realizando manobras com somente a chave fictícia que conecta a subestação a um setor real que está na parte desenergizada do sistema.

Finalmente, é necessário transformar a trinca correspondente à manobra da chave NA em uma trinca aplicável pelo LRO (que consiste em um CAO que leva setores da porção desenergizada para a energizada). Essa conversão é dada por:

1) o nó $\mathrm{P}$ é o nó $\mathrm{R}$ da trinca original;

2) o nó $R$ é igual ao nó P;

3) o nó A é o nó adjacente ao nó P, por meio de uma chave NA que, ao ser fechada, conecta a porção energizada e a desenergizada.

Aplicando toda essa sequência para sair da situação da Figura 13 para a da Figura 14, seriam observadas, em ordem, as seguintes configurações na RNP fictícia:

1) após a aplicação do operador $\mathrm{CAO}$ (utilizando a trinca [1 4 SE $\mathrm{SE}$ ) para reorganizar a RNP fictícia (manobras fictícias não contabilizam tempo), seria obtida a configuração da Figura 15, onde o nó do lado desenergizado da chave NA operada passa a ter profundidade 1 na RNP fictícia;

Figura 15 - Grafo da porção desenergizada reorganizado para aplicação de manobras

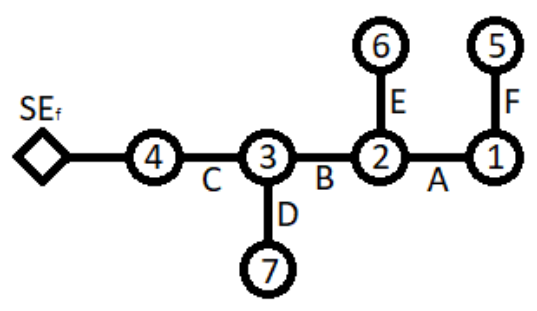

Fonte: Elaborado pelo autor.

2) uma vez reorganizada, aplica-se o conjunto de manobras de abertura de chaves NF na RNP através de um operador PAO (com a trinca [3 $\left.-1 \mathrm{SE}_{\mathrm{f}}\right]$ ) preparado para tratar de manobras com nós $\mathrm{P}, \mathrm{R}$ e $\mathrm{A}$ da mesma RNP, o que leva a obtenção da configuração observada na Figura 16;

3) agora, basta aplicar o operador LRO com a trinca [-2 $4 \mathrm{X}]$, correspondente a conectar o setor 4 com o setor X, resultando nos grafos observados na Figura 17, que, apesar de possuir um grafo diferente da Figura 14, possui os mesmos setores restaurados. 
Figura 16 - Grafo após abertura da chave NF C

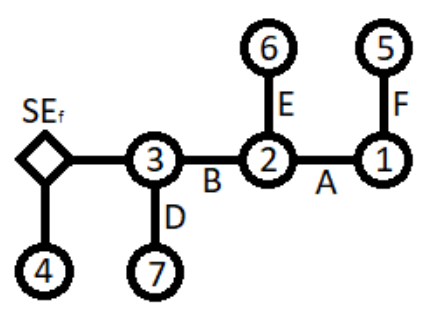

Fonte: Elaborado pelo autor.

Figura 17 - Novas configurações dos grafos após a aplicação de todas as manobras

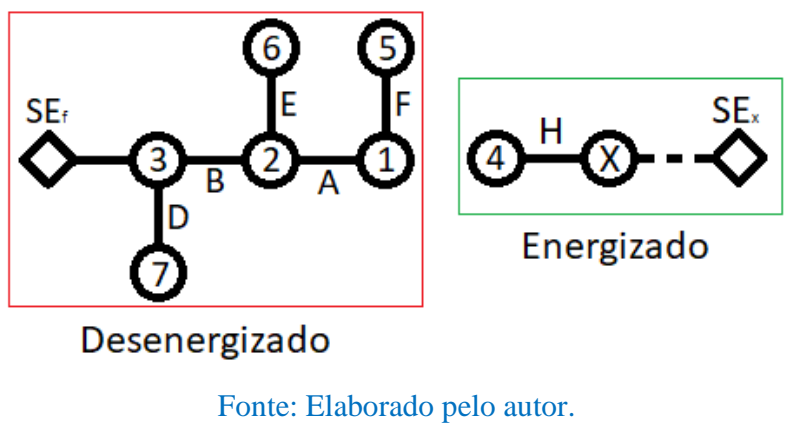

Este processo completo de construção e conversão deve ser realizado para cada chave NA com valor igual a 1 no vetor de combinações.

Observa-se que, para um caso simples como o exemplificado, tudo poderia ser feito pela simples aplicação de um operador PAO que levasse o setor 4 a se conectar com o setor X. Mas, supondo que a combinação fosse dada por $\left[\begin{array}{lllllllll}0 & 1 & 0 & 0 & 0 & 0 & 1 & 0\end{array}\right]$, implicando que a chave $\mathrm{C}$ também estará fechada, uma aplicação direta do operador PAO afetaria drasticamente a factibilidade da sequência de chaveamento, já que o setor 7 seria carregado, juntamente aos setores 3 e 4, para o lado energizado, implicando na aplicação posterior de uma manobra de abertura da chave D para remover o setor 7 novamente. Casos em que há mais de uma chave NA a ser fechada, ou que a chave NA fechada não está em um nó folha, também provocariam os mesmos problemas. Portanto, o processo apresentado tem como finalidade generalizar a geração de indivíduos pela busca exaustiva considerando a factibilidade da sequência de chaveamento. A seguir, é mostrado como a generalização do processo é relevante, a partir do exemplo da combinação [0 $100000010]:$

1) a primeira manobra será a mesma do exemplo anterior, levando o grafo a ter a mesma topologia da Figura 15;

2) neste caso, será necessário separar o setor 7 e os setores 1, 2, 5 e 6 através de duas manobras (Figura 18); 
Figura 18 - Grafo após abertura das chaves NF B e D

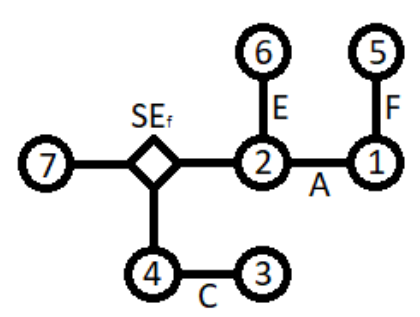

Fonte: Elaborado pelo autor.

3) por fim, os setores 3 e 4 podem ser conectados com a porção energizada, obtendo a configuração desejada (Figura 19).

Figura 19 - Novos grafos após a aplicação das manobras necessárias

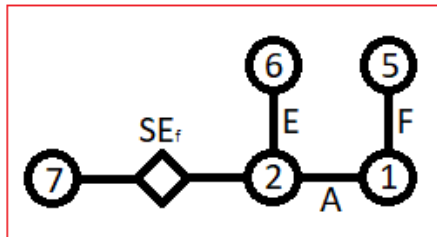

Desenergizado

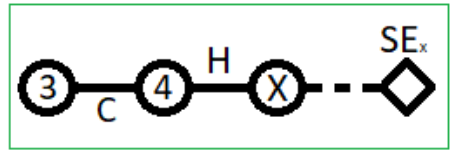

Energizado

Fonte: Elaborado pelo autor.

Este processo será feito para cada combinação válida obtida. A verificação da validade da função é feita através de um filtro, que será explicado na próxima seção. É importante destacar que, para obtenção do indivíduo correspondente a uma combinação, será necessário sempre gerar uma quantidade de indivíduos maior ou igual ao número de manobras realizadas para sair da configuração inicial e chegar a configuração desejada, resultando em um aumento considerável no consumo de memória desta etapa. Outro ponto a ser observado é que, a cada combinação válida, contabiliza-se uma geração, reduzindo assim o número de gerações a serem executadas posteriormente na etapa evolutiva.

\subsubsection{Filtro de Combinações}

$\mathrm{Na}$ antiga busca exaustiva usada pelo método base, apenas combinações com chaves NA da primeira vizinhança eram consideradas, gerando uma quantidade não muito grande de combinações. Na busca local, no entanto, a consideração de chaves NF aumenta consideravelmente o número de combinações, sendo que grande parte sequer atende a restrição de radialidade (note que seria impossível obtê-las diretamente pelos operadores da RNP) ou 
possui manobras que afetam apenas a RNP fictícia, o que significa que essas manobras são inúteis no que diz respeito aos objetivos do problema.

A manutenção da radialidade da rede é uma das restrições do problema de restabelecimento, portanto, as combinações geradas pela busca local que formem anéis devem ser descartadas. Isso só poderá ocorrer caso (i) pelo menos duas chaves NAs que conectam o agrupamento desenergizado ao energizado sejam fechadas ou (ii) houver alguma chave NA que conecta dois setores desenergizados, caso estes sejam energizados posteriormente por outra manobra. Como o segundo caso não é tratado pela busca local, por motivos que serão discutidos adiante neste trabalho, sobra apenas o primeiro caso.

No que diz respeito às manobras que afetam apenas a RNP fictícia, o próprio método de construção da topologia da rede a partir dos elementos do vetor de combinação, já ignorará essas manobras, sendo necessário apenas garantir que não será perdido tempo e nem haverá gasto de memória para gerar indivíduos repetidos.

Para que seja possível descartar as combinações que se encaixem nas condições especificadas, existe um filtro que analisa quais são as combinações válidas e como podem ser ignoradas as inválidas sem a necessidade de percorrer todas elas. Veja que, para percorrer todas as combinações, seria necessário realizar todo o processo de verificação da combinação $2^{\mathrm{n}}$, onde n é o número total de chaves no vetor de combinações.

Parte das combinações já é descartada ao ordenar o vetor com as chaves NAs primeiro e as NFs em sequência. Dado que nenhuma combinação em que todos os elementos correspondentes às NAs valem 0 restaurará setor algum, a referência para se iniciar a contagem das combinações será sempre a configuração inicial, ou seja, todas NFs valendo 1 e todas as NAs valendo 0 .

As demais combinações passam por processos de verificação que identificam se em algum momento houve a conexão entre dois setores energizados e se, após a formação de todos os caminhos com elementos iguais a 1 no vetor de combinação, ainda há algum elemento com valor 1 que não foi usado. Qualquer um desses dois casos fará a combinação ser ignorada e o algoritmo seguirá para a próxima combinação, mas nestes casos ela não será necessariamente fruto da contagem positiva de números binários.

Para explicar como são realizados os descartes e a escolha de qual será a próxima combinação a ser analisada, será retomado o caso apresentado na Figura 13, agora representado pela Figura 20, onde foi incluída também a representação das chaves NAs.

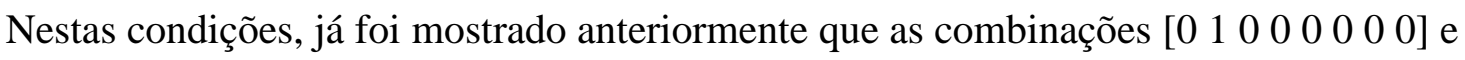

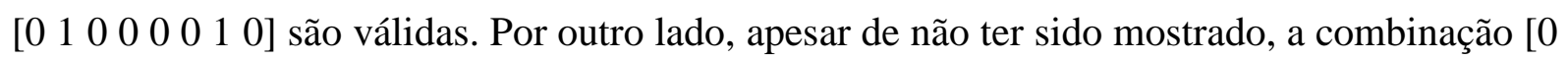


$\left.\begin{array}{llllll}0 & 0 & 0 & 0 & 0 & 1\end{array}\right]$, que está entre as duas, não seria válida pois a chave NF D, sozinha, não consegue reconectar setor algum. Deste modo, até aí, tem-se, na sequência binária:

$$
\begin{aligned}
& {\left[\begin{array}{llllllll}
0 & 0 & 1 & 1 & 1 & 1 & 1 & 1
\end{array}\right] \stackrel{+1}{\longrightarrow}\left[\begin{array}{cccccccc}
0 & 1 & 0 & 0 & 0 & 0 & 0 & 0
\end{array}\right] \text { VÁLIDO }} \\
& {\left[\begin{array}{lllllllll}
0 & 1 & 0 & 0 & 0 & 0 & 0 & 0
\end{array}\right] \stackrel{+1}{\longrightarrow}\left[\begin{array}{llllllll}
0 & 1 & 0 & 0 & 0 & 0 & 0 & 1
\end{array}\right] \text { INVÁLIDO }} \\
& {\left[\begin{array}{llllllllll}
0 & 1 & 0 & 0 & 0 & 0 & 0 & 1
\end{array}\right] \stackrel{+1}{\longrightarrow}\left[\begin{array}{llllllll}
0 & 1 & 0 & 0 & 0 & 0 & 1 & 0
\end{array}\right] \text { VÁLIDO }}
\end{aligned}
$$

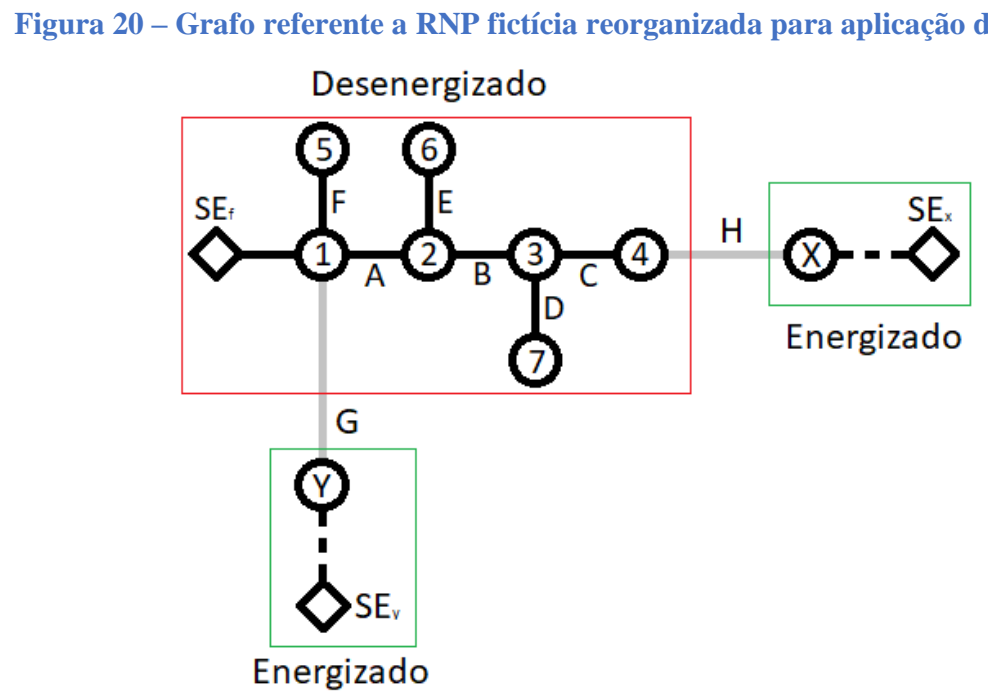

Fonte: Elaborado pelo autor.

Sendo:

$$
C=\left[\begin{array}{llllllll}
G & H & A & F & B & E & C & D
\end{array}\right]
$$

Até este momento, não é necessário nenhum artifício para acelerar o processo, mas continuando esta contagem, ocorrerá o seguinte:

$$
\begin{aligned}
& {\left[\begin{array}{llllllll}
0 & 1 & 0 & 0 & 0 & 0 & 1 & 0
\end{array}\right] \stackrel{+1}{\longrightarrow}\left[\begin{array}{llllllll}
0 & 1 & 0 & 0 & 0 & 0 & 1 & 1
\end{array}\right] \text { VÁLIDO }} \\
& {\left[\begin{array}{llllllll}
0 & 1 & 0 & 0 & 0 & 0 & 1 & 1
\end{array}\right] \stackrel{+1}{\longrightarrow}\left[\begin{array}{llllllll}
0 & 1 & 0 & 0 & 0 & 1 & 0 & 0
\end{array}\right] \text { INVÁLIDO }} \\
& {\left[\begin{array}{llllllll}
0 & 1 & 0 & 0 & 0 & 1 & 0 & 0
\end{array}\right] \stackrel{+1}{\longrightarrow}\left[\begin{array}{llllllll}
0 & 1 & 0 & 0 & 0 & 1 & 0 & 1
\end{array}\right] \text { INVÁLIDO }} \\
& {\left[\begin{array}{llllllll}
0 & 1 & 0 & 0 & 0 & 1 & 0 & 1
\end{array}\right] \stackrel{+1}{\longrightarrow}\left[\begin{array}{llllllll}
0 & 1 & 0 & 0 & 0 & 1 & 1 & 0
\end{array}\right] \text { INVÁLIDO }} \\
& {\left[\begin{array}{llllllll}
0 & 1 & 0 & 0 & 0 & 1 & 1 & 0
\end{array} \stackrel{+1}{\longrightarrow}\left[\begin{array}{llllllll}
0 & 1 & 0 & 0 & 0 & 1 & 1 & 1
\end{array}\right]\right. \text { INVÁLIDO }} \\
& {\left[\begin{array}{llllllll}
0 & 1 & 0 & 0 & 0 & 1 & 1 & 1
\end{array}\right] \stackrel{+1}{\longrightarrow}\left[\begin{array}{llllllll}
0 & 1 & 0 & 0 & 1 & 0 & 0 & 0
\end{array}\right] \text { INVÁLIDO }} \\
& {\left[\begin{array}{llllllll}
0 & 1 & 0 & 0 & 1 & 0 & 0 & 0
\end{array} \stackrel{+1}{\longrightarrow}\left[\begin{array}{llllllll}
0 & 1 & 0 & 0 & 1 & 0 & 0 & 1
\end{array}\right]\right. \text { INVÁLIDO }} \\
& {\left[\begin{array}{llllllll}
0 & 1 & 0 & 0 & 1 & 0 & 0 & 1
\end{array}\right] \stackrel{+1}{\longrightarrow}\left[\begin{array}{llllllll}
0 & 1 & 0 & 0 & 1 & 0 & 1 & 0
\end{array}\right] \text { VÁLIDO }}
\end{aligned}
$$


Existem 6 combinações inválidas entre duas válidas. Para cada uma, a busca local tentará montar a estrutura correspondente e convertê-la para trincas PRA que podem ser aplicadas em RNPs, gastando tempo, especialmente relevante ao problema de restabelecimento, e memória, recurso limitado dos computadores.

Para reduzir os consumos de tempo e recursos computacionais, o filtro, ao identificar que uma combinação é inválida, descobrirá o motivo disso acontecer. Caso seja identificado que o único problema é a presença de chaves NF com valores 1 que não precisam ser percorridas, o que é feito pela verificação da existência de valores 1 no vetor de combinações que não são utilizados em nenhum “caminho" energizado, a posição na qual está a chave não usada mais à direita do vetor será salva e o filtro irá procurar por alguma chave a direita desta posição no vetor, indo da direita para a esquerda, que se conecte com qualquer um dos setores conectados por esta chave. De modo genérico, os passos executados são:

1) Verificar se a combinação é válida;

2) Caso seja inválida devido à presença de chaves NF não percorridas, identificar qual a chave NF mais à direita do vetor não percorrida. Caso seja válida, pular para o passo 6;

3) Procurar por alguma chave com valor 0 entre a posição mais a direita do vetor e a chave imediatamente a direita da chave identificada na etapa anterior (partindo da direita para a esquerda) que se conectem com algum dos setores da chave identificada;

4) Caso seja encontrada alguma chave possível no passo 3, atribuir 1 a ela no vetor de combinações, caso não seja encontrada, atribuir 1 à primeira chave com valor 0 à esquerda da identificada no passo 2 e 0 a todas as chaves à direita da que foi atribuído 1 ;

5) Voltar para o passo 1;

6) Gerar trincas PRA e dar sequência ao processo.

No caso do exemplo, nota-se que a chave problemática em questão é a E, que tem a sua direita no vetor apenas as chaves $\mathrm{C}$ e $\mathrm{D}$, ou seja, nenhum dos setores que se conectam a estas chaves também se conecta a chave E. Deste modo, sabe-se que nenhuma combinação será válida enquanto não forem feitas manobras nas posições a esquerda de E. Assim, o algoritmo irá buscar a primeira posição à esquerda de E com valor 0 , modificá-lo para 1, e zerar E e todos os valores a sua direita. Ao fazer isso, garante-se que não está sendo ignorada nenhuma 
potencial solução válida, mas o processo é acelerado. Para demonstrar o que acontece, seja o caso citado anteriormente representado abaixo. Passo a passo, o filtro irá:

1) verificar se a combinação é válida:

$$
C=\left[\begin{array}{cccccccc}
G & H & A & F & B & E & C & D \\
0 & 1 & 0 & 0 & 0 & 1 & 0 & 0
\end{array}\right]
$$

2) como a combinação não é válida, encontrar a chave mais à direita que causa problemas (chave E), e verificar se as chaves à direita dela, no sentido da direita para esquerda, se conecta com os seus setores ( 2 ou 6, extremos da chave E);

3) como a primeira chave (D) não afeta a responsável pelo problema (E) diretamente, verificar se a próxima (C) se conecta com algum de seus setores (2 ou 6);

4) como não foi encontrada chave que afete a problemática (E) diretamente, e a próxima chave já é ela mesma, zerar todos os valores dela para a direita;

5) encontrar o primeiro zero no vetor a esquerda da chave problemática (será B);

$$
C=\left[\begin{array}{cccccccc}
G & H & A & F & B & E & C & D \\
0 & 1 & 0 & 0 & 1 & 0 & 0 & 0
\end{array}\right]
$$

6) verificar se a combinação obtida é válida;

7) como a combinação continua não sendo válida por causa de outra chave problemática $(\mathrm{B})$, repetir o processo;

8) como foi encontrada uma chave (D) que afeta o problema, a nova combinação será gerada:

$$
C=\left[\begin{array}{cccccccc}
G & H & A & F & B & E & C & D \\
0 & 1 & 0 & 0 & 1 & 0 & 0 & 1
\end{array}\right]
$$

9) verificar se a combinação obtida é válida;

10) como a combinação não é válida por causa de uma chave problemática (D), e também não há chaves a sua direita para serem testadas, ela é zerada; 
11) encontrar a primeira chave com valor 0 a esquerda da chave problemática (será C), gerando a nova combinação:

$$
C=\left[\begin{array}{cccccccc}
G & H & A & F & B & E & C & D \\
0 & 1 & 0 & 0 & 1 & 0 & 1 & 0
\end{array}\right]
$$

12) verificar se a combinação obtida é válida;

13) como a combinação é válida, seguir com a formação das trincas PRA para gerar o novo indivíduo;

14) os próximos indivíduos serão gerados pela contagem binária positiva, até que se encontre algum caso em que o filtro deve atuar.

Através da aplicação do filtro, que é feita em cada nova combinação gerada, nota-se que (i) não serão gerados indivíduos que diferem entre si apenas pela topologia da RNP fictícia e (ii) o número de combinações testadas será reduzido (observa-se, no exemplo, uma redução de 6 para 3 combinações inválidas entre duas válidas).

O efeito deste filtro, no que diz respeito à número de combinações ignoradas, ou seja, não avaliadas, será maior quanto a RNP fictícia misturar trechos lineares com ramificações. Para RNPs totalmente lineares e com apenas uma chave NA num nó de profundidade 1 ou num nó folha, o que é incomum em casos reais, o filtro não irá ignorar combinação alguma.

Além de verificar a validade das combinações quanto ao fato de todas as chaves NF serem percorridas ou não, para não repetir indivíduos, o filtro ainda irá verificar a presença de anéis na estrutura construída dentro da busca local. Esta verificação é consideravelmente mais simples que a anterior, mas falhas nela provocariam erros graves nos indivíduos gerados, devido ao fato de os operadores da RNP não trabalharem com a possiblidade de formar anéis.

Para impedir a formação de anéis, basta verificar se alguma das chaves no vetor de combinações foi utilizada para construir mais de um caminho. Já que cada chave NA fechada irá, necessariamente, construir um caminho, se algum dos setores de uma chave NF participar de mais de um caminho, significa que ele está sendo energizado por dois alimentadores diferentes.

Caso seja verificado que houve a formação de algum anel a partir de uma combinação, o filtro irá identificar qual foi a última chave manobrada (valor mais à direita do vetor que trocou de 0 na combinação anterior para 1). Em seguida, irá procurar o primeiro valor 0 a 
esquerda da posição identificada, igualá-lo a 1 e zerar todos os valores a sua direita. O vetor obtido será a combinação a ser analisada. Passo a passo, o processo é dado por:

1) Verificar se a combinação é válida;

2) Caso a combinação não seja válida devido à formação de anéis, encontrar a última chave "manobrada" (modificada de 0 para 1 da combinação anterior para a atual), caso seja válida, seguir para o passo 7;

3) Encontrar o primeiro valor 0 à esquerda da última chave manobrada;

4) Atribuir 1 à chave identificada no passo 3;

5) Atribuir 0 a todas as chaves à direita da identificada no passo 3;

6) Voltar para o passo 1;

7) Obter trincas PRA e dar sequência ao processo.

Para explicar melhor o funcionamento do filtro contra a formação de anéis, considere novamente a situação proposta na Figura 20. Combinações que fechem as chaves A, B, C, G e $\mathrm{H}$, formam, independente das demais chaves, um anel. Portanto, partindo da combinação em que todas essas valem 1 , no vetor de combinações, e todas as demais valem 0 , o filtro atuará da seguinte forma:

1) verificar se a combinação é válida;

$$
C=\left[\begin{array}{cccccccc}
G & H & A & F & B & E & C & D \\
1 & 1 & 1 & 0 & 1 & 0 & 1 & 0
\end{array}\right]
$$

2) como a combinação não é válida, por formar um anel, encontrar a última chave manobrada (primeiro valor 1 da direita para a esquerda), que será C;

3) encontrar o primeiro valor 0 à esquerda da última chave manobrada (C), que será E;

4) igualar a chave do primeiro 0 à esquerda $(\mathrm{E})$ à 1 ;

5) zerar os valores à direita da chave E;

$$
C=\left[\begin{array}{cccccccc}
G & H & A & F & B & E & C & D \\
1 & 1 & 1 & 0 & 1 & 1 & 0 & 0
\end{array}\right]
$$


6) voltar ao passo 1 ;

1) verificar se a combinação é válida;

2) como a combinação é válida, vá para o passo 7;

7) seguir com a formação das trincas PRA para gerar o novo indivíduo;

8) os próximos indivíduos serão gerados pela contagem binária positiva, até que se encontre algum caso em que o filtro deve atuar.

Assim como o primeiro caso, onde o filtro avalia a presença de chaves não percorridas, esta aplicação do filtro também irá descartar combinações indesejadas e acelerar consideravelmente o processo. Sem o filtro, seria observada a seguinte sequência:

$$
\begin{aligned}
& {\left[\begin{array}{llllllll}
1 & 1 & 1 & 0 & 1 & 0 & 0 & 0
\end{array}\right] \stackrel{+1}{\longrightarrow}\left[\begin{array}{cccccccc}
1 & 1 & 1 & 0 & 1 & 0 & 0 & 1
\end{array}\right] \text { VÁLIDO }} \\
& {\left[\begin{array}{lllllllll}
1 & 1 & 1 & 0 & 1 & 0 & 0 & 1
\end{array}\right] \stackrel{+1}{\longrightarrow}\left[\begin{array}{llllllll}
1 & 1 & 1 & 0 & 1 & 0 & 1 & 0
\end{array}\right] \text { INVÁLIDO }} \\
& {\left[\begin{array}{lllllllll}
1 & 1 & 1 & 0 & 1 & 0 & 1 & 0
\end{array}\right] \stackrel{+1}{\longrightarrow}\left[\begin{array}{llllllll}
1 & 1 & 1 & 0 & 1 & 0 & 1 & 1
\end{array}\right] \text { INVÁLIDO }} \\
& {\left[\begin{array}{lllllllll}
1 & 1 & 1 & 0 & 1 & 0 & 1 & 1
\end{array}\right] \stackrel{+1}{\longrightarrow}\left[\begin{array}{llllllll}
1 & 1 & 1 & 0 & 1 & 1 & 0 & 0
\end{array}\right] \text { VÁLIDO }}
\end{aligned}
$$

Enquanto sem o uso do filtro a sequência passaria por duas combinações inválidas até desfazer o anel, com o uso dele, apenas uma precisa ser verificada. Além disso, o filtro impedirá a geração de trincas PRA para os indivíduos inválidos, evitando erros durante a formação das RNPs, que ocorrerá após a execução da busca local.

A verificação da formação de anéis será mais atuante em sistemas com muitas chaves NAs, principalmente em casos que um mesmo setor possui mais de uma chave NA disponível para restabelecimento.

Por fim, sempre que o filtro identificar que não existe mais possibilidades de gerar combinações novas, seja pelo fato de a contagem binária ter chegado à combinação em que todos os elementos valem 1 ou pelo fato de não encontrar chaves iguais a 0 a esquerda da chave que casou problemas após todas as verificações serem realizadas, ele indicará que a busca local deve ser encerrada por não existir mais nenhuma combinação possível com chances de ser válida.

Em conjunto, essas funções do filtro permitem que o processo de busca local seja rápido e tenha um gasto reduzido de memória. 


\subsubsection{Aplicações em Sistemas de Grande Porte}

Devido ao altíssimo consumo de memória observado nos testes considerando a aplicação da busca local conforme apresentado anteriormente, foi incluído um sistema de ajustes do filtro para casos em que o número de chaves e setores envolvidos nessa busca é muito alto, o que normalmente ocorre com SDs de grande porte (com milhares de barras e chaves), onde os indivíduos gerados consomem muita memória.

O número de combinações possíveis durante a BL depende exclusivamente da quantidade de chaves envolvidas no problema (na região de falta e primeira vizinhança). Logo, a análise do uso de memória será necessária quando estes valores forem muito altos. Esta análise é importante porque permite, mesmo que sem a realização da BL completa, que sejam obtidos indivíduos promissores para preencher as tabelas do AEMT, melhorando o desempenho do processo evolutivo. A análise pode também ser adaptada aos recursos disponíveis para a aplicação do método, aumentando o número de soluções a serem geradas conforme aumenta a memória RAM disponível.

Em situações como esta, realiza-se uma execução prévia do processo de busca local em que não são gerados indivíduos após a obtenção das trincas PRA. Esta execução irá fazer uma previsão aproximada de quantos indivíduos somariam todas as configurações intermediárias e finais geradas (assumindo que cada manobra gera um novo indivíduo, mesmo que seja intermediário) ao longo de uma busca local simplificada considera apenas configurações obtidas por vetores de combinações com, no máximo, $2 n$ elementos com valor igual a zero. Esses zeros podem aparecer até $n$ vezes nas posições do vetor correspondentes às chaves NAs e até $n$ vezes entre as posições correspondentes às chaves NF. Por exemplo, se existirem 5 chaves NAs e 20 chaves NFs e $n=3$, uma combinação deverá ter, no mínimo, duas posições de NAs iguais a 1 e 17 posições de NFs iguais a 1, conforme mostrado a seguir (sendo 1 a 5 chaves NAs e 6 a 25 chaves NF).

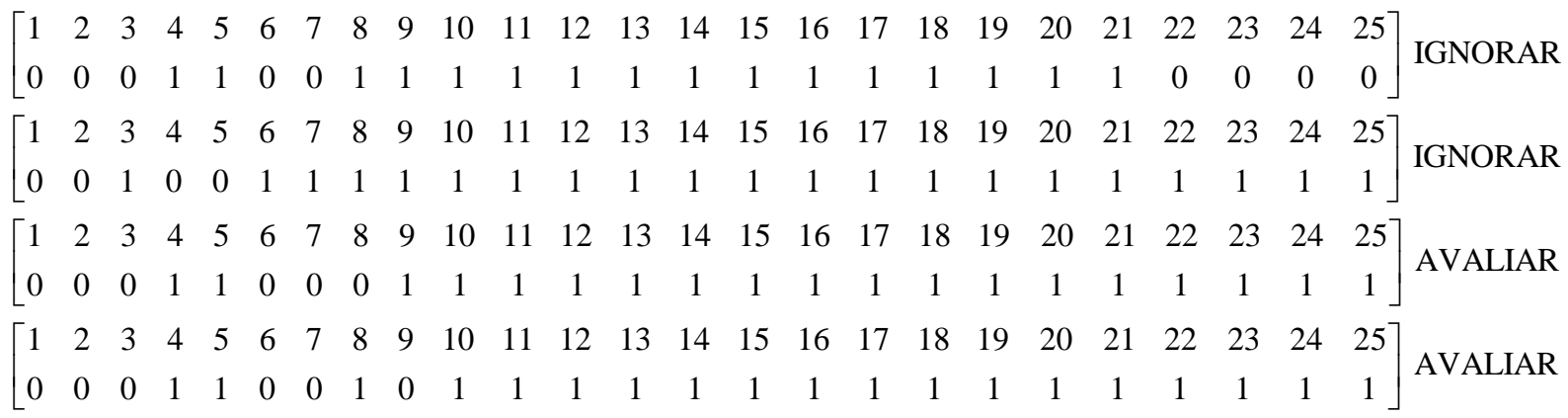


Neste caso, a primeira combinação é ignorada por ter 6 NFs valendo zero, a segunda por ter 4 NAs valendo zero. A terceira e a quarta correspondem às duas primeiras combinações a serem testadas que o filtro consideraria. Acrescenta-se que ele faz essa operação diretamente, não precisando percorrer todas as combinações entre elas.

A determinação aproximação do número de manobras leva em conta que cada chave NA fechada significa até duas manobras (a preparação da RNP fictícia e a transferência do trecho para a RNP real), e cada chave NF aberta significa uma manobra. Logo, a aproximação é dada por:

$$
T_{\text {manobras }}=\sum(\text { manobras em NFs })+2 \cdot \sum(\text { manobras em NAs })
$$

Sempre que o total aproximado de manobras $\left(T_{\text {manobras }}\right)$ for maior que o número de indivíduos permitidos na BL, conforme definido pelo operador do SD, for ultrapassado, o valor de $n$ deve ser reduzido em 1 unidade. Caso $n$ chegue ao valer 0 , ao invés de não realizar manobras, a BL irá tentar encontrar apenas configurações que restaurem todos os setores.

Para simplificar a busca por soluções que restaurem tudo, são testadas combinações em que o número de chaves NFs com valor 0 no vetor de combinações é igual ao número de chaves NAs com valor 1 decrescido do número de RNPs fictícias envolvidas no problema. Esta condição é necessária, mas não suficiente para que não sejam formados anéis.

Nestes casos, é importante considerar, para ajustar $n$ inicial, a quantidade de chaves NAs envolvidas (chaves NAs do tier 1) e o total de chaves (soma de chaves NAs e NFs do tier 1). Números muito altos de chaves NAs envolvidas tornam impraticável a realização deste processo em computadores com limitações na memória RAM e também exigem um grande tempo de processamento, não sendo recomendado para uso em tempo real. Quando o número total de chaves envolvidas no problema for muito alto (por exemplo, mais de 50), recomendase ignorar a busca local e trabalhar apenas com o processo evolutivo.

A escolha deste modo de operação para a busca local simplificada deve-se ao fato de as configurações geradas por combinações com poucos zeros se concentrarem em uma região promissora do problema de restabelecimento para os objetivos considerados. Por deixarem poucos setores desenergizados, esses indivíduos apresentam baixos valores de ENS, assim como não é necessário a realização de muitas manobras para ir da configuração inicial até as configurações a serem geradas. 


\subsubsection{Visão Geral da Busca Local}

O processo de busca local vai desde a identificação das chaves e setores a serem considerados (chaves do tier 1 e setores saudáveis que se encontram desenergizados) até a obtenção da última combinação possível entre elas. Trata-se de um processo iterativo que ajudará a preencher as tabelas de populações a serem utilizadas no processo evolutivo.

Muitas vezes, são encontradas soluções que se mantem entre as melhores ao longo de todo o processo já na busca local, pois ela permite ganhos significativos nos valores de energia não suprida e na factibilidade das sequências, ao considerar apenas manobras em que setores que permaneceram energizados após a isolação dos setores em falta não serão desligados em momento algum.

A Figura 21 mostra, de maneira sucinta, um fluxograma do que acontece desde a etapa de identificação do espaço que a busca local trabalha até a obtenção de sua última solução.

Figura 21 - Fluxograma representando o funcionamento geral do conjunto de operações realizadas no processo de busca local

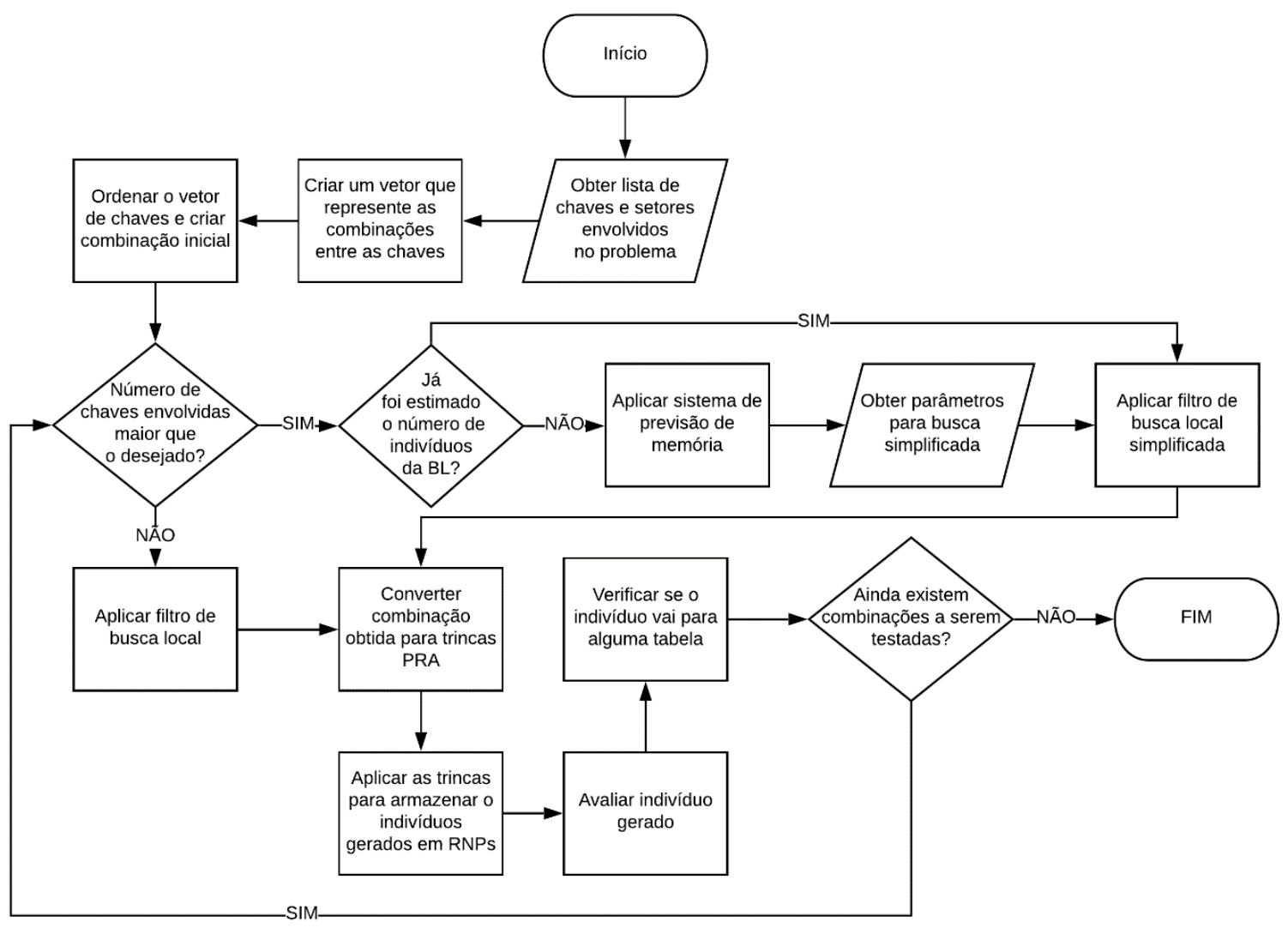




\subsubsection{Operador de Corte de Cargas}

Após o fim do processo de busca local, o método proposto segue para a aplicação do processo evolutivo, baseado no AEMT, assim como ocorre no método base desenvolvido por MARQUES (2018). Porém, agora existe a possibilidade de serem realizados, nesta etapa, cortes de cargas de setores que continuaram energizados após o isolamento dos setores em falta, o que não era permitido nas versões anteriores do AEMT.

O corte de cargas será realizado pelo operador Load Shedding Operator (LSO), proposto neste trabalho, que irá agora "concorrer" com o LRO. O operador LSO consiste basicamente em um caso específico do CAO em que é feito corte em uma RNP real (porção energizada) e enxerto em uma RNP fictícia (porção desenergizada), conforme mostram as Figuras 22 e 23. Nas figuras, um indivíduo qualquer que não tem nós, fora o nó fictício, na RNP fictícia (desenergizada), abre a chave $\mathrm{C}$ para cortar o setor 4.

Figura 22 - Grafos de um SD com conjunto desenergizado vazio
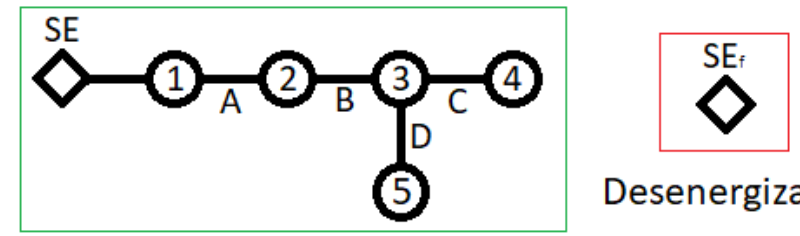

Desenergizado

Energizado

Fonte: Elaborado pelo autor.

Figura 23 - Grafos de um SD após a realização de uma manobra de corte de cargas
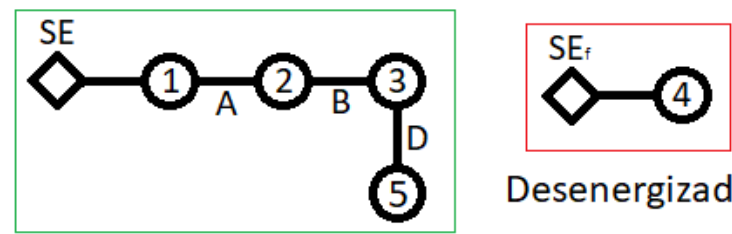

Desenergizado

Energizado

Fonte: Elaborado pelo autor.

A inclusão do corte de cargas aumenta o espaço de buscas do AEMT ao permitir que sejam retirados de serviço setores não desligados após o isolamento da falta. Assim, é possível buscar por soluções que permitam o restabelecimento de uma maior quantidade de cargas prioritárias em alguns casos e até mesmo obter soluções factíveis com menor energia não suprida a partir de configurações previamente infactíveis. 
Apesar das possibilidades acrescentadas, a realização de uma manobra de corte de cargas demanda tempo, assim como as demais manobras, e aumenta o número de manobras total a ser realizado, afetando negativamente os dois principais objetivos do problema de restabelecimento. Por isso, é necessário estabelecer critérios para a aplicação desta operação.

Para controlar a aplicação do operador de corte, que é aleatória, mas não poderá ser aplicada em qualquer indivíduo, são estabelecidos alguns critérios:

1) Só são feitos cortes em indivíduos que sejam infactíveis, pois assim é possível desfazer manobras anteriores ou obter indivíduos factíveis com sequências de chaveamento dentro das restrições relaxadas;

2) Indivíduos que já sejam resultado da realização de um número elevado de manobras (5 neste trabalho, conforme observado o comportamento do algoritmo para os sistemas testados), não terão cargas cortadas, pois o alto número de manobras somado à aplicação de cortes leva a um grande crescimento na energia não suprida total;

3) Apenas alimentadores envolvidos na sequência de chaveamento do indivíduo selecionado para receber a operação de corte podem ter cargas cortadas.

Juntas, essas regras evitam a aplicação de cortes desnecessários e não deixam que o processo evolutivo encha as tabelas com indivíduos que realizam cortes de cargas, já que, apesar de favorecer a variabilidade de soluções, não é desejável cortar consumidores saudáveis.

Outra observação importante a ser feita diz respeito ao LRO. Como, ao incluir o LSO, existe aleatoriedade para escolher entre o LRO e o LSO, configurações com potência não suprida maior que 0 poderão não passar pelo LRO, o que aumenta a presença de indivíduos com restauração parcial. Para compensar essa situação, já que é desejável restaurar o máximo de consumidores possível, os critérios de seleção usados no algoritmo consideram que o LRO tem $90 \%$ de chances de ser aplicado contra apenas 10\% do LSO, que ainda depende de a configuração selecionada ter poucas manobras e ter configuração final infactível.

Ainda que as limitações impostas à aplicação do LSO sejam bastante restritivas, a presença deste operador se mostrou extremamente importante para compensar o fato de não serem testadas ordens variadas durante a busca local e para evitar a polarização criada pelos indivíduos da busca local, que muitas vezes preenche todas as tabelas com indivíduos semelhantes. Merece destaque ainda o fato de o operador de corte servir para "desfazer" algumas manobras em indivíduos infactíveis, já que, caso seja aberta uma chave, que havia sido 
fechada anteriormente, essas manobras são descartadas no momento da verificação da sequência de chaveamento (etapa inclusa dentro do processo de avaliação dos indivíduos no fluxograma das Figuras 12 e 24 para simplificação).

\subsubsection{Visão Geral do Método Proposto}

Assim como apresentado para o método base na Figura 12, o novo método é composto pela junção de todas as etapas realizadas no processo. A Figura 24 mostra como se encaixam todas as etapas dentro do método proposto.

Figura 24 - Fluxograma mostrando de maneira resumida o funcionamento completo do método proposto

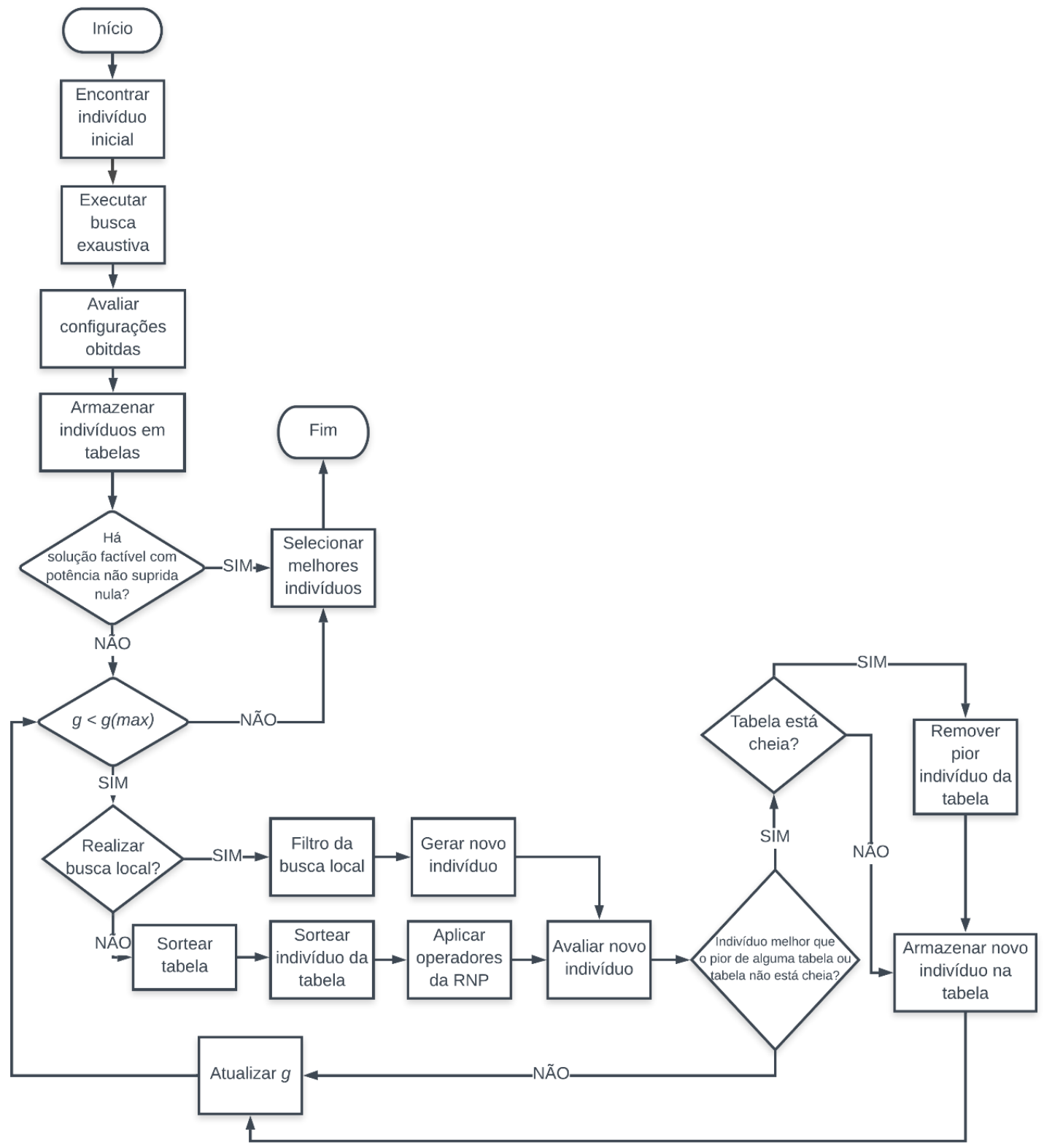

Fonte: Elaborado pelo autor. 
Para facilitar a interpretação e visualização do fluxograma, novamente algumas etapas foram simplificadas. A inclusão do operador de corte de cargas está no processo de "Aplicar operadores da RNP”. Pelo mesmo motivo, os processos de ajuste e geração de indivíduos da busca local ficaram simplificados apenas pelos blocos "Filtro da busca local" e "Gerar novo indivíduo". O bloco "Realizar busca local?" se refere a verificação da existência de novas combinações a serem geradas e da viabilidade de aplicação da BL.

\subsubsection{Limitações do Algoritmo Proposto}

Alguns itens importantes do problema de restabelecimento foram simplificados para viabilizar a implementação da busca local. O primeiro e mais drástico, no que diz respeito ao desempenho da metodologia, foi na montagem da sequência de chaveamento que foi simplificada apenas para garantir que operações de corte sejam feitas primeiro para não afetar a factibilidade da sequência. Isso significa que não há preferência para que chaves NAs que restauram mais cargas serem manobradas primeiro, elas sempre serão manobradas na sequência em que aparecem no vetor de combinações, partindo da esquerda para a direita.

O segundo item simplificado foi a desconsideração de chaves NAs entre dois setores desenergizados para as combinações da busca local. Estas chaves aumentam consideravelmente o número de indivíduos gerados na busca local e também a complexidade do processo, sendo uma situação observada em pouquíssimos dos casos simulados.

As duas simplificações são bastante importantes para garantir a viabilidade das execuções em computadores com configurações razoáveis em tempo real, principalmente quanto ao uso de memória, conforme será discutido na seção 3.2.5.

Mesmo que sejam simplificações consideráveis, os operadores LRO e LSO ajudam a contornar em parte os problemas causados. O LSO pelos motivos discutidos anteriormente ajuda muito a questão da variabilidade nas sequências de chaveamento. Já o LRO consegue compensar o fato de as chaves NAs entre dois setores em falta não serem contabilizadas, pois, após um dos setores ligados a ela ser energizado na busca local, ela se torna uma opção de aplicação do LRO. 


\subsubsection{Uso de Recursos Computacionais}

Para que a execução do algoritmo proposto ocorra sem problemas, é preciso tomar cuidado na escolha dos parâmetros referentes ao número de gerações e limites da busca local, especialmente em sistemas de grande porte.

As principais medidas adotadas para controlar o consumo de memória RAM do programa foram a contabilização das gerações, já a partir da busca local, e a implementação de um sistema de previsão e ajuste do número de indivíduos para situações em que há uma grande quantidade de chaves envolvidas na busca local.

Os testes foram feitos com os mesmos sistemas usados em (MARQUES, 2018), o SD apresentado em (ROMERO et al. ,2016) e o da região metropolitana de Londrina, a fim de ter valores adequados para comparação. No caso de Londrina foi necessário utilizar a busca simplificada, descartando a execução da busca local em alguns casos para as simulações serem viáveis considerando 45.000 gerações, somando busca local e processo evolutivo. Os valores utilizados serão discutidos no Capítulo 4. No SD apresentado em (ROMERO et al. ,2016), não foram observados problemas com o gasto de memória por se tratar de um sistema pequeno, mesmo realizando a busca local completa.

Tratando especificamente do consumo de memória RAM, no caso do sistema de Londrina, foi observado que, a cada 10.000 gerações no processo evolutivo, há um consumo de aproximadamente $1,2 \mathrm{~GB}$. No entanto, durante a BL, o consumo cresce consideravelmente, de modo que para a obtenção 10.000 indivíduos (não necessariamente gerações), pode chegar a 8GB em casos mais críticos, indicando que esta etapa ainda precisa de otimizações consideráveis no uso da memória. Uma possibilidade de melhoria considerada foi a de procurar por configurações intermediárias que se repetiam ao longo do processo, para reaproveitar os indivíduos já salvos, porém os testes realizados mostraram que o tempo gasto cresce a ponto o processo tornar-se inviável para aplicação em tempo real. De qualquer forma, a BL requer o armazenamento das combinações obtidas ao longo do processo e a geração de diversos vetores e matrizes com informações para a conversão do modelo construtivo para as RNPs, o que aumenta o consumo de memória.

Quanto ao tempo de processamento especificamente, não foram observadas diferenças significativas na implementação realizada. De fato, em média, o algoritmo proposto se mostrou levemente mais rápido que o algoritmo de MARQUES (2018), considerando simulações realizadas em um mesmo computador. Isso se deve principalmente aos fatos de a busca local, 
que contabiliza uma geração executada a cada combinação válida, não necessitar de nenhuma verificação de viabilidade na hora de manipular as RNPs, já que não há aleatoriedade envolvida.

\subsection{Comparação Entre os Métodos}

Para deixar claro as características compartilhadas e as diferenças entre o método base, apresentado em (MARQUES, 2018), e o método proposto neste trabalho, foi elaborada a Tabela 1.

\begin{tabular}{|c|c|c|}
\multicolumn{1}{c|}{} & \multicolumn{1}{c}{ Tabela 1-Comparação entre os dois métodos } \\
\cline { 2 - 3 } \multicolumn{1}{c|}{$\begin{array}{c}\text { Forma de representação } \\
\text { do SD }\end{array}$} & Método Base & Método proposto \\
\hline $\begin{array}{c}\text { Geração da } \\
\text { população inicial }\end{array}$ & Busca exaustiva & $\begin{array}{c}\text { Busca exaustiva + Busca } \\
\text { local (quando viável) }\end{array}$ \\
\hline $\begin{array}{c}\text { Algoritmo evolutivo } \\
\text { adotado }\end{array}$ & AEMT com 26 tabelas & AEMT com 26 tabelas \\
\hline $\begin{array}{c}\text { Operadores usados no } \\
\text { processo evolutivo }\end{array}$ & LRO, PAO, CAO & LRO, LSO, PAO, CAO \\
\hline $\begin{array}{c}\text { Possibilidade de não } \\
\text { restabelecimento total }\end{array}$ & SIM & SIM \\
\hline $\begin{array}{c}\text { Possibilidade de } \\
\text { corte de cargas }\end{array}$ & NÃO & SIM \\
\hline $\begin{array}{c}\text { Escolhativos } \\
\text { soluções finais }\end{array}$ & Minimizar $\varepsilon(G), \psi(G)$ & Minimizar $\varepsilon(G), \psi(G)$ \\
\hline
\end{tabular}

Fonte: Elaborado pelo autor.

A análise da Tabela 1 mostra que a estrutura do método base foi mantida para o desenvolvimento do método proposto, sendo que houve apenas a adição de algumas funções. Esta tabela, em conjunto com o fluxograma da Figura 24, permite um melhor entendimento das diferenças entre os dois métodos. 



\section{RESULTADOS}

Neste capítulo são apresentados os resultados obtidos pelo método proposto e discutido a sistemática utilizada para avaliação dos resultados, assim como parâmetros para execução dos programas que implementam os métodos base e proposto.

\subsection{Sistemática de Avaliação}

As simulações para avaliar o desempenho do método proposto foram realizadas em dois SDs diferentes: o sistema teste de 53 barras apresentado em (ROMERO et al. ,2016) e o SD real de grande porte da região metropolitana de Londrina. Todas as simulações consideradas são de casos de faltas simples e os resultados obtidos foram comparados com os obtidos a partir da aplicação do método base, desenvolvido por MARQUES (2018).

A alternativa escolhida foi a comparação entre os melhores indivíduos obtidos quanto à energia não suprida e número de manobras, objetivos considerados no enunciado formal do problema apresentado no Capítulo 2.

Além da comparação a partir dos valores dos objetivos, foram incluídas outras variáveis em alguns casos, como queda de tensão e carregamento, para explicar a diferença entre os resultados obtidos. Também foi considerado o tempo médio de execução das simulações, por se tratar de um dado importante para trabalhos em tempo real.

Todas as simulações foram feitas em dois hardwares diferentes. O primeiro conta com um processador Core i7 4770 e 32GB RAM DDR3 a 1600MHz, rodando o sistema Ubuntu 16.04 LTS. O segundo conta com processador Core i3 8100 e 16GB RAM DDR4 a 2400MHz, além de um disco rígido híbrido com $8 \mathrm{~GB}$ de memória flash, bastante útil para compensar parte da diferença de quantidade de RAM entre os sistemas, rodando o sistema Ubuntu 18.04 LTS. O segundo sistema se mostrou mais rápido para a realização das simulações, portanto, foram considerados seus tempos de simulação nos resultados.

Como foi utilizado um computador com 16GB de RAM, nos casos do sistema de pequeno porte, não houve necessidade de simplificação da BL. No entanto, para o sistema de grande porte foram feitos ajustes que restringiram a BL a um número menor de indivíduos. Os valores usados para as simulações são mostrados na Tabela 2 


\begin{tabular}{|c|c|c|}
\hline & $\begin{array}{c}\text { Sistema da Região } \\
\text { Metropolitana de Londrina }\end{array}$ & Sistema teste de 53 barras \\
\hline $\begin{array}{c}\text { Quantidade de simulações } \\
\text { por setor em falta }\end{array}$ & 35 & 35 \\
\hline Número de gerações & 45.000 & 20.000 \\
\hline Busca local & $\begin{array}{l}\text { Ajustada pelo número de chaves } \\
\text { no tier } 1\end{array}$ & Completa \\
\hline $\begin{array}{c}\text { n inicial para ajuste da } \\
\text { busca local }\end{array}$ & $\begin{array}{c}5 \text { (até } 5 \text { chaves NAs no tier } 1) \\
3 \text { (de } 5 \text { a } 10 \text { chaves NAs no tier } 1) \\
\left.0^{*} \text { (mais de } 10 \text { NAs no tier } 1\right)\end{array}$ & Não se aplica \\
\hline $\begin{array}{c}\text { Limite de indivíduos } \\
\text { gerados pela busca local }\end{array}$ & 7.500 & $\begin{array}{l}\text { Igual ao número de } \\
\text { gerações }\end{array}$ \\
\hline $\begin{array}{l}\text { Limite de chaves no tier } 1 \\
\text { para execução da busca } \\
\text { local completa }\end{array}$ & 15 (sendo pelo menos $1 \mathrm{NF}$ ) & Não se aplica \\
\hline $\begin{array}{l}\text { Limite de chaves no tier } 1 \\
\text { para execução da busca } \\
\text { local limitada }\end{array}$ & 50 (sendo no máximo 15 NAs) & Não se aplica \\
\hline $\begin{array}{l}\text { Limite de manobras para } \\
\text { aplicação do LSO }\end{array}$ & 5 & 5 \\
\hline
\end{tabular}

Para garantir que não haja distorções nos resultados, as simulações foram feitas com os mesmos parâmetros para o algoritmo proposto em (MARQUES, 2018). Obviamente, os parâmetros relativos à BL não o afetam, portanto considera-se apenas a quantidade de simulações e o número de gerações.

Quanto às características dos sistemas testados, os dados elétricos das configurações pré-falta, tipos de chaves e consumidores conectados às redes são apresentados na Tabela 3,4 e 5 , respectivamente. 


\begin{tabular}{|c|c|c|}
\multicolumn{1}{c|}{} & Tabela 3- Informações dos sistemas nas configuraçoes pré-falta \\
\cline { 2 - 3 } & $\begin{array}{c}\text { Sistema da Região } \\
\text { Metropolitana de Londrina }\end{array}$ & Sistema teste de 53 barras \\
\hline Subestações & 15 & 3 \\
\hline Alimentadores & 83 & 6 \\
\hline Setores & 3.479 & 53 \\
\hline Barras & 40.606 & 53 \\
\hline
\end{tabular}

Fonte: Elaborado pelo autor.

\begin{tabular}{|c|c|c|}
\multicolumn{1}{c|}{} & Tabela 4- Chaves disponiveis nos sistemas estudados \\
\cline { 2 - 3 } \multicolumn{1}{c|}{} & $\begin{array}{c}\text { Sistema da Região } \\
\text { Metropolitana de Londrina }\end{array}$ & Sistema teste de 53 barras \\
\hline CCMs & 3.712 & 61 \\
\hline CCRs & 181 & 0 \\
\hline Total & 3.893 & 61 \\
\hline
\end{tabular}

Fonte: Elaborado pelo autor.

\begin{tabular}{|c|c|c|}
\hline \multicolumn{1}{|c}{} & Tabela 5 - Consumidores por nível de prioridade nos sistemas estudados \\
\cline { 2 - 3 } & $\begin{array}{c}\text { Sistema da Região } \\
\text { Metropolitana de Londrina }\end{array}$ & Sistema teste de 53 barras \\
\hline Prioridade Alta & 107 & 0 \\
\hline Prioridade Intermediária & 154 & 0 \\
\hline Prioridade Baixa & 254 & 50 \\
\hline Sem Prioridade & 6.763 & 50 \\
\hline Total & 7.278 & \\
\hline
\end{tabular}




\subsection{Resultados com a Busca Local Completa}

Foi escolhido para os testes o sistema apresentado em (ROMERO et al., 2016) por ser um sistema de fácil visualização (Figura 25) e bem documentado quanto ao problema de restabelecimento (ROMERO et al., 2016; MARQUES, 2018). Os parâmetros deste sistema podem ser encontrados nas Tabelas 3, 4 e 5 .

Também foram definidos os limites operacionais da rede e parametrizado o tempo gasto por manobra nas chaves manuais e automáticas, assim como o tempo estimado total para uma falta. Os valores estabelecidos e apresentados na Tabela 6 seguem o que foi proposto por ROMERO et al. (2016) e ZIDAN, EL-SAADANY (2012) e valem para todas as simulações realizadas neste sistema.

Tabela 6 - Restrições do problema e tempos utilizados para a simulação com o sistema de pequeno porte

\begin{tabular}{|c|c|c|c|c|c|c|}
\hline Parâmetro & $\boldsymbol{\delta}$ & $\Delta \boldsymbol{B}$ & $\Delta \boldsymbol{V}$ & $\boldsymbol{T}$ & $\boldsymbol{t}_{\boldsymbol{C C R}}$ & $\boldsymbol{t}_{\boldsymbol{C C M}}$ \\
\hline Valor & $10 \%$ & $50 \%$ & $10 \%$ & 4 horas/falta & 50 segundos & 25 minutos \\
\hline
\end{tabular}

Fonte: Elaborado pelo autor.

Assim, foram realizadas 35 simulações de falta simples em cada um dos setores do sistema. Casos que são resolvidos pela busca exaustiva ou não possuem possibilidade de restabelecimento de nenhum setor foram desconsiderados para as avaliações, já que os resultados obtidos pelo método proposto nestes casos são iguais aos obtidos pelo método base. Sem contar os setores que foram desconsiderados, sobraram 14 setores a serem testados: 1, 3, $4,7,11,12,14,15,30,38,44,45,46$ e 47.

Antes de partir para uma análise mais detalhada do desempenho dos métodos em casos específicos, a Tabela 7 mostra o número de manobras, o valor de energia não suprida total e a PNS total da configuração final da solução com menor energia não suprida que apareceu em pelo menos metade das simulações em cada caso de falta simples considerado. Apenas as soluções de menor ENS estão sendo destacadas por não terem sido observadas diferenças relevantes nos indivíduos de menor número de manobras. Casos específicos, no entanto, são destacados em seguida, tratando de todos os indivíduos obtidos. 
Figura 25 - Sistema de 53 barras representado no formato barra-chave em sua configuração pré-falta

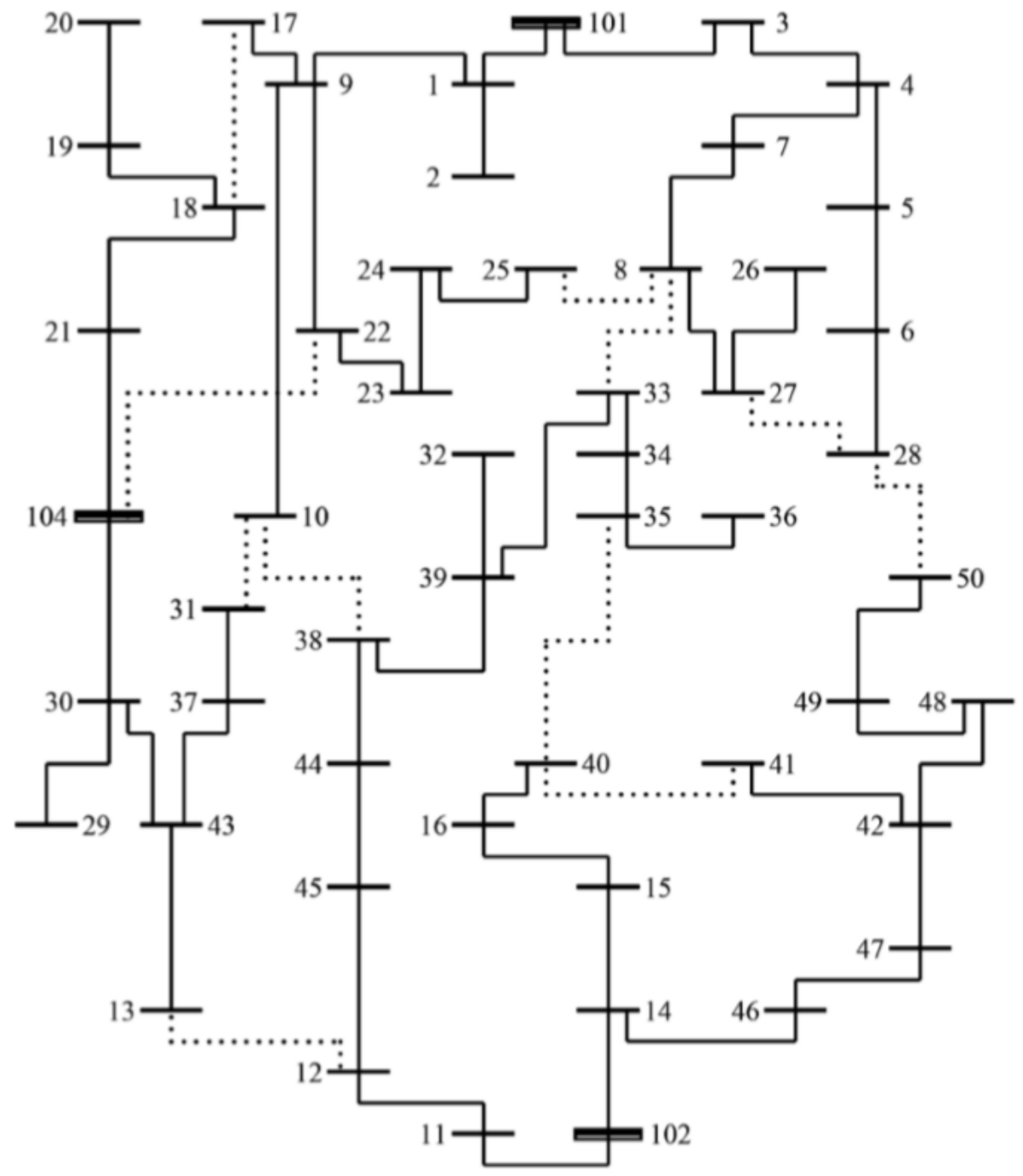

Fonte: ROMERO et al (2016).

O motivo de mostrar a Tabela 7, que não leva em conta totalmente o conjunto ParetoÓtimo encontrado em cada caso, mas sim os menores valores de ENS, é exemplificar como um tratamento baseado em potência não suprida resulta em valores consideravelmente diferentes da abordagem baseada em ENS. Observa-se, nos setores 3 e 4, que a PNS pode ser maior ao final das manobras, porém a ENS é menor, nesses dois casos precisando, inclusive, de menos manobras. Novamente, deve-se destacar que a PNS não é um dos objetivos tratados pelos métodos, logo, levando em conta os objetivos considerados, o método proposto obtém soluções mais adequadas. 
Tabela 7 - Melhores valores de energia não suprida obtidos em cada caso que apareceram em pelo menos metade das simulações, com respectivos números de manobras e potências não suprida finais

\begin{tabular}{|c|c|c|c|c|c|c|}
\hline \multirow[b]{2}{*}{ Setor } & \multicolumn{3}{|c|}{ Método Base } & \multicolumn{3}{|c|}{ Método Proposto } \\
\hline & $\varepsilon(G)$ & $\operatorname{PNS}(G)$ & $\boldsymbol{\psi}(\boldsymbol{G})$ & $\varepsilon(G)$ & $P N S(G)$ & $\boldsymbol{\psi}(\boldsymbol{G})$ \\
\hline $1 *$ & 6352,5 & 0 & 5 & 5486,25 & 0 & 5 \\
\hline 3 & 20131,65 & 3257,1 & 8 & 19790,92 & 5128,2 & 7 \\
\hline 4 & 17371 & 2494,8 & 9 & 15557,85 & 4365,9 & 8 \\
\hline $7 *$ & 3205,13 & 0 & 5 & 3205,13 & 0 & 5 \\
\hline $11 *$ & 16227,75 & 2772 & 6 & 17353,88 & 2772 & 6 \\
\hline 12 & 12277,65 & 1524,6 & 6 & 11434,5 & 0 & 7 \\
\hline 14 & 19507,95 & 6652,8 & 5 & 18220,12 & 4851 & 8 \\
\hline 15 & 3551,63 & 0 & 5 & 3551,63 & 0 & 5 \\
\hline $30 *$ & 3696 & 0 & 5 & 3205,13 & 0 & 4 \\
\hline $38 *$ & 6237 & 0 & 5 & 4966,5 & 0 & 5 \\
\hline $44^{*}$ & 6352,5 & 0 & 5 & 5948,25 & 0 & 5 \\
\hline 45 & 10522,05 & 970,2 & 6 & 10510,5 & 0 & 7 \\
\hline 46 & 5832,75 & 693 & 6 & 5832,75 & 693 & 6 \\
\hline $47 *$ & 3031,88 & 0 & 5 & 2685,38 & 0 & 5 \\
\hline
\end{tabular}

*Nestes casos, apesar de os valores de PNS final e número de manobras serem iguais, as sequências de chaveamento são diferentes, levando a valores diferentes de ENS.

**Valores de $\varepsilon(G)$ e $P N S(G)$ em $\mathrm{kWh} /$ fase.

Fonte: Elaborado pelo autor.

Merece destaque também o caso de falta no setor 45. Ainda que o método proposto apresente vantagens, tanto em energia não suprida quanto em potência não suprida, o fato de ser necessária mais uma manobra para uma redução praticamente desprezível na energia não suprida pode tornar desinteressante a aplicação do PRE por ele obtido, dependendo dos custos operacionais.

Percebe-se que, no geral, o desempenho do método proposto é superior, no que diz respeito à energia não suprida, que é a responsável direta pelos indicadores DEC e FEC. Ao todo, em 10 dos 14 casos foram encontradas soluções com valores menores de $\varepsilon(G)$ em mais da metade das simulações, sendo que em outros três casos foram obtidas as mesmas soluções pelos dois métodos. Em somente um caso (falta no setor 11), o método proposto não foi consistente, tendo obtido na maioria das simulações uma solução com pior valor de $\varepsilon(G)$. Neste caso especificamente, nota-se que a PNS final das soluções obtidas pelos 
dois métodos é igual, assim como a configuração final, sendo a diferença na ENS causada pela sequência de chaveamento realizada.

Para falta no setor 3, sabe-se que existe uma solução que restaura todas as cargas (ou seja, tem potência não suprida final nula) com a realização de nove manobras, conforme apresentado em (ROMERO et al., 2016). Lembrando que o método apresentado nesse trabalho tem por objetivo a redução da PNS. No entanto, métodos cujos objetivos incluem minimizar a ENS não encontram a mesma solução. Em (MARQUES, 2018), após 35 soluções, são observadas nos conjuntos Pareto-Ótimo as soluções mostradas na Tabela 8.

Já o método proposto encontrou soluções diferentes, sendo que duas delas apareceram nos 35 conjuntos Pareto-Ótimo obtidos. Os PREs obtidos são mostrados na Tabela 9.

Tabela 8 - Características dos indivíduos finais obtidos nas 35 simulações para falta no setor 3 com o método base

\begin{tabular}{|c|c|c|c|}
\hline Aparições & $\boldsymbol{\varepsilon}(\boldsymbol{G})(\mathbf{k W h} / \mathbf{f a s e})$ & $\boldsymbol{P N S}(\boldsymbol{G})(\mathbf{k W} / \mathbf{f a s e})$ & $\boldsymbol{\psi}(\boldsymbol{G})$ \\
\hline 33 de 35 & 20778,5 & 4227,3 & 6 \\
\hline 35 de 35 & 21217,4 & 6444,9 & 8 \\
\hline 30 de 35 & 20131,7 & 3257,1 & 8 \\
\hline
\end{tabular}

Fonte: Elaborado pelo autor.

Tabela 9 - Características dos indivíduos finais obtidos nas 35 simulações para faltas no setor 3 com o método proposto

\begin{tabular}{|c|c|c|c|}
\hline Aparições & $\boldsymbol{\varepsilon}(\boldsymbol{G})(\mathbf{k W h} / \mathbf{f a s e})$ & $\boldsymbol{P N S}(\boldsymbol{G})(\mathbf{k W} / \mathbf{f a s e})$ & $\boldsymbol{\psi}(\boldsymbol{G})$ \\
\hline 3 de 35 & 20957,47 & 6098,4 & 5 \\
\hline 35 de 35 & 21217,4 & 6444,9 & 4 \\
\hline 35 de 35 & 19790,92 & 5128,2 & 7 \\
\hline
\end{tabular}

Pela análise das tabelas, é possível notar que o método proposto conseguiu encontrar a mesma solução considerando o mínimo de manobras (4) e encontrou uma solução melhor em termos de energia não suprida, e com menos manobras que a melhor obtida pelo método base, em todas as simulações. Outra diferença fica por conta do que seria a solução que estabelece um compromisso entre número de manobras e energia não suprida. Neste caso, o método proposto encontrou uma solução com energia não suprida menos de 5\% maior, mas realizando uma manobra a menos. Note que esta solução apareceu poucas vezes neste caso.

No que diz respeito às manobras realizadas e demais parâmetros da rede elétrica, a sequência de chaveamento do indivíduo de menor energia não suprida obtido pelo método proposto, mostrada na Tabela 10, tem todas as manobras realizadas dentro do tier 1 , não 
causando nenhum desligamento temporário de setores que não foram desligados em função do isolamento da falta.

Tabela 10 - Sequência de chaveamento do indivíduo com melhor energia não suprida obtido pelo método proposto

\begin{tabular}{|c|c|c|c|c|}
\hline Abrir & Fechar & $\boldsymbol{X}(\boldsymbol{g})(\boldsymbol{\%})$ & $\boldsymbol{V}(\boldsymbol{g})(\boldsymbol{\%})$ & $\boldsymbol{B}(\boldsymbol{g})(\boldsymbol{\%})$ \\
\hline $101-3 *$ & - & - & - & 13,35 \\
\hline $3-4^{*}$ & - & - & 2,85 & 13,35 \\
\hline $5-6$ & - & 85,05 & 2,85 & 81,55 \\
\hline- & $28-50$ & 85,05 & 2,85 & 81,55 \\
\hline $7-8$ & - & 85,05 & 2,85 & 81,55 \\
\hline $8-27$ & - & 85,05 & 2,85 & 81,55 \\
\hline
\end{tabular}

*Estas duas manobras são responsáveis por isolar a falta, não sendo calculados todos os valores de carregamento e queda de tensão após a realização das mesmas.

Fonte: Elaborado pelo autor.

Essa sequência gera um PRE que não restaura os setores 4, 5, 7, 26 e 27, enquanto a solução de menor energia não suprida proposta por MARQUES (2018) deixa desligados os setores 4,5 e 7 somente, mas a sequência que leva até ela resulta em uma energia não suprida mais alta, como mostra a Tabela 11 .

Note que os setores 34, 35 e 36 são momentaneamente desligados pela abertura de 3334, sendo posteriormente restaurados pela manobra de fechar 35-40. Mesmo assim, o tempo que os setores ficam desligados causa um enorme prejuízo à energia não suprida. Ainda que as demais manobras sejam similares, há perdas significativas ao desligar setores que não foram desligados em função do isolamento da falta.

Tabela 11 - Sequência de chaveamento do indivíduo com melhor energia não suprida obtido pelo método base

\begin{tabular}{|c|c|c|c|c|}
\hline Abrir & Fechar & $\boldsymbol{X}(\boldsymbol{g})(\boldsymbol{\%})$ & $\boldsymbol{V}(\boldsymbol{g})(\boldsymbol{\%})$ & $\boldsymbol{B}(\boldsymbol{g})(\boldsymbol{\%})$ \\
\hline $101-3 *$ & - & - & - & - \\
\hline $3-4^{*}$ & - & - & 2,31 & 85,35 \\
\hline $33-34$ & $35-40$ & 91,49 & 4,05 & 85,05 \\
\hline $7-8$ & $8-33$ & 96,64 & 4,05 & 89,95 \\
\hline $5-6$ & $28-50$ & 96,64 & & - \\
\hline
\end{tabular}

*Estas duas manobras são responsáveis por isolar a falta, não sendo calculados todos os valores de carregamento e queda de tensão após a realização das mesmas. 
As melhores soluções obtidas ao considerar as 35 simulações com cada método são mostradas na Figura 26.

Figura 26 - Fronteira formada pelas melhores soluções encontradas para falta no setor 3

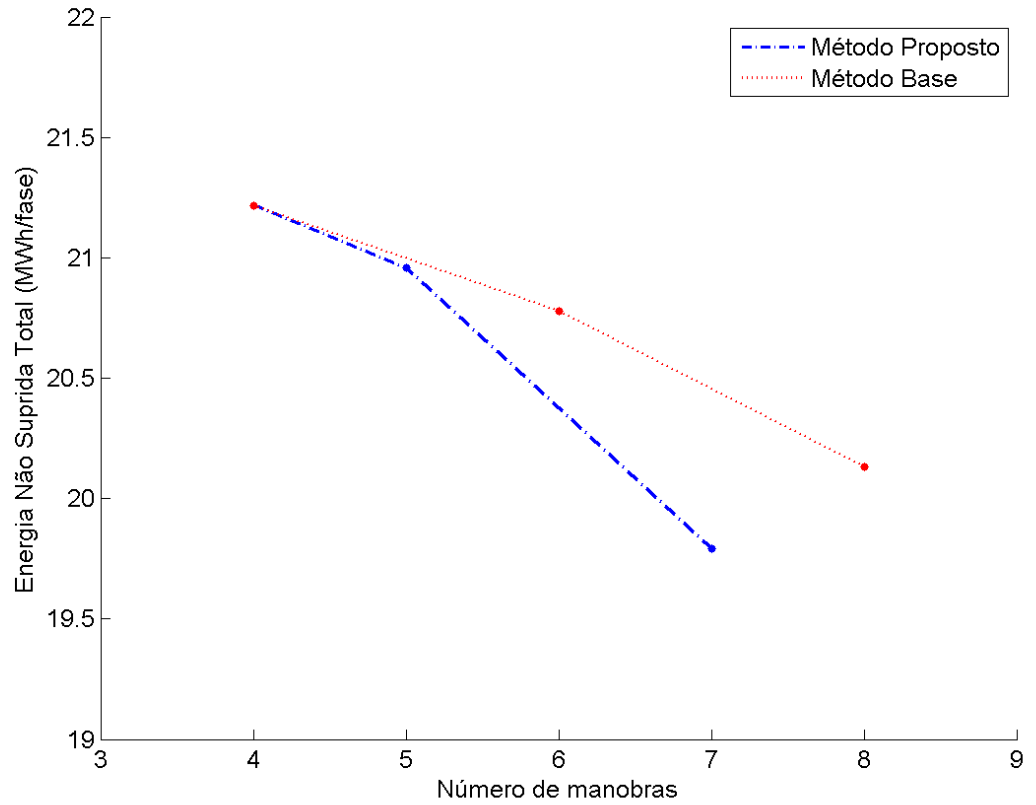

Fonte: Elaborado pelo autor.

Na solução de menor energia não suprida, além de reduzir o número de manobras, o método proposto encontrou uma configuração com menor carregamento para a rede e os transformadores, e menor queda de tensão. Tudo isso, em conjunto, resulta ainda em menos perdas resistivas, tornando a rede mais eficiente. Destaca-se ainda que o mesmo resultado foi obtido em todas as 35 simulações.

Para a falta no setor 45 , enquanto no método base foi obtido exatamente o mesmo conjunto Pareto-Ótimo, com apenas duas soluções, nas 35 simulações o método proposto encontrou soluções diferentes, além das soluções encontradas pelo método base. As Tabelas 12 e 13 mostram as características dos indivíduos encontrados nos dois casos.

Tabela 12 - Características dos indivíduos finais obtidos nas 35 simulações para faltas no setor 45 com o método base

\begin{tabular}{|c|c|c|c|}
\hline Aparições & $\boldsymbol{\varepsilon}(\boldsymbol{G})(\mathbf{k W h} /$ fase $)$ & $\boldsymbol{P N S}(\boldsymbol{G})(\mathbf{k W} / \mathbf{f a s e})$ & $\boldsymbol{\psi}(\boldsymbol{G})$ \\
\hline 35 de 35 & 10522,05 & 970,2 & 6 \\
\hline 35 de 35 & 14472,15 & 3603,6 & 4 \\
\hline
\end{tabular}

Fonte: Elaborado pelo autor. 
Tabela 13 - Características dos indivíduos finais obtidos nas 35 simulações para faltas no setor 45 com o método

\begin{tabular}{|c|c|c|c|}
\hline Aparições & $\boldsymbol{\varepsilon}(\boldsymbol{G})(\mathbf{k W h} / \mathbf{f a s e})$ & $\boldsymbol{P N S}(\boldsymbol{G})(\mathbf{k W} / \mathbf{f a s e})$ & $\boldsymbol{\psi}(\boldsymbol{G})$ \\
\hline 34 de 35 & 10522,05 & 970,2 & 6 \\
\hline 35 de 35 & 14472,15 & 3603,6 & 4 \\
\hline 35 de 35 & 10510,5 & 0 & 7 \\
\hline
\end{tabular}

Fonte: Elaborado pelo autor.

Figura 27 - Fronteira formada pelas melhores soluções encontradas para a falta no setor 45

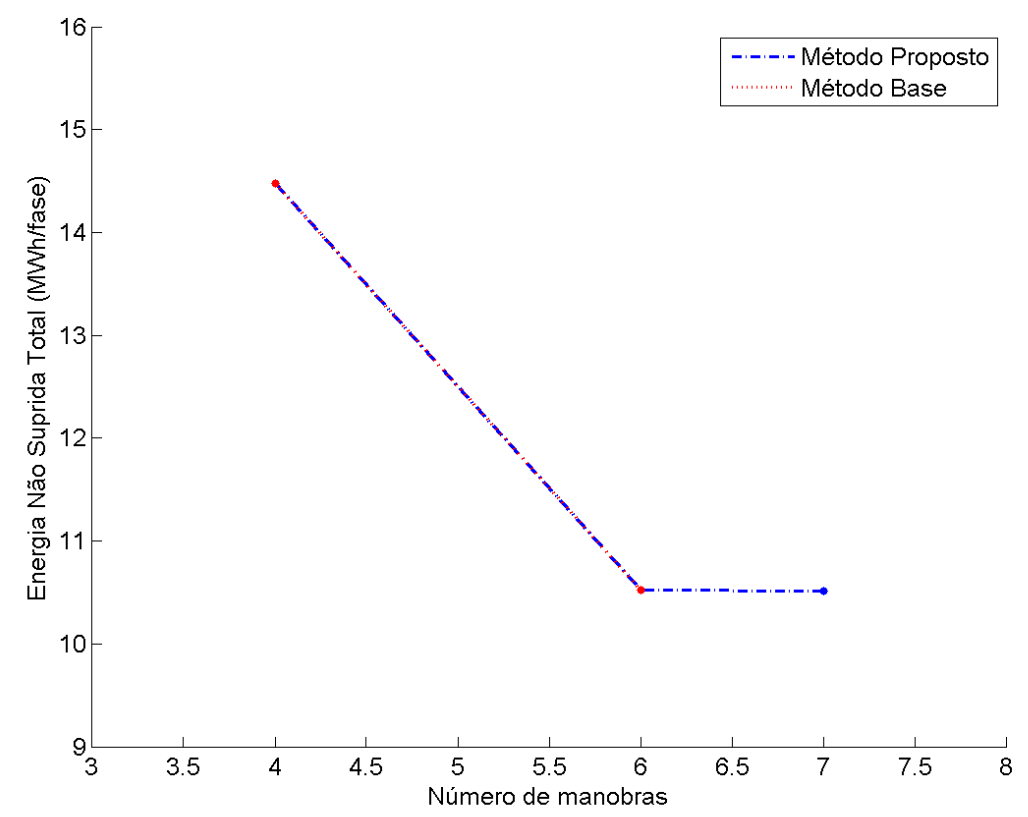

Fonte: Elaborado pelo autor.

Percebe-se que uma das soluções obtidas pelo método proposto apresenta energia não suprida menor e possui potência não suprida nula, no entanto ela requer uma manobra a mais e a diferença na energia não suprida não chega a ser muito significativa. Em casos como este, é importante que o operador da rede pondere qual plano é mais adequado à sua filosofia de operação. Observa-se ainda que as soluções encontradas pelo método base continuam aparecendo consistentemente no proposto, sendo que este oferece maior variabilidade de soluções, apresentando sempre três alternativas, ante duas do método base, o que pode ser interessante quando existirem restrições no controle ou custos operacionais muito variáveis.

Deve-se observar também que, assim como na simulação de falta no setor 3, os extremos do Pareto-Ótimo (configurações com menor energia não suprida ou com menor número de manobras) foram encontrados em todas as 35 execuções pelos dois métodos. A Figura 27 
mostra como se distribuem todas as soluções finais diferentes encontradas pelos métodos ao final das simulações.

Para finalizar a análise de casos deste sistema, o caso de falta no setor 11, assim como nos setores 7 e 46, teve resultados iguais para as soluções de menor energia não suprida nos dois métodos. Os conjuntos Pareto-Ótimo, no entanto, foram bastante diferentes, mostrando uma variabilidade maior no método proposto, mas um desempenho menos consistente em termos de energia não suprida. As Tabelas 14 e 15 mostram as características dos indivíduos obtidos.

Como pode ser visto, o método proposto teve um número maior de soluções diferentes encontradas, além de ter sempre três soluções, ao invés de apenas duas como no método base (exceto em uma simulação). A solução de menor energia não suprida apareceu menos vezes no método proposto, porém a de menor número de manobras foi consistente nos dois casos. Já em termos de diversidade de soluções, houve um ganho considerável, principalmente ao colocar uma nova solução, que conta com 5 manobras apenas, preenchendo a lacuna deixada no método base.

Tabela 14 - Características dos indivíduos finais obtidos nas 35 simulações para faltas no setor 11 com o método base

\begin{tabular}{|c|c|c|c|}
\hline Aparições & $\boldsymbol{\varepsilon}(\boldsymbol{G})(\mathbf{k W h} / \mathbf{f a s e})$ & $\boldsymbol{P N S}(\boldsymbol{G})(\mathbf{k W} / \mathbf{f a s e})$ & $\boldsymbol{\psi}(\boldsymbol{G})$ \\
\hline 34 de 35 & 16227,75 & 2772 & 6 \\
\hline 35 de 35 & 20177,85 & 5405,4 & 4 \\
\hline 1 de 35 & 17209,5 & 0 & 9 \\
\hline 1 de 35 & 17902,5 & 2772 & 6 \\
\hline
\end{tabular}

Fonte: Elaborado pelo autor

Tabela 15 - Características dos indivíduos finais obtidos nas 35 simulações para faltas no setor 11 com o método

\begin{tabular}{|c|c|c|c|}
\hline Aparições & $\varepsilon(G)(\mathrm{kWh} /$ fase $)$ & $P N S(G)(\mathrm{kW} /$ fase $)$ & $\boldsymbol{\psi}(G)$ \\
\hline 29 de 35 & 17353,88 & 2772 & 6 \\
\hline 29 de 35 & 19715,85 & 4365,9 & 5 \\
\hline 35 de 35 & 20177,85 & 5405,4 & 4 \\
\hline 6 de 35 & 16227,75 & 2772 & 6 \\
\hline 5 de 35 & 16522,28 & 1524,6 & 8 \\
\hline
\end{tabular}


No que diz respeito à diminuição no número de aparições do indivíduo de menor energia não suprida, isso se deve em grande parte à "polarização" da população inicial provocada pela BL. Como os indivíduos apresentados nas duas primeiras linhas da Tabela 13 são obtidos pela BL, as tabelas do AEMT ficam cheias de configurações semelhantes, dificultando a saída desta região de busca. Essa característica foi observada em outros casos em que a BL fica muito próxima dos pontos de ótimo encontrados pelo AEMT. É interessante ainda destacar que em testes sem o operador de corte LSO, para este caso de falta no setor 11, não foi possível em nenhuma das simulações igualar o desempenho do método base, mostrando que, ainda que restrito e normalmente não desejável pelo operador, a inclusão do LSO é fundamental para garantir maior diversidade. Porém, mesmo com energia não suprida maior, pesa o fato de os indivíduos gerados pela busca local exclusivamente não provocarem desligamento temporário de setor algum, o que é vital principalmente para a melhoria do indicador FEC. Os melhores indivíduos obtidos pelos testes de falta no setor 11 são mostradas na Figura 28.

\section{Figura 28 - Fronteira formada pelas melhores soluções encontradas para a falta no setor 11}

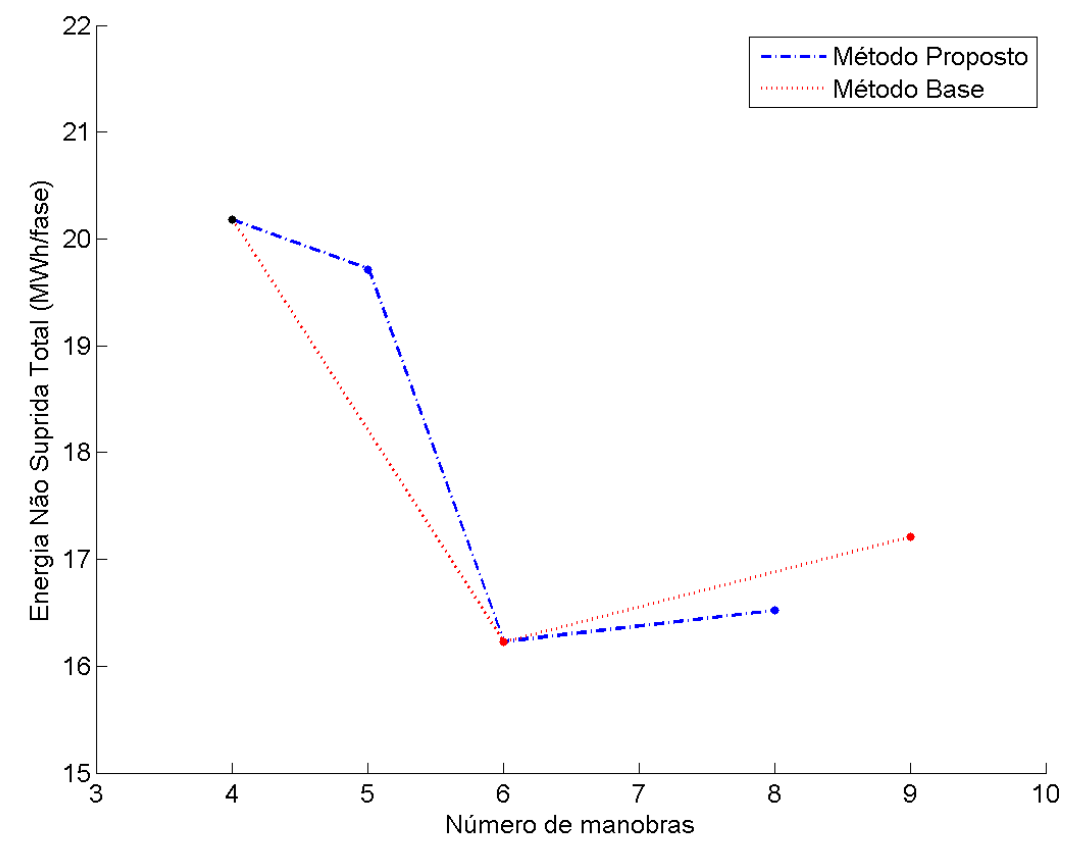

Fonte: Elaborado pelo autor.

Quanto aos tempos de simulação, os valores médios para os três casos detalhados são apresentados na Tabela 16, mostrando diferenças praticamente irrelevantes. 
Tabela 16 - Tempos de simulação médios em segundos

\begin{tabular}{|c|c|c|}
\hline Setor & Método Base & Método Proposto \\
\hline 3 & 2,4702 & 2,4774 \\
\hline 11 & 2,5263 & 2,0160 \\
\hline 45 & 1,9714 & 2,5952 \\
\hline
\end{tabular}

Fonte: Elaborado pelo autor

Acrescenta-se que, nos casos resolvidos pela busca exaustiva, não há diferenças significativas nos tempos de execução dos dois métodos. Ambos terminam suas execuções em menos de 1s no sistema teste de 53 barras, obtendo as mesmas soluções.

Os resultados obtidos indicam que em sistemas de pequeno porte, que não causam problemas no uso de memória, a BL traz ganhos consideráveis em vários casos, sendo importante a presença de mecanismos que evitem que o sistema fique preso em ótimos locais, como é o caso do LSO.

\subsection{Resultados com a Busca Local Limitada}

Em sistemas de grande porte é necessário limitar a BL, conforme apresentado no Capítulo 3. Para viabilizar a execução do método proposto no SD real da cidade de Londrina, foi preciso utilizar os parâmetros mostrados na Tabela 2.

Assim como foi feito anteriormente, foram escolhidos 20 casos que não são resolvidos pela busca exaustiva para serem simulados, sendo quatro dos 20 casos analisados detalhadamente. Estes casos consistem em: dois casos analisados em (MARQUES ,2018) (faltas nos setores 1587 e 2532); um caso de falta em que a BL não atua, mas o LSO sim (falta no setor 2571); e um caso de falta em que as soluções obtidas são consistentes ao longo das 35 simulações para os dois métodos (falta no setor 1349). Também foram utilizados os mesmos limites operacionais utilizados nas simulações discutidas na seção anterior, conforme a Tabela 17.

Tabela 17 - Restrições do problema e tempos utilizados para a simulação com o sistema de grande porte

\begin{tabular}{|c|c|c|c|c|c|c|}
\hline Parâmetro & $\boldsymbol{\delta}$ & $\Delta \boldsymbol{B}$ & $\Delta \boldsymbol{V}$ & $\boldsymbol{T}$ & $\boldsymbol{t}_{\boldsymbol{C C R}}$ & $\boldsymbol{t}_{\boldsymbol{C C M}}$ \\
\hline Valor & $10 \%$ & $50 \%$ & $10 \%$ & 4horas/falta & 50 segundos & 25 minutos \\
\hline
\end{tabular}

Fonte: Elaborado pelo autor 
Começando pelo caso de falta no setor 2532, também analisado em (MARQUES, 2018), diferenças consideráveis podem ser observadas mesmo sendo executada somente a busca local limitada. Neste caso, a BL ficou limitada a utilizar $n=3$, gerando 233 configurações únicas durante a execução da BL. Vale lembrar que indivíduos obtidos a partir dela são os mesmos em todas as simulações.

Utilizando o método base, foram obtidos os resultados apresentados na Tabela 18, enquanto, com o novo, foram obtidos os resultados observados na Tabela 19. Por se tratar de um sistema mais complexo, onde existem cargas com prioridades diferentes e chaves manuais e remotas, para facilitar a visualização das tabelas foram retirados os valores de potência não suprida, dado que as simulações do sistema de pequeno porte já deixaram claro que não necessariamente a menor potência não suprida terá a menor energia não suprida.

Tabela 18 - Características dos indivíduos finais obtidos nas 35 simulações para faltas no setor 2532 com o método base

\begin{tabular}{|c|c|c|c|c|c|c|c|c|c|}
\hline Aparições & $\varepsilon_{A}(G)$ & $\varepsilon_{I}(G)$ & $\varepsilon_{B}(G)$ & $\varepsilon_{S}(G)$ & $\psi_{M}(G)$ & $\psi_{R}(G)$ & $X(g)$ & $V(g)$ & $B(g)$ \\
\hline 35 de 35 & 54,2 & 532,6 & 85,6 & 9580,1 & 4 & 3 & 77,34 & 5,84 & 82,38 \\
\hline 35 de 35 & 33,9 & 223,0 & 296,5 & 6781,5 & 6 & 3 & 97,48 & 8,10 & 83,06 \\
\hline 35 de 35 & 54,2 & 623,9 & 85,6 & 14200,8 & 4 & 1 & 70,47 & 2,66 & 82,38 \\
\hline
\end{tabular}

*Energia não suprida em kWh/fase; carregamentos e queda de tensão em \%.

Fonte: Elaborado pelo autor.

Tabela 19 - Características dos indivíduos finais obtidos nas 35 simulações para faltas no setor 2532 com o método proposto

\begin{tabular}{|c|c|c|c|c|c|c|c|c|c|}
\hline Aparições & $\varepsilon_{A}(G)$ & $\varepsilon_{I}(\boldsymbol{G})$ & $\varepsilon_{B}(G)$ & $\varepsilon_{S}(G)$ & $\boldsymbol{\psi}_{M}(G)$ & $\psi_{R}(G)$ & $X(g)$ & $V(g)$ & $B(g)$ \\
\hline 35 de 35 & 54,2 & 532,6 & 85,6 & 9580,1 & 4 & 3 & 77,34 & 5,84 & 82,38 \\
\hline 35 de 35 & 79,2 & 124,8 & 13,47 & 5714,9 & 6 & 2 & 95,48 & 6,81 & 83,06 \\
\hline 35 de 35 & 54,2 & 623,9 & 85,6 & 14200,8 & 4 & 1 & 70,47 & 2,66 & 82,38 \\
\hline
\end{tabular}

*Energia não suprida em $\mathrm{kWh} /$ fase; carregamentos e queda de tensão em \%.

Fonte: Elaborado pelo autor.

Observa-se que o método proposto conseguiu encontrar, no conjunto Pareto-Ótimo obtido, dois dos indivíduos encontrados pelo método base. A grande mudança fica por conta do indivíduo da segunda linha da Tabela 19. Nesta configuração, apesar de haver um aumento na energia não suprida de alta prioridade, em todos os demais níveis de prioridade são observados ganhos significativos, sendo também realizada uma manobra a menos. Também há uma leve redução no carregamento do sistema e na queda de tensão, se comparado com o segundo indivíduo da Tabela 18, o que reduz as perdas técnicas. 
Este indivíduo, citado anteriormente, é resultado da abertura de uma chave NF na região desenergizada, seguida pelo fechamento de todas as chaves NAs disponíveis para reconexão. Deste modo, essa configuração não provoca desligamentos temporários adicionais e sempre será encontrada independentemente de aleatoriedades na etapa evolutiva. Destaca-se que este indivíduo foi obtido pela BL limitada, do modo que foi proposta, mostrando que a estratégia de simplificar a busca já ajuda a obter resultados significativos em sistemas de grande porte.

Neste caso, a abertura da chave que liga os setores desenergizados 2533 e 1388, faz que nenhuma manobra em chaves NAs do tier 1 seja infactível, enquanto sem a realização desta manobra, apenas uma das três chaves NAs disponíveis resultará em sequência factível. É importante notar como uma manobra de separação das cargas na região desenergizada pode tornar factível uma sequência de chaveamento.

É importante também levar em conta o fato de que há um pequeno aumento na energia não suprida de alta prioridade no método proposto. Isso deve ser levado em conta pelo operador da rede antes de escolher qual PRE será aplicado, pois dependerá da filosofia de operação adotada pela prestadora de serviços.

Também foram observados casos em que o método proposto, ainda que não traga mudanças significativas, consegue aumentar consideravelmente a variabilidade dos indivíduos que compõem o conjunto Pareto-Ótimo. Isso pode ser observado no caso de falta no setor 2571.

A falta simples no setor 2571 gera uma região desenergizada com uma quantidade bastante alta do total de chaves (63, observando que o custo computacional da BL independe da chave ser remota ou manual), sendo ignorado pela BL (com os parâmetros propostos). Ainda assim, obtém-se um aumento na diversidade de soluções dos conjuntos Pareto-Ótimo. Enquanto o método proposto encontrou 14 indivíduos diferentes (sendo 5 exclusivos dele) ao longo das 35 simulações, o método base encontrou 10 (sendo 1 exclusivo dele). Destaca-se um dos encontrados pelo método proposto, que apareceu em 5 das 35 execuções e é mostrado na Tabela 20.

A configuração da Tabela 20 apresenta o menor valor de ENS, considerando todas as simulações realizadas com os dois métodos. Para fins de comparação, o melhor resultado obtido em termos de ENS pelo método base, encontrado em 8 de 35 execuções (e em 5 de 35 no método proposto), é apresentado na Tabela 21.

O indivíduo representado na Tabela 21, apesar de ter menor ENS sem prioridade, tem uma piora considerável no desempenho para prioridade intermediária, além de um aumento mínimo no carregamento dos transformadores. 
Tabela 20 - Características de um indivíduo obtido exclusivamente pelo método proposto para faltas no setor 2571

\begin{tabular}{|c|c|c|c|c|c|c|c|c|c|}
\hline Apariçõoes & $\varepsilon_{A}(G)$ & $\varepsilon_{I}(\boldsymbol{G})$ & $\varepsilon_{B}(G)$ & $\varepsilon_{S}(G)$ & $\psi_{M}(G)$ & $\psi_{R}(G)$ & $X(g)$ & $V(g)$ & $B(g)$ \\
\hline 5 de 35 & 2,68 & 0,62 & 1,64 & 533,28 & 3 & 2 & 76,06 & 4,61 & 98,83 \\
\hline
\end{tabular}

*Energia não suprida em $\mathrm{kWh} /$ fase; carregamentos em \%.

Fonte: Elaborado pelo autor.

Tabela 21 - Características do indivíduo com menor energia não suprida obtido pelo método base para faltas no setor 2571

\begin{tabular}{|c|c|c|c|c|c|c|c|c|c|}
\hline Aparições & $\boldsymbol{\varepsilon}_{\boldsymbol{A}}(\boldsymbol{G})$ & $\boldsymbol{\varepsilon}_{\boldsymbol{I}}(\boldsymbol{G})$ & $\boldsymbol{\varepsilon}_{\boldsymbol{B}}(\boldsymbol{G})$ & $\boldsymbol{\varepsilon}_{\boldsymbol{S}}(\boldsymbol{G})$ & $\boldsymbol{\psi}_{\boldsymbol{M}}(\boldsymbol{G})$ & $\boldsymbol{\psi}_{\boldsymbol{R}}(\boldsymbol{G})$ & $\boldsymbol{X}(\boldsymbol{g})$ & $\boldsymbol{V}(\boldsymbol{g})$ & $\boldsymbol{B}(\boldsymbol{g})$ \\
\hline 8 de 35 & 2,68 & 63,15 & 1,64 & 489,52 & 3 & 2 & 76,06 & 4,61 & 98,85 \\
\hline
\end{tabular}

*Energia não suprida em $\mathrm{kWh} /$ fase; carregamentos em \%.

\section{Fonte: Elaborado pelo autor.}

Este é um caso em que, mesmo com a inviabilidade de se executar a BL completa, o método proposto consegue se beneficiar ao trabalhar com o LSO. Percebe-se que as soluções apresentadas nas Tabelas 20 e 21 apresentam até cinco manobras, valor dentro dos limites utilizados para aplicação do LSO, indicando que o operador de corte do método proposto está sendo fator decisivo para obtenção de soluções mais otimizadas. Apesar de parecer contraditório, ao permitir o corte de cargas, a ENS total foi reduzida, ainda levando em conta os níveis de prioridade.

Enquanto houve casos com diferenças entre os indivíduos obtidos pelos métodos, em outros, as mudanças ficam apenas na frequência que aparecem. Considerando o setor 1587, também analisado em (MARQUES, 2018), que conta com 17 chaves no tier 1, o que resultou em uma BL limitada com $n=3$ para obtenção de 603 indivíduos, não são encontrados indivíduos diferentes entre os métodos nas simulações. Porém, a frequência que cada solução é obtida pelos métodos sofreu variações consideráveis, conforme as Tabelas 22 e 23.

Tabela 22 - Características dos indivíduos finais obtidos nas 35 simulações para faltas no setor 1587 com o método

\begin{tabular}{|c|c|c|c|c|c|c|c|c|c|}
\hline \multicolumn{10}{|c|}{ proposto } \\
\hline Aparições & $\varepsilon_{A}(G)$ & $\varepsilon_{I}(G)$ & $\varepsilon_{B}(G)$ & $\varepsilon_{S}(G)$ & $\psi_{M}(G)$ & $\psi_{R}(G)$ & $X(g)$ & $V(g)$ & $B(g)$ \\
\hline 24 de 35 & 32,4 & 75,8 & 342,6 & 4431,4 & 7 & 1 & 98,06 & 5,15 & 99,51 \\
\hline 23 de 35 & 32,4 & 139,9 & 342,6 & 7020,3 & 6 & 1 & 98,06 & 5,15 & 86,57 \\
\hline 24 de 35 & 89,1 & 139,9 & 342,6 & 7505,0 & 6 & 0 & 98,06 & 5,15 & 84,67 \\
\hline 2 de 35 & 0,53 & 75,8 & 342,6 & 4162,9 & 7 & 1 & 98,06 & 5,15 & 99,51 \\
\hline 11 de 35 & 0,53 & 139,9 & 342,6 & 6245,1 & 4 & 1 & 50,43 & 1,51 & 86,57 \\
\hline 7 de 35 & 0,53 & 25,8 & 342,6 & 1638,8 & 5 & 1 & 71,88 & 3,44 & 99,51 \\
\hline
\end{tabular}

*Energia não suprida em $\mathrm{kWh} /$ fase; carregamentos em \%. 
Tabela 23 - Características dos indivíduos finais obtidos nas 35 simulações para faltas no setor 1587 com o método base

\begin{tabular}{|c|c|c|c|c|c|c|c|c|c|}
\hline Aparições & $\varepsilon_{A}(G)$ & $\varepsilon_{I}(G)$ & $\varepsilon_{B}(G)$ & $\varepsilon_{S}(\boldsymbol{G})$ & $\psi_{M}(G)$ & $\boldsymbol{\psi}_{R}(\boldsymbol{G})$ & $X(g)$ & $V(g)$ & $B(g)$ \\
\hline 28 de 35 & 32,4 & 75,8 & 342,6 & 4431,4 & 7 & 1 & 98,06 & 5,15 & 99,51 \\
\hline 28 de 35 & 32,4 & 139,9 & 342,6 & 7020,3 & 6 & 1 & 98,06 & 5,15 & 86,57 \\
\hline 28 de 35 & 89,1 & 139,9 & 342,6 & 7505,0 & 6 & 0 & 98,06 & 5,15 & 84,67 \\
\hline 3 de 35 & 0,53 & 75,8 & 342,6 & 4162,9 & 7 & 1 & 98,06 & 5,15 & 99,51 \\
\hline 7 de 35 & 0,53 & 139,9 & 342,6 & 6245,1 & 4 & 1 & 50,43 & 1,51 & 86,57 \\
\hline 4 de 35 & 0,53 & 25,8 & 342,6 & 1638,8 & 5 & 1 & 71,88 & 3,44 & 99,51 \\
\hline
\end{tabular}

*Energia não suprida em $\mathrm{kWh} /$ fase; carregamentos em \%.

$$
\text { Fonte: Elaborado pelo autor. }
$$

O último caso a ser analisado mostra uma situação observada em pouquíssimos dos casos simulados em que o método proposto apresenta ganhos significativos em todos os níveis de prioridade de carga quando comparadas as configurações com menor número de manobras. Se forem observados todos os resultados apresentados até então, é possível perceber que em nenhum caso houve diferenças entre as soluções que favorecem a minimização do número de manobras. Esta situação pode ser vista no caso de falta no setor 1349.

Ao simular falta no setor 1349, mesmo com a BL limitada por $n=0$ (gerando 224 configurações únicas), foram dois indivíduos que formaram o conjunto Pareto-Ótimo encontrado pelos dois métodos. Diferentemente do observado na maioria das simulações, os conjuntos compartilharam o mesmo indivíduo no que diz respeito a menor energia não suprida, porém foi observada uma diferença considerável (no que diz respeito aos objetivos considerados) a favor do método proposto no indivíduo com menor número de manobras.

Neste caso, os dois métodos foram consistentes, encontrando exatamente o mesmo conjunto em todas as 35 simulações. Ressalta-se ainda que o indivíduo de menor número de manobras, obtido pelo método proposto, é encontrado ainda no processo de BL, não resultando em desligamentos temporários para sua implementação. Os resultados encontrados são mostrados nas Tabelas 24 e 25.

\begin{tabular}{|c|c|c|c|c|c|c|c|c|c|}
\hline Aparições & $\varepsilon_{A}(G)$ & $\varepsilon_{I}(G)$ & $\varepsilon_{B}(G)$ & $\varepsilon_{S}(G)$ & $\psi_{M}(G)$ & $\psi_{R}(G)$ & $X(g)$ & $V(g)$ & $B(g)$ \\
\hline 35 de 35 & 5,94 & 11,2 & 238,8 & 1017,2 & 3 & 2 & 93,39 & 7,59 & 91,73 \\
\hline 35 de 35 & 42,3 & 115,1 & 1583,0 & 5692,2 & 3 & 1 & 89,17 & 6,56 & 91,73 \\
\hline
\end{tabular}

*Energia não suprida em $\mathrm{kWh} /$ fase; carregamentos em \%. 
Tabela 25 - Características dos indivíduos finais obtidos nas 35 simulações para faltas no setor 1349 com o método

\begin{tabular}{|c|c|c|c|c|c|c|c|c|c|}
\hline \multicolumn{10}{|c|}{ proposto } \\
\hline Aparições & $\varepsilon_{A}(\boldsymbol{G})$ & $\varepsilon_{I}(\boldsymbol{G})$ & $\varepsilon_{B}(G)$ & $\varepsilon_{S}(\boldsymbol{G})$ & $\boldsymbol{\psi}_{M}(\boldsymbol{G})$ & $\psi_{R}(G)$ & $X(g)$ & $V(g)$ & $B(g)$ \\
\hline 35 de 35 & 5,94 & 11,2 & 238,8 & 1017,2 & 3 & 2 & 93,39 & 7,59 & 91,73 \\
\hline 35 de 35 & 5,74 & 72,3 & 232,2 & 4485,5 & 3 & 1 & 99,14 & 4,72 & 94,24 \\
\hline
\end{tabular}

*Energia não suprida em $\mathrm{kWh} /$ fase; carregamentos em \%.

Fonte: Elaborado pelo autor.

Ainda é possível observar que o indivíduo obtido pelo método proposto consegue reduzir os valores de energia não suprida em alta e baixa prioridade, devido ao não desligamento temporário de setores.

Por se tratar de um sistema real com uma quantidade de barras muito alta, foram escolhidos apenas alguns casos que retratam as diferenças e semelhanças no desempenho dos métodos. Dos 20 casos simulados, 35 vezes cada, de faltas simples, em caso algum, considerando todas as simulações, o método proposto não conseguiu igualar ou superar o desempenho do método base ao comparar os conjuntos Pareto-Ótimo resultantes da análise de todas as execuções de cada caso. No entanto, como mostrado anteriormente, houve casos em que o desempenho do método proposto foi menos consistente.

Em sistemas reais, ainda é muito importante levar em conta o tempo de execução do método de restabelecimento, principalmente por poder ser necessário fazer mais de uma execução, já que se trata de um método com etapas que envolvem aleatoriedade. Ao contrário do que foi observado no sistema teste de 53 barras que foi também testado, para este sistema houve um leve ganho de velocidade, devido principalmente ao fato de não serem necessárias várias das verificações usadas na etapa evolutiva durante a BL. A Tabela 26 mostra os tempos médios de execução dos casos de faltas analisados anteriormente.

Tabela 26 - Tempos de simulação médios em segundos

\begin{tabular}{|c|c|c|}
\hline Setor & Método base & Método proposto \\
\hline 1349 & 40,5010 & 41,2817 \\
\hline 1587 & 41,8591 & 40,0472 \\
\hline 2532 & 71,3071 & 60,2883 \\
\hline 2571 & 55,1946 & 52,0612 \\
\hline
\end{tabular}

Fonte: Elaborado pelo autor. 
Em geral, os dois métodos tiveram desempenho similar em tempo, com pequena vantagem para o proposto. No entanto, o consumo de memória RAM do método proposto é consideravelmente maior, sendo necessário hardware mais robusto para sua execução.

Assim como observado no sistema teste de 53 barras, casos resolvidos pela busca exaustivas não apresentaram diferenças significativas nos tempos de execução, ficando sempre abaixo de $5 \mathrm{~s}$.

Também foi observado que os resultados obtidos pelos métodos foram muito semelhantes, considerando todo o conjunto de soluções. Deste modo, testes de hipóteses utilizados para comparação dos resultados acusaram empates em praticamente todos os casos. Portanto, a comparação utilizada entre os métodos acabou sendo feita somente pelo desempenho de suas soluções finais, que são as fornecidas ao operador da rede. 



\section{CONCLUSÕES}

Neste capítulo são apresentadas as considerações finais e perspectivas futuras para a continuidade deste trabalho. Também são listados os artigos publicados e submetidos, frutos de pesquisas realizadas no processo de elaboração e desenvolvimento do método proposto.

\subsection{Observações Finais e Contribuições}

O método base para o desenvolvimento do trabalho já possui um conjunto bastante robusto de tratamentos para o problema de restabelecimento. Este trabalho traz algumas contribuições que melhoram seu desempenho. São elas:

1) Desenvolvimento de um procedimento de busca voltada para operações em chaves na região de falta capaz de operar em tempo real, produzindo configurações que evitam desligamentos temporários de setores saudáveis SDs;

2) Desenvolvimento de um sistema de ajuste da sequência de chaveamento em soluções formadas apenas por chaves da região desenergizada para aumento do número de configurações factíveis;

3) Criação de uma nova estrutura para representação de porções do sistema de distribuição em análise adequada à natureza combinatória do problema de restabelecimento, capaz de representar trechos do sistema a partir de valores binários e reduzir o tempo de processamento necessário;

4) Desenvolvimento de um processo inteligente para ajustar a busca por combinações na região de falta a fim de garantir sua viabilidade em sistemas de grande porte, mesmo em computadores com memória RAM limitada;

5) Aprimoramento do processo evolutivo através da inclusão do operador LSO, aumentando o espaço de buscas e possibilitando soluções antes não consideradas.

Combinando as características do método base com as contribuições apresentadas, o método proposto se mostra bastante promissor mesmo com as limitações impostas para tornalo viável em sistemas de grande porte. Em sistemas de pequeno porte, como o sistema teste de 53 barras apresentado em (ROMERO et al. 2016), os benefícios que a inclusão da BL e do corte de carga trazem são nítidos, observando grandes ganhos em quase todos os casos simulados. 
Após o ajuste de todos os parâmetros de execução, não houve caso algum em que o método proposto não fosse capaz de ao menos encontrar resultados iguais ao método base, apresentado em (MARQUES, 2018), ainda que exista casos em que a BL preencha todas as tabelas do AEMT com indivíduos semelhantes, afetando a frequência com que as soluções são vistas.

Os resultados produzidos ao longo do desenvolvimento deste trabalho também levam a crer que as funções adicionadas no método proposto têm mais impacto na otimização da energia não suprida e de soluções que busquem um meio termo entre manobras realizadas e energia não suprida. Nenhum dos casos estudados a fundo, incluindo os que não foram mostrados ao longo do texto, mostrou diferenças entre os melhores indivíduos em termos de número de manobras.

\subsection{Propostas para o Futuro}

Ao longo do desenvolvimento deste trabalho foram percebidos dois pontos que afetam consideravelmente o desempenho do método proposto: (i) a não otimização das sequências de chaveamento geradas pela BL e (ii) a não consideração do tempo de deslocamento das equipes para operação das chaves manuais.

O primeiro problema até chegou a ser considerado no desenvolvimento do método, porém, devido às dificuldades para gerenciamento de memória usada pela BL e a natureza de tempo real, acabou sendo "simplificado". De fato, há um nível de otimização nessas sequências. As manobras de corte que afetam a factibilidade da restauração de um bloco de setores sempre são feitas antes da manobra de reconexão, que é feita imediatamente após serem separados todos os setores envolvidos nessa etapa, não ficando manobras em chaves NA "pendentes", para minimizar a energia não suprida. No entanto, o ideal seria organizar as manobras de modo que a energia não suprida final fosse mínima, o que requer análises combinatórias em um problema onde a memória já é restrita.

A existência do operador de corte ajuda a minimizar o problema de não otimização completa das sequências de chaveamento. Porém, por ser um operador que acontece aleatoriamente, e com diversas restrições por ser indesejado cortar cargas, seu efeito é bastante restrito.

O segundo problema já vem sendo discutido em outros trabalhos. Um procedimento para tratamento dos tempos de deslocamento é proposto por GOULART (2019), por exemplo. Seria uma contribuição muito grande a junção da consideração do tempo de restabelecimento com a BL e um algoritmo de otimização de sequência de chaveamento, afinal, na BL, espera- 
se que todas as chaves estejam fisicamente próximas, por se concentrar na região desenergizada. Todas essas funções juntas têm potencial para trazer enormes avanços aos algoritmos de obtenção de PREs, pois incluiriam uma série de questões práticas que ainda não são consideradas juntamente.

Antes de tratar desses problemas, no entanto, é necessário lidar com as limitações computacionais. $\mathrm{O}$ algoritmo de BL requer várias otimizações no uso de memória, mas ainda precisa ser capaz de operar em tempo real para ser aplicável. Mesmo em servidores com grandes quantidades de memória, o consumo de RAM observado nas simulações realizadas indica que, no estado atual, a sua aplicação completa (sem a utilização da busca simplificada pelo método explicado na seção 3.2.1.3) é inviável em sistemas de grande porte.

Existem ainda outras melhorias que seriam importantes de se adicionar ao modelo, como, por exemplo, a modelagem trifásica do sistema (novamente, limitações computacionais podem dificultar bastante este ponto) e a inclusão de geração distribuída no problema, que, conforme discutido em (FERNANDES et al., 2018), pode ter um impacto relevante nos resultados obtidos.

Resumindo, abaixo são listados os pontos a serem otimizados, com prioridade para os quatro primeiros, que ajudarão bastante o processo de BL, que se mostrou muito promissor:

1) Validação do modelo de BL para faltas múltiplas.

2) Otimização do uso de memória no processo de BL;

3) Elaboração de um algoritmo que permita a otimização das sequências de chaveamento conforme o interesse do operador;

4) Inclusão do tempo de deslocamento das equipes de manutenção na modelagem do problema;

5) Modelagem trifásica dos sistemas de distribuição;

6) Inclusão da geração distribuída no problema de restabelecimento;

Novas demandas podem surgir com as mudanças no setor elétrico, a inclusão de sistemas inteligentes deve abrir a possibilidade de controles descentralizados, legislações diferentes podem trazer novas variáveis ao problema. Portanto, é importante manter aberta a discussão, sempre levando em conta a aplicabilidade dos modelos desenvolvidos em sistemas reais. 


\subsection{Publicações}

Ao longo deste mestrado foram desenvolvidos trabalhos em parceria com professores e colegas da Universidade de São Paulo (USP) e da Universidade Federal do Triângulo Mineiro (UFTM), contando ainda com apoio financeiro da Fundação de Amparo à Pesquisa do Estado de São Paulo (FAPESP - processo 2017/23728-0) e do Programa de Pós-Graduação em Engenharia Elétrica da EESC-USP. Os trabalhos desenvolvidos são listados a seguir:

Trabalhos publicados como primeiro autor:

1) “Alocação otimizada de unidades de medição fasorial em sistemas de transmissão utilizando otimização por enxame de partículas", proveniente do trabalho realizado em conjunto com a Prof. Dra. Madeleine Rocio Medrano, da Universidade Federal do Triângulo Mineiro, apresentado no XXII Congresso Brasileiro de Automação, realizado em setembro de 2018 na cidade de João Pessoa-PB;

2) "Considerando a Existência de Geradores Distribuídos para Solução do Problema de Restabelecimento de Energia", em conjunto com o Prof. Dr. José Carlos de Melo Vieira Júnior, Prof. Dr. João Bosco Augusto London Junior e do então doutorando Leandro Tolomeu Marques, apresentado no XXII Congresso Brasileiro de Automação, em setembro de 2018;

3) "Estratégias Evolutivas para Redução de Perdas em Sistemas de Distribuição de Grande Porte”, em conjunto com o Prof. Dr. João Bosco Augusto London Junior, o então graduando Breno Ruy, o então doutorando Leandro Tolomeu Marques e o professor Dr. Augusto César dos Santos, apresentado no XXII Congresso Brasileiro de Automação, realizado em setembro de 2018 na cidade de João Pessoa-PB.

Trabalhos publicados como coautor:

1) "Estimador de Demanda Trifásico em Tempo Real com Tratamento para Transformadores Conectados em $\Delta-Y_{N}$ ", em conjunto com o Prof. Dr. João Bosco Augusto London Junior, o doutorando Júlio Augusto Druzina Massignan e a então mestranda Luana Locatelli Avelino, apresentado no XXII Congresso Brasileiro de Automação, realizado em setembro de 2018 na cidade de João Pessoa-PB. 
Trabalhos aceitos para publicação como coautor:

1) "Improved multi-objective evolutionary algorithm in subpopulation tables with features from NSGA-II for the service restoration problem", em conjunto com o Prof. Dr. João Bosco Augusto London Junior e o Prof. Dr. Leandro Tolomeu Marques, da Universidade Federal do Triângulo Mineiro, aceito para o IEEE PES PowerTech, a ser realizado em 2019, na cidade de Milão, Itália.

Trabalhos submetidos como primeiro autor:

1) "Restabelecimento de Energia com Busca Local na Região de Falta e Possibilidade de Corte de Carga", em conjunto com a aluna de mestrado Etiane Oliveira Ponciano de Carvalho, o Prof. Dr. João Bosco Augusto London Junior e o Prof. Dr. Leandro Tolomeu Marques, da Universidade Federal do Triângulo Mineiro, submetido para o 14 Simpósio Brasileiro de Automação Inteligente, a ser realizado em 2019, na cidade de Ouro Preto (MG). 



\section{REFERÊNCIAS}

AGÊNCIA NACIONAL DE ENERGIA ELÉTRICA - ANEEL. Procedimentos de Distribuição de Energia Elétrica no Sistema Elétrico Nacional - Módulo 8. Rev. 10, Brasília, 2018. 88p.

AGÊNCIA NACIONAL DE ENERGIA ELÉTRICA - ANEEL, "Regulação de Serviços de Distribuição". Disponível em: http://www.aneel.gov.br/regulacao-da-distribuicao//asset_publisher/nHNpDfkNeRpN/content/regulacao-dos-servicos-de-distribuicao/656827?in heritRedirect=false \& redirect=http $\% 3 \mathrm{~A} \% 2 \mathrm{~F} \% 2 \mathrm{Fwww}$.aneel.gov.br\%2Fregulacao-dadistribuic ao\%3Fp_p_id\%3D101_INSTANCE_nHNpDfkNeRpN\%26p_p_lifecycle\%3D0\%26p_p_state \%3Dnormal\%26p_p_mode\%3Dview\%26p_p_col_id\%3Dcolumn-2\%26p_p_col_count\%3D4. Acesso em: 01 fev 2018.

AOKI, K.; NARA, K.; ITOH, M.; SATOH, T.; KUWABARA, H., "A new algorithm for service restoration in distribution systems", IEEE Transactions on Power Delivery 4(3): 18321839. 1989.

BENAYOUN, R.; MONTGOLFIER, J.; LARITCHEV, O., "Linear programming with multiple objective functions: Step method (stem)", Journal Mathematical Programming 1(1): 366-375. 1971.

CAMILlO, M. H. M., "Métodos para Tratamento de Diversas Etapas do Processo de Restabelecimento de Energia em Sistemas de Distribuição”. 2017. 125 f. Tese (Doutorado em Ciências pelo Programa de Pós-Graduação em Engenharia Elétrica. Área de concentração: Sistemas Elétricos de Potência) - Escola de Engenharia de São Carlos (EESC/USP), São Carlos $-\mathrm{SP}$.

CAMILLO, M. H. M. et al., "Determination of switching sequence of Service Restoration in Distribution Systems: Application and analysis on a real and large-scale radial system", IEEE Transmission and Distribution Conference and Exposition, Dallas, TX, USA, May 2016a. 
CAMILLO, M. H.M. et al., "Combining exhaustive search and multi-objective evolutionary algorithm for service restoration in large-scale distribution systems". Electric Power Systems Research (Print), v. 134, p. 1-8, 2016 b.

CARRANO, E.; SILVA, G. S.; CARDOSO, E.; TAKAHASHI, R., "Subpermutation based evolutionary multiobjective algorithm for load restoration in power distribution networks", IEEE Transactions on Evolutionary Computation, vol. 20, No. 4, pp. 546-562, August 2016.

CARRENO, E. M.; ROMERO, R.; PADILHA-FELTRIN, A., "An efficient codification to solve distribution network reconfiguration for loss reduction problem". IEEE Transactions on Power Systems, vol. 23, N.4, pp. 1542-1551, November 2008.

CHEN, B.; CHEN, C.; WANG, J.; BUTTER-PURRY, K. L., "Multi-Time Step Service Restoration for Advanced Distribution Systems and Microgrids". IEEE Transactions on Smart Grid, vol. 9, no. 6, pp. 6793-6805, 2018.

CHEN, C-S.; LIN, C-H.; TSAI, H-Y., “A rule-based expert system with colored Petri net models for distribution system service restoration". IEEE Transactions on Power Systems, vol. 17, N.4, pp. 1073-1080, November 2002.

DEB, K., "Multi-Objective Optimization Using Evolutionary Algorithms". Chichester, UK: Wiley. 2001.

DEB, K.; PRATAP, A.; AGARWAL, S.; MEYARIVAN, T., "A fast and elitist multiobjective genetic algorithm: NSGA-II", IEEE Transactions on Evolutionary Computation, vol. 6, N.2, pp. 182-197, April 2002.

DelbeM, A. C. B.; CARVAlhO, A. C. P. L. F.; POliCASTRO, C.; PINTO, A. K. O.; GARCIA, A.; HONDA, K., "Node-depth Encoding for Evolutionary Algorithms Applied to Network Design”, Genetic and Evolutionary Computation Conference. 2004.

Delbem, A. C. B.; CARVAlho, A. C. P. L. F.; BretAS, N. G., "Main Chain Representation for Evolutionary Algorithm Applied to Distribution System Reconfiguration”. IEEE Transactions on Power Systems, v. 20, n. 1, p. 425-436. 2005. 
DIMITRIJEVIC, S.; RAJAKOVIC, N., "Service Restoration of Distribution Networks Considering Switching Operation Costs and Actual Status of Switching Equipment", IEEE Transactions on Smart Grid, vol. 6, pp. 1227-1232. 2015.

DRAYER, E.; KECHAGIA, N.; HEGEMANN, J.; BRAUN, M.; GABEL, M.; CAIRE, R., "Distributed Self-Healing for Distribution Grids With Evolving Search Space". IEEE Transactions on Power Delivery, vol. 33, no. 4, pp. 1755-1764, 2018.

FERNANDES, J. P. R.; VIEIRA JR., J. C. M.; LONDON JR., J. B. A.; MARQUES, L. T., "Considerando a Existência de Geradores Distribuídos para Solução do Problema de Restabelecimento de Energia”. Anais do XXII Congresso Brasileiro de Automática, João Pessoa (PB), Setembro, 2018.

GOULART, F., "Permutation-based Optimization for the Load Restoration Problem with Improved Time Estimation of Maneuvers". 229p. Tese (Doutorado). Universidade Federal de Minas Gerais, 2019.

HAFEZ, A. A.; OMRAN, W. A.; HEGAZY, Y. G., “A Decentralized Technique for Autonomous Service Restoration in Active Radial Distribution Networks". IEEE Transactions on Smart Grid, vol. 9, no. 3, pp. 1911-1919, 2018.

KAGAN et al., "Fast reconfiguration of distribution systems considering loss minimization", IEEE Transactions on Power Systems, vol. 20, pp. 1311-1319, August 2005.

KUMAR, Y.; DAS, B.; SHARMA, J., "Multiobjective, Multiconstraint Service Restoration of Electric Power Distribution System With Priority Customers", IEEE Transactions on Power Delivery, vol. 23, pp. 261-270, January 2008.

LATARE, N. A.; BHAT, S. S.; SRIVASTAVA, I., "Literature Review of Service Restoration in Distribution System", Second International Conference on Electrical, Computer and Communication Technologies. 2017. 
LIN, C.H.; CHEN, C.S.; KU, T.T.; TSAI, C. T; HO, C.Y., “A multiagent based distribution automation system for service restoration of fault contingencies", European Transactions on Electrical Power, vol. 21, no. 1, pp. 239-253. 2011.

LÓPEZ, J. C.; FRANCO, J. F.; RIDER, M. J.; ROMERO, R., "Optimal Restoration/Maintenance Switching Sequence of Unbalanced Three-Phase Distribution Systems”. IEEE Transactions on Smart Grid, vol. 9, no. 6, pp. 6058-6068, 2018.

MANTOVANI, J. R. S.; LEITE, J. B., "Development of a Self-Healing Strategy With Multiagent Systems for Distribution Networks", IEEE Transactions on Smart Grid, vol. 8, no. 5, pp. 2198-2206. September 2017.

MARQUES, L. T., "Restabelecimento de Energia por Reconfiguração de Redes em Sistemas de Distribuição de Grande Porte com Priorização de Chaves, Consumidores e Definição de Sequência de Chaveamento”. 129p. Dissertação (Mestrado) - Escola de Engenharia de São Carlos, Universidade de São Paulo, 2013.

MARQUES, L. T., CAMILlO, M. H. M., de LIMA, T. W., "A new multi-objective evolutionary algorithm for service restoration: Non-dominated Sorting Genetic Algorithm-II in Subpopulation Tables", PowerTech, IEEE Manchester. July 2017.

MARQUES, L. T., DELBEM, A. C. B., LONDON JR, J. B. A., "Service Restoration with Prioritization of Costumers and Switches and Determination of Switching Sequence", IEEE Transactions on Smart Grid. February 2017.

MARQUES, L. T., "Restabelecimento de Energia em Sistemas de Distribuição Considerando Aspectos Práticos”. 169p. Tese (Doutorado) - Escola de Engenharia de São Carlos, Universidade de São Paulo, São Carlos, 2018.

MENDOZA, F.; BERNAL-AGUSTIN, J. L.; DOMINGUEZ-NAVARRO, J. A., "NSGA and SPEA Applied to Multiobjective Design of Power Distribution Systems", IEEE Transactions on Power Systems, vol. 21, pp. 1938-1945, November 2006. 
MERLIN, A., BACK. H., "Search for a Minimal-Loss Operating Spanning Tree Configuration in an Urban Power Distribution System”, Power Systems Computation Conference, pp. 1-18. 1995.

MIU, K. N., CHIANG, H-D., McNUlTY, R. J., "Multi-Tier Service Restoration through Network Reconfiguration and Capacitor Control for Large-Scale Radial Distribution Systems", IEEE Transactions on Power Systems, Vol. 15, No. 3, pp. 1001-1007, August 2000.

MOAZAMI, E.; MIRZAEI, M.; AB KADIR, M. Z. A.; HIZAM, H.; IZADI, M., “Optimal penalty method in distribution service restoration using Genetic Algorithm", IEEE 7yh International Power Engineering and Optimization Conference, pp. 397-401. 2013.

MOHAMMADI, F.; AFRAKHTEH, H. “Optimal load restoration in distribution network using intentional islanding”. Journal of Electrical Engineering, vol. 12, n. 4, pp. 108-113. 2012

NGUYEN, C. P., FLUECK, A. J., “Agent Based Restoration With Distributed Energy Storage Support in Smart Grids”, IEEE Transactions on Smart Grid, vol. 3, no. 2, June 2012.

PORTAL O SETOR ELÉTRICO, “Artigos Técnicos”. Disponível em: < https://www.osetorele trico.com.br/category/artigos-tecnicos/>. Acesso em: 01 fev 2018.

PRADO, R. S.; PEDROSA SILVA R. C.; NETO, O. M.; GUIMARÃES, F. G., SANCHES, D. S., LONDON JR, J. B. A.; DELBEM, A. C. B., "Differential evolution using ancestor tree for service restoration in power distribution systems", ELSEVIER Applied Soft Computing, vol. 23, pp. 498-508, June 2014.

ROMERO, R. et al., "A New Mathematical Model for the Restoration Problem in Balanced Radial Distribution Systems", IEEE Transaction on Power Systems, no. 2, v. 31, pp. 12591268. 2016.

SANCHES, D. S.; MARQUEZ, R. C. ; SILVA, M. ; DELBEM, A.C.B. ; LONDON JR., J. B. A., "Integrando Relevantes Aspectos de Algoritmos Evolutivos Multi-Objetivo Para Tratamento do Problema de Restabelecimento de Energia em Sistemas de Distribuição de Grande Porte”. In: XIX Congresso Brasileiro de Automática, Campina Grande, 2012. 
SANCHES, D. S., "Algoritmos Evolutivos Multi-Objetivo para Reconfiguração de Redes em Sistemas de Distribuição de Energia Elétrica”. 152f. Tese (Doutorado) - Escola de Engenharia de São Carlos, Universidade de São Paulo, São Carlos, Janeiro de 2013.

SANCHES, D. S.; LONDON JR, J. B. A.; DELBEM, A. C. B., "Multiobjective evolutionary algorithm with a discrete differential mutation operator developed for service restoration in distribution systems". International Journal of Electrical Power and Energy Systems, No 2014, p. 700-711, London, November 2014.

SANTOS, A. C.; DELBEM, A. C. B.; LONDON, JR., J. B. A.; BRETAS, N. G., "Node-Depth Encoding and Multi-Objective Evolutionary Algorithm Applied to Large-Scale Distribution System Reconfiguration”. IEEE Transactions on Power Systems, p. 1-12, 2010.

SANTOS, A. C.; NANNI, M.; MANSOUR, M. R.; DELBEM, A.C.B.; LONDON Jr., J.B. A.; BRETAS, N. G., "A power flow method computationally efficient for large-scale distribution systems". In: 2008 IEEE PES Transmission and Distribution Conference and Exposition, Bogota. Proceedings (CD; 6 páginas), 2008.

SHIN, D.-J.; KIM, J.-O.; KIM, T.-K.; CHOO, J.-B.; SINGH, C., “Optimal service restoration and reconfiguration of network using genetic-tabu algorithm". Electric Power Systems Research, Elsevier, vol. 71, no. 2, pp. 145-152, 2004.

YAGIURA, M.; IBARAKI, T., "Metaheuristics as Robust and Simple Optimization Tools", IEEE International Conferecence on Evolutionary Computation, Nagoya, Japan, May 1996.

ZHOU, A.; QU, B.-Y.; LI, H.; ZHAO, S.-Z.; SUGANTHAN, P. N.; ZHANG, Q., "Multiobjective evolutionary algorithms: A survey of the state of the art", Elservier Swarm and Evolutionary Computation 1, pp. 32-49, 2011.

ZHU, J.Z., "Optimal reconfiguration of electrical distribution network using the refined genetic algorithm", Electric Power Systems Research, vol. 62, pp. 37-42, May 2002. 
ZIDAN, A.; KHAIRALLA, M.; ABDRABOU, A. M.; KHALIFA, T.; SHABAN, K.; ABDRABOU, A.; EL SHATSHAT, R.; GAOUDA, A. M., "Fault Detection, Isolation, and Service Restoration in Distribution Systems: State-of-the-Art and Future Trends”. IEEE Transactions on Smart Grid, vol. 8, no. 5, pp. 2170-2185, 2017.

ZIDAN, A.; EL-SAADANY, E., "A Cooperative Multiagent Framework for Self-Healing Mechanisms in Distribution Systems”. IEEE Transactions on Smart Grid, vol. 3, no. 3, pp. 1525-1539, 2012.

ZITZLER, E.; LAUMANNS, M.; THIELE, L., "SPEA2: Improving the Strength Pareto Evolutionary Algorithm", Technical Report 103, Computer Engineering and Networks Laboratory (TIK), Swiss Federal Institute of Technology (ETH) Zurich, Gloriastrasse 35, CH8092, Zurich, Switzerland, 2001. 

Apêndices 



\section{APÊNDICE A - REPRESENTAÇÃO NÓ-PROFUNDIDADE}

Uma das características mais importantes ao lidar computacionalmente com um problema qualquer é como o objeto de estudo é representado no computador. No problema de restabelecimento, a modelagem dos sistemas elétricos nos algoritmos desenvolvidos pela equipe do LACOSEP-USP tem se baseado na RNP proposta por DELBEM et al. (2004).

As principais vantagens da RNP são sua eficiência computacional na representação das redes e o fato de seus operadores garantirem a radialidade de todas as configurações por eles geradas, o que garante automaticamente o cumprimento dessa restrição do problema.

Com o uso da RNP, o sistema elétrico pode ser representado por um conjunto de matrizes de tamanho $2 \times n$, no qual cada matriz se refere a um alimentador e $n$ indica o número de nós deste conjunto. Cada coluna das matrizes contém as informações referentes aos nós presentes na rede e suas respectivas profundidades.

Para exemplificar como um SD é armazenado através da RNP, a Figura A.1 mostra um grafo que representa o alimentador de um SD qualquer, em que o nó 1 representa a subestação, os demais nós são setores de cargas e as arestas são chaves seccionadoras NFs.

Do modo como está organizado este grafo sua representação computacional é relativamente complexa, demandando um maior processamento para ser identificada a topologia da rede correspondente, assim como a visualização para o operador demanda uma maior atenção. No entanto, ao reorganizar conforme as "distâncias" de cada nó até a subestação, já se pode interpretar mais facilmente como o sistema está disposto, conforme a Figura A.2 mostra.

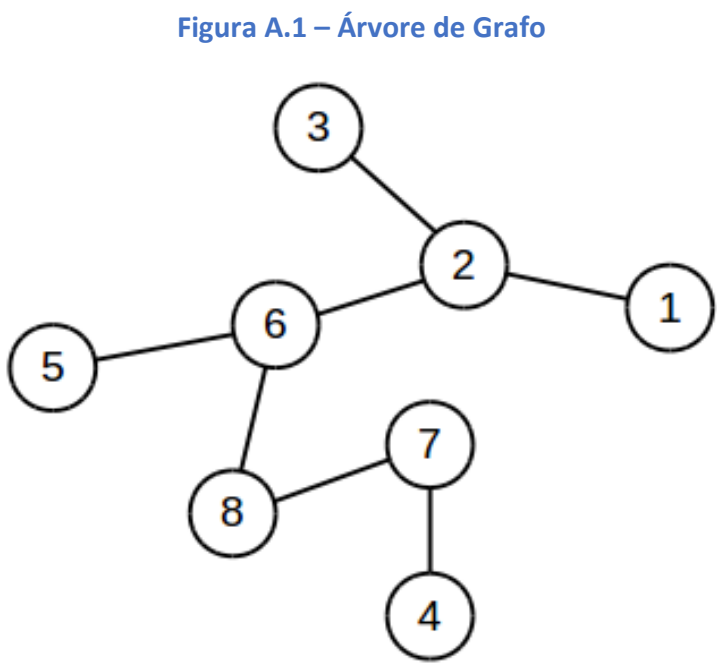


Figura A.2 - Árvore de Grafo destacando os Nós e correspondentes Profundidades

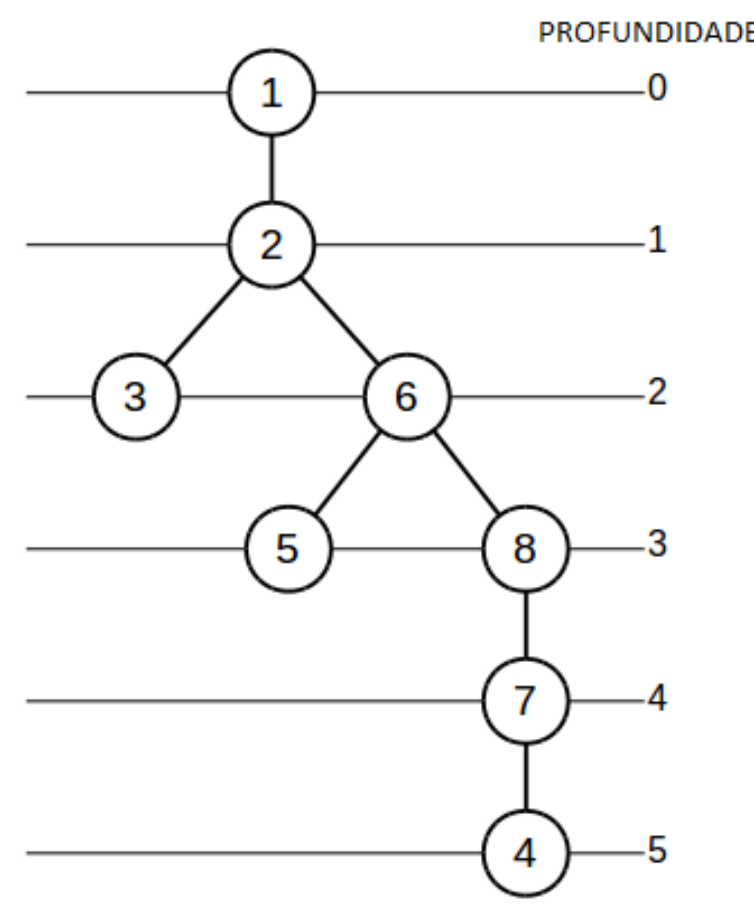

Fonte: Adaptado de BONILHA, 2014.

Com o grafo redesenhado de uma forma mais organizada, a topologia do correspondente SD se torna visivelmente mais simples de se visualizar. Assim, a RNP representará esse grafo no computador através de uma matriz organizada de modo que cada par $\left(n_{x} ; p_{x}\right)$ é armazenado em uma coluna da matriz, onde $n_{x}$ representa o nó e $p_{x}$ sua profundidade. Para armazenar um nó e a sua respectiva profundidade na RNP, é utilizado um algoritmo de busca em profundidade (CORMEN, 2002) que, começando a busca a partir do nó raiz da árvore, produz uma lista de pares $\left(n_{x} ; p_{x}\right)$ em uma sequência apropriada enquanto um nó $n_{x}$ é visitado. Portanto, para o grafo organizado na Figura A.2, sua RNP, será dada por:

$$
T=\left[\begin{array}{c}
\text { nó } \\
\text { profundidade }
\end{array}\right]=\left[\begin{array}{llllllll}
1 & 2 & 3 & 6 & 5 & 8 & 7 & 4 \\
0 & 1 & 2 & 2 & 3 & 3 & 4 & 5
\end{array}\right]
$$

A partir dessa matriz, podem ser feitas várias operações relevantes ao problema de restabelecimento. O mais importante neste caso é o fato de que os operadores da RNP garantem que sempre serão geradas configurações radiais.

Em (DELBEM et al., 2004) são propostos dois operadores distintos (Apêndices D e E) para manipular RNPs: Preserve Ancestor Operator (PAO) e Change Ancestor Operator (CAO). Estes operadores, quando aplicados em uma árvore de grafos $T$ produzem somente 
novas árvores $T^{\prime}$. Suas utilizações práticas no problema de restabelecimento, no entanto, são a transferência de uma sub-árvore obtida de uma árvore $T_{d e}$ para outra árvore $T_{\text {para }}$.

A principal diferença entre os operadores $\mathrm{CAO}$ e PAO é que o PAO usa o mesmo nó raiz da sub-árvore cortada de $T_{d e}$ como nó raiz na hora de realizar o "enxerto" em $T_{\text {para }}$, enquanto no CAO este nó poderá ser qualquer um presente na sub-árvore cortada de $T_{d e}$. Exemplos de aplicação destes operadores podem ser vistos nos Apêndices D e E.

Por fim, o uso da RNP, em conjunto com os dados elétricos do SD, ainda permite realizar fluxos de carga por varredura direta-inversa facilmente e avaliar o desempenho da rede para cada configuração gerada pelos operadores da RNP e por ela armazenada.

No problema de restabelecimento, o uso de RNPs é ainda acompanhando pela existência de uma matriz $\Pi$, que armazena a árvore à qual um nó pertence, seu índice e sua profundidade dentro desta árvore. Esta estrutura vai sendo atualizada a cada mudança de posição do nó realizada por uma operação na RNP. A atualização é feita através da inserção de novas colunas nesta matriz. Deste modo, é possível conhecer a relação de ancestralidade (dentro do processo evolutivo) entre as florestas produzidas (DELBEM et al., 2004). Neste contexto as florestas de grafo representam o SD em análise 



\section{APÊNDICE B - ALGORITMO EVOLUTIVO MULTIOBJETIVO EM TABELAS}

Problemas multiobjetivos requerem um tratamento adequado para lidar com características conflitantes. Deste modo, a busca por soluções para o problema de restabelecimento precisa ser coordenada por alguma lógica que seja capaz de gerar configurações com bom desempenho em vários objetivos. Uma alternativa para lidar com este tipo de problema é o uso de um AEMT. Estes algoritmos possuem características de AEs mas favorecem o tratamento de problemas multiobjetivos.

Proposto em (BENAYOUN et al., 1971), o funcionamento deste algoritmo se baseia no uso de processos evolutivos semelhantes ao observado em AEs para gerar soluções, que são avaliadas conforme uma série de parâmetros considerados relevantes ao problema em estudo, e então, caso tenham bom desempenho em algum desses parâmetros, são armazenadas em tabelas de subpopulações. Por exemplo, para tratamento de um problema com objetivos $f_{1}$ e $f_{2}$ e restrições $g_{1}$ e $g_{2}$ poderia conter quatro tabelas, $T_{1}$ e $T_{2}$ para os objetivos e $T_{3}$ e $T_{4}$ para as restrições. Esta abordagem elimina a necessidade de atribuir pesos aos diferentes objetivos avaliados e trata restrições como se fossem objetivos a serem otimizados. Há ainda a possibilidade de se utilizar tabelas que combinem mais de uma característica do problema.

As tabelas contendo os indivíduos de melhor desempenho para cada característica do problema (objetivo, restrição ou combinações entre eles) servem de base para a geração de novos indivíduos (no caso do problema de restabelecimento, esses indivíduos podem ser gerados a partir da aplicação dos operadores da RNP), garantindo assim uma variabilidade de soluções de bom desempenho para várias características do problema.

Este tipo de algoritmo é bastante adaptável e pode incorporar várias outras técnicas para melhorar seu desempenho. Um exemplo disso é o que foi apresentado em (MARQUES et al., 2017), onde o NSGA-II é incorporado ao AEMT para possibilitar o estabelecimento de compromissos entre os valores de diferentes objetivos para obtenção de um conjunto de soluções não dominadas.

Por se tratar de um AE, onde há ainda o fator de aleatoriedade, não se pode dizer que o AEMT garanta a solução ótima do problema. No entanto, os resultados observados nos trabalhos desenvolvidos utilizando AEMTs em problemas de reconfiguração de rede indicam que o uso de tabelas de subpopulações possibilita um mapeamento mais eficiente do espaço de busca, com maior diversidade de soluções e evitando que as buscas fiquem restritas a pontos ótimos locais. 



\section{APÊNDICE C - DOMINÂNCIA DE PARETO}

Em problemas multiobjetivo não é possível comparar diretamente duas soluções, já que cada uma pode ser melhor em um conjunto de objetivos específico. Uma alternativa para estabelecer uma relação de compromisso entre os diferentes objetivos de um problema multiobjetivo é o uso do conceito de Dominância de Pareto. Determina-se, então, um conjunto de soluções não dominadas, chamado de Pareto Ótimo (DEB, 2001). Admite-se que uma solução x domina outra solução y se x é melhor que y em pelo menos um dos objetivos e não pior em todos os demais objetivos. O conjunto formado pelos valores das funções objetivo das soluções não dominadas do problema é chamado Fronteira de Pareto.

Para exemplificar os conceitos citados anteriormente, a Figura A.3 apresenta um problema com dois objetivos, dados pelas funções $f_{1}$ e $f_{2}$. Os pontos em azul escuro são as soluções dominadas, os pontos em azul claro são soluções não dominadas e a curva em verde unindo os pontos em azul claro representa a fronteira de Pareto, que é normalmente o que se deseja encontrar ao aplicar o AEMO.

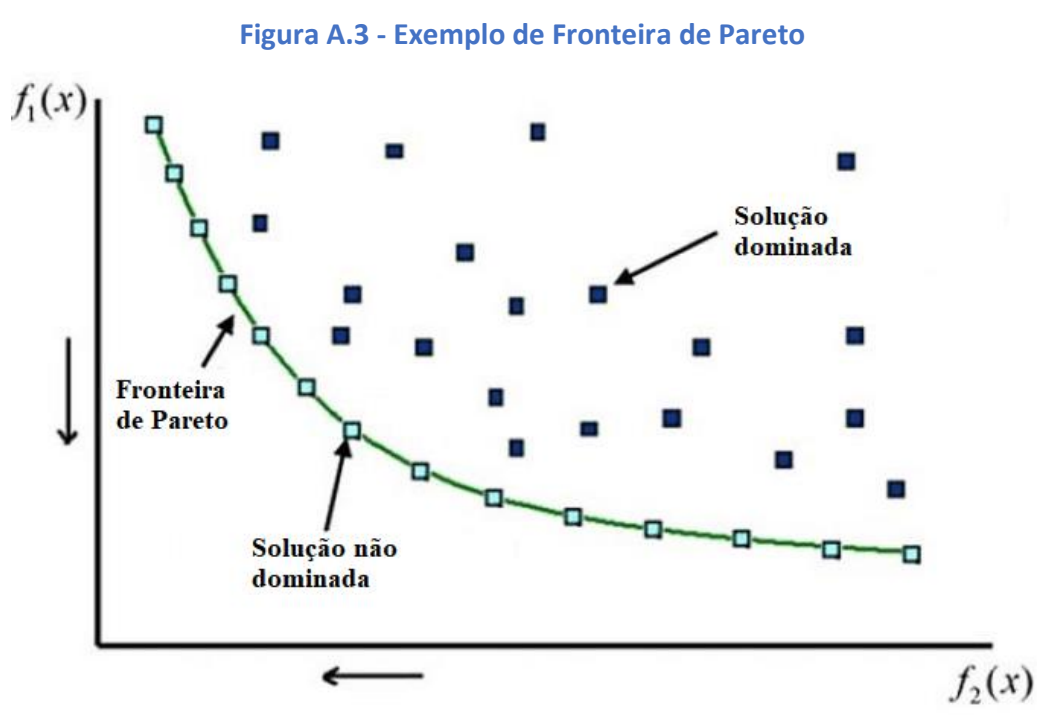

Fonte: Adaptado de SOMMA, 2016.

Conforme discutido anteriormente, não é possível garantir que um $\mathrm{AE}$ encontre a Fronteira de Pareto do problema multiobjetivo analisado. Apesar disso, algumas regras podem ser seguidas para garantir um bom desempenho do algoritmo de acordo com (DEB, 2001):

1) Deve-se buscar um conjunto de soluções que esteja o mais próximo possível da Fronteira de Pareto; 
2) O conjunto de soluções encontrado deve ter a maior diversidade possível;

3) O algoritmo deve ser capaz de realizar a busca de maneira computacionalmente eficiente.

As duas primeiras regras podem ser aplicadas em praticamente qualquer problema de otimização, principalmente em casos multiobjetivo, pois deseja-se de fato que as soluções sejam bastante otimizadas (primeira regra) e também é importante ter opções para melhorar o desempenho em cada um dos objetivos, dependendo da necessidade do problema (segunda regra). Já a terceira regra se faz importante no problema de restabelecimento por sua natureza de tempo real.

Nota-se que, mesmo não havendo a garantia de que um AE encontrará a Fronteira de Pareto, ao seguir as regras propostas em (DEB, 2001) é possível montar um conjunto de soluções não dominadas entre si a partir do universo de soluções encontradas ao longo do processo evolutivo. 


\section{APÊNDICE D - OPERADOR CAO}

O operador CAO tem a finalidade de realizar cortes em RNPs e enxertar os segmentos cortados em uma RNP destino, com a possibilidade de a conexão ser feita por um nó diferente do ponto de corte.

Os nós envolvidos na operação formam uma trinca, chamada de PRA, onde:

$p$ é o nó de poda da sub-árvore a ser cortada;

$r$ é o nó que servirá de ponto de conexão entre a sub-árvore podada e a árvore destino;

$a$ é o nó destino, onde será inserida a sub-árvore podada.

A seguir é mostrado um exemplo de aplicação deste operador entre duas RNPs:

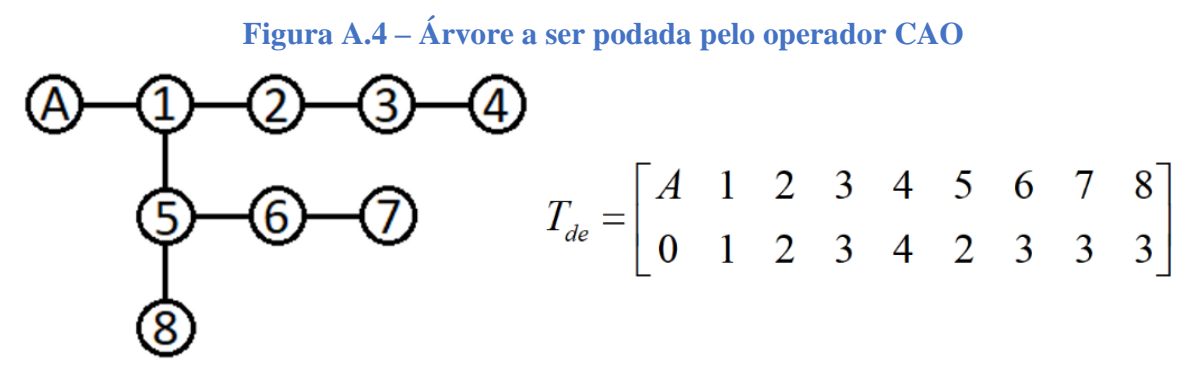

Fonte: Elaborado pelo autor.

Figura A.5 - Árvore que receberá o enxerto do operador CAO

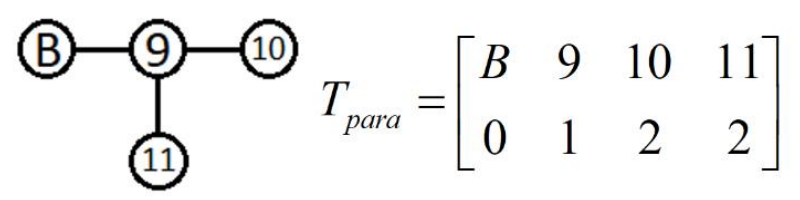

Fonte: Elaborado pelo autor.

Caso sejam escolhidos os nós $p=5, r=6, a=10$, a RNP resultante será:

Figura A.6 - Árvore resultante da operação CAO

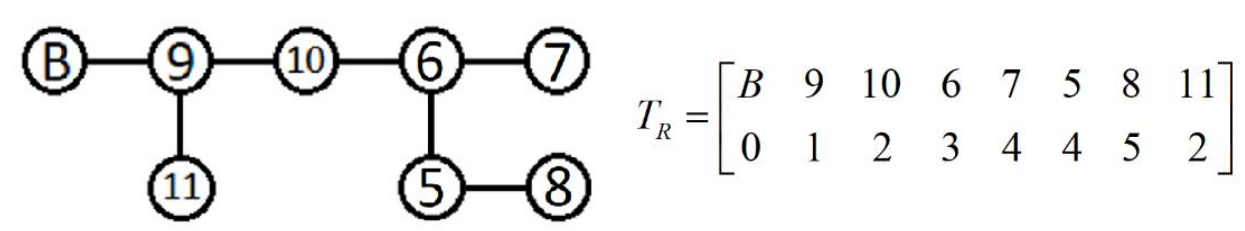

Fonte: Elaborado pelo autor. 
A versão adaptada deste operador para atuar na busca local faz a mesma operação, mas com uma trinca PRA formada apenas por nós de uma mesma RNP fictícia (desenergizada).

O operador LRO também pode ser considerado uma variação do CAO em que a RNP de poda é sempre fictícia e a RNP destino é sempre real (energizada).

No caso do problema de restabelecimento, na etapa evolutiva, em que são feitas seleções aleatórias das trincas PRA, existem métodos de verificação da validade da operação. Mais detalhes podem ser encontrados na dissertação de MARQUES (2013). 


\section{APÊNDICE E - OPERADOR PAO}

O operador PAO tem a finalidade de realizar cortes em RNPs e enxertar os segmentos cortados em uma RNP destino, fazendo a conexão sempre através do ponto de corte. Esta operação equivale a um caso específico do operador CAO, onde a trinca PRA possui valores iguais para P e R. Sendo assim, só é necessário estabelecer dois nós:

$p$ é o nó de poda da sub-árvore a ser cortada, que servira também de ponto de conexão entre a sub-árvore podada e a árvore destino;

$a$ é o nó destino, onde será inserida a sub-árvore podada.

Considerando novamente as RNPs das Figuras A.5 e A.6, supondo $p=5$ e $a=10$, o resultado da aplicação de um PAO será a RNP apresentada na Figura A.7.

A versão modifica do operador PAO para utilização no processo de busca local terá sempre nós $p$ e a de uma mesma RNP fictícia, sendo que o nó a será sempre o nó de profundidade 0 desta RNP.

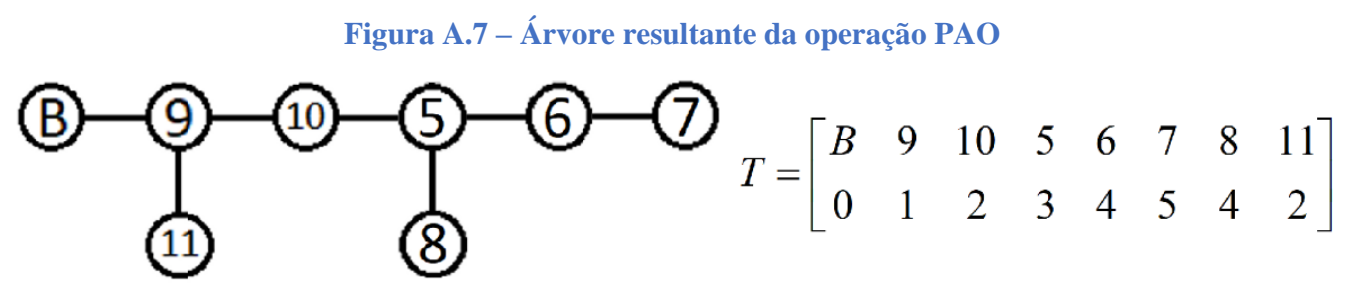

Fonte: Elaborado pelo autor.

O operador LSO é uma variação do PAO em que sempre o nó $p$ é de uma RNP real e o nó $a$ de uma RNP fictícia.

Do mesmo modo que no CAO, para o problema de restabelecimento, na etapa evolutiva, em que são feitas seleções aleatórias das trincas PRA, existem métodos de verificação da validade da operação. Mais detalhes podem ser encontrados na dissertação de MARQUES (2013). 



\section{APÊNDICE F - TABELAS USADAS NO AEMT}

O AEMT utilizado segue o modelo proposto em (MARQUES, 2018), onde são utilizadas nele as 26 tabelas descritas a seguir. Mais detalhes quanto aos critérios de entrada dos indivíduos em cada tabela podem ser encontrados no trabalho citado anteriormente.

As primeiras cinco tabelas são para minimização do número total de manobras $\psi(G)$, um dos objetivos do problema (considere que $G^{B E}$ se refere às configurações obtidas pela busca exaustiva):

$P_{1}-$ indivíduos $G$ para os quais $\psi(G) \leq\left[\psi\left(G^{B E}\right) \div 2\right]$;

$P_{2}-$ indivíduos $G$ para os quais $\left[\psi\left(G^{B E}\right) \div 2\right]<\psi(G) \leq\left[\psi\left(G^{B E}\right)\right]$;

$P_{3}-$ indivíduos $G$ para os quais $\left[\psi\left(G^{B E}\right)\right]<\psi(G) \leq\left[\psi\left(G^{B E}\right)+6\right]$;

$P_{4}-$ indivíduos $G$ para os quais $\left[\psi\left(G^{B E}\right)+6\right]<\psi(G) \leq\left[\psi\left(G^{B E}\right)+12\right]$;

$P_{5}-$ indivíduos $G$ para os quais $\psi(G)>\left[\psi\left(G^{B E}\right)+12\right]$.

Assim como as cinco primeiras, a sexta até a décima tabela são utilizadas para tratar diretamente um dos objetivos do problema, minimizar a energia não suprida (considere que $G^{1}$ se refere à configuração obtida após a falta ser isolada):

$P_{6}-$ indivíduos $G$ para os quais $\varepsilon(G) \leq\left[0,2 \cdot \varepsilon\left(G^{1}\right)\right]$;

$P_{7}$-indivíduos $G$ para os quais $\left[0,2 \cdot \varepsilon\left(G^{1}\right)\right]<\varepsilon(G) \leq\left[0,4 \cdot \varepsilon\left(G^{1}\right)\right]$;

$P_{8}$-indivíduos $G$ para os quais $\left[0,4 \cdot \varepsilon\left(G^{1}\right)\right]<\varepsilon(G) \leq\left[0,6 \cdot \varepsilon\left(G^{1}\right)\right]$;

$P_{9}-$ indivíduos $G$ para os quais $\left[0,6 \cdot \varepsilon\left(G^{1}\right)\right]<\varepsilon(G) \leq\left[0,8 \cdot \varepsilon\left(G^{1}\right)\right]$;

$P_{10}$ - indivíduos $G$ para os quais $\varepsilon(G)>\left[0,8 \cdot \varepsilon\left(G^{1}\right)\right]$.

As tabelas 11 a 20 aplicam a seleção por não dominância presente no NSGA-II e tratam das diferenças entre níveis de prioridade de energia não suprida e dos tipos de chaves manobradas:

$P_{11}$ - indivíduos que possuem os menores grau de dominância em relação à minimização de $\varepsilon_{A}(G)$ e $\psi_{R}(G)$ 
$P_{12}$ - indivíduos que possuem os menores grau de dominância em relação à minimização de $\varepsilon_{I}(G)$ e $\psi_{R}(G)$

$P_{13}$ - indivíduos que possuem os menores grau de dominância em relação à minimização de $\varepsilon_{B}(G)$ e $\psi_{R}(G)$

$P_{14}$ - indivíduos que possuem os menores grau de dominância em relação à minimização de $\varepsilon_{S}(G)$ e $\psi_{R}(G)$

$P_{15}$ - indivíduos que possuem os menores grau de dominância em relação à minimização de $\varepsilon_{A}(G)$ e $\psi_{M}(G)$

$P_{16}$ - indivíduos que possuem os menores grau de dominância em relação à minimização de $\varepsilon_{I}(G)$ e $\psi_{M}(G)$

$P_{17}$ - indivíduos que possuem os menores grau de dominância em relação à minimização de $\varepsilon_{B}(G)$ e $\psi_{M}(G)$

$P_{18}$ - indivíduos que possuem os menores grau de dominância em relação à minimização de $\varepsilon_{S}(G)$ e $\psi_{M}(G)$

$P_{19}$ - indivíduos que possuem os menores grau de dominância em relação à minimização de $\varepsilon_{T}(G)$ e $\psi_{T}(G)$;

$P_{20}$ - indivíduos factíveis que possuem os menores grau de dominância em relação à minimização de $\varepsilon_{T}(G)$ e $\psi_{T}(G)$.

As tabelas 20 a 25 são baseadas em conceitos clássicos de tabelas de subpopulação, onde cada uma analisa um critério apenas para a seleção dos indivíduos salvos. Nenhuma delas trata diretamente de objetivos do problema:

$P_{21}$ - indivíduos que possuem os menores valores de $X\left(G^{e}\right)$;

$P_{22}$ - indivíduos que possuem os menores valores de $B\left(G^{e}\right)$;

$P_{23}$ - indivíduos que possuem os menores valores de $V\left(G^{e}\right)$;

$P_{24}$ - indivíduos que possuem os menores valores de $f_{a}(G)$;

$P_{25}$ - indivíduos que possuem os menores valores de $\gamma(G)$.

Sendo $f_{a}(G)$ uma função de agregação dada por:

$$
f_{a}(G)=\frac{\gamma(G)}{\gamma\left(G^{p f}\right)}+w_{X} \frac{X(G)}{X\left(G^{p f}\right)}+w_{B} \frac{B(G)}{B\left(G^{p f}\right)}+w_{V} \frac{V(G)}{V\left(G^{p f}\right)}
$$


Onde $G^{p f}$ se refere à configuração pré-falta e $w_{K}$ é dado por:

$$
w_{K}=\left\{\begin{array}{c}
1, \text { se } K(G)>1, \text { para } K=X, B \text { e } V \\
0, \text { caso contrário }
\end{array}\right.
$$

A última tabela trata da priorização de atendimento aos consumidores prioritários e da filosofia para operação das manobras de transferência de cargas entre os alimentadores:

$$
P_{26} \text { - indivíduos que possuem os menores valores de } P T R_{P}(G) \text {. }
$$

Sendo $P T R_{P}(G)$ o somatório de potência ativa dos consumidores energizados com prioridade alta, intermediária, baixa ou sem prioridade que foram transferidos entre alimentadores para obtenção da nova configuração do sistema. 